\title{
السذاجة وعلاقتها بالذكاء الاجتماعي لدى طلبة الجامعة
}

\author{
أ.م.د. علي تركي ناقل القريشي
}

كلية الآداب - جامعة بغداد

\section{ali.turkey.61@yahoo.com}

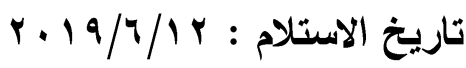

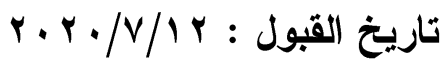

\section{(c) (i)}

This work is licensed under a Creative Commons Attribution 4.0 International License

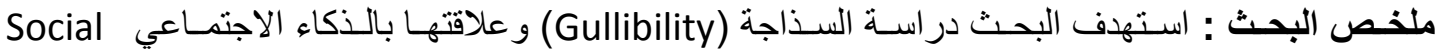

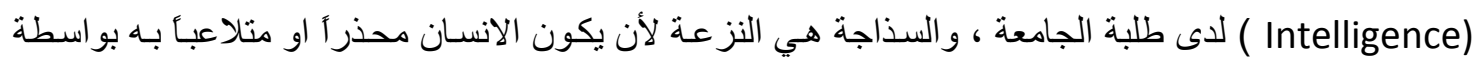

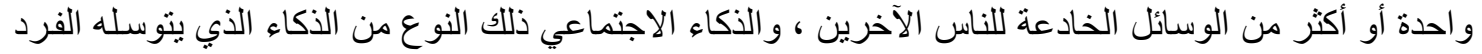

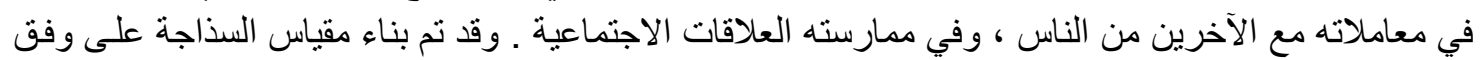

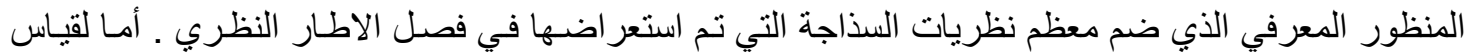

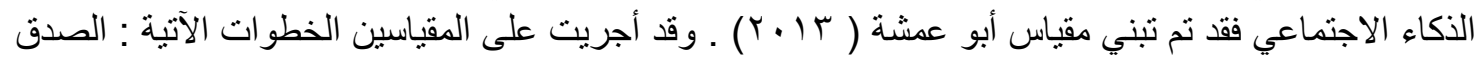

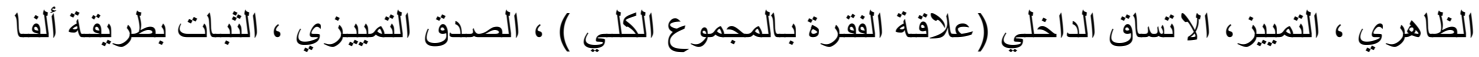

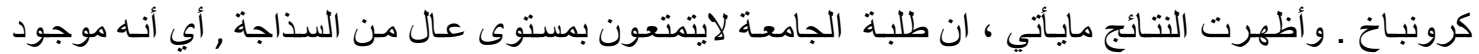

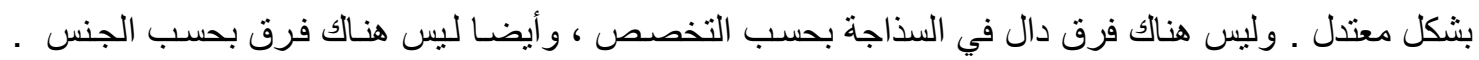

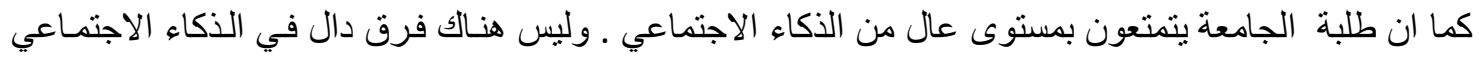

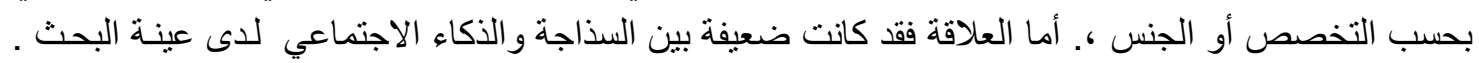

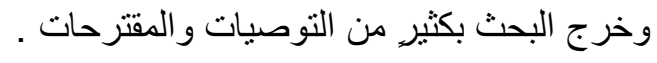

الكلمات المفتاحية: السذاجة ، الثقة ، سرعة التصديق ، الأكاء الاجتماعي ، الحماقة 


\title{
Gullibility and its relationship to social intelligence among university students .
}

\section{Assistant Professor Dr. Ali Turki Nafel Al-Quraishi College of Arts - University of Baghdad}

\begin{abstract}
:
The research aimed at studying gullibility and its relationship to social intelligence in university students, and gullibility is the tendency for a person to be drugged or manipulated by one or more of the deceptive means of other people . And social intelligence is the kind of intelligence that an individual pleads with in his dealings with other people, and in practicing social relations. The gullibility scale was built according to the cognitive perspective, which included most of the gullibility theories reviewed in the theoretical framework chapter. As for measuring social intelligence, the Abu Amsha scale (2013) was adopted. The following steps were performed on the two measures : Face validity, Discrimination, internal consistency (the relationship of the Item to the sum total), discriminatory validity, Reliability in the Alpha Cronbach method. The results showed the following, that university students do not enjoy a high level of gullibility, that is, it is present moderately. There is no significant difference in gullibility according to specialization, and also there is no difference according to gender. Also, university students enjoy a high level of social intelligence. There is no significant difference in social intelligence by specialization, and there is no difference by gender. As for the relationship, it was weak between gullibility and social intelligence in the research sample. The research came out with many recommendations and proposals.
\end{abstract}

Key words : Gullibility, trust, Credulity, social intelligence . Foolishness . 


\section{الفصل الأول / مشكلة البحث :}

يبدو و اضحا للمختصين ولربما لغير هم ايضا ، ان للسذاجة علاقة بالاحتيال و النصب و الخداع لان الساذج غالبا

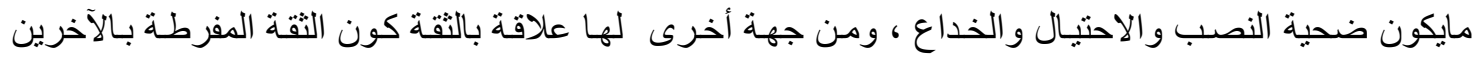
تؤدي بالفرد الى الاحباط و الخذلان و الخسارة.

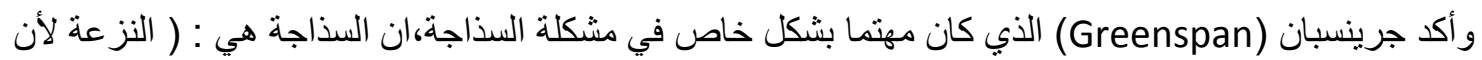

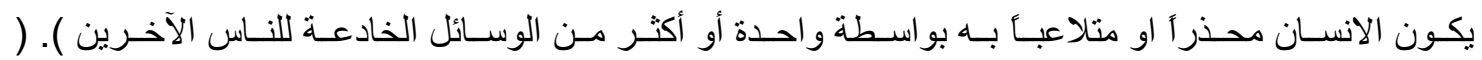

(Tennisse,2015, p.3

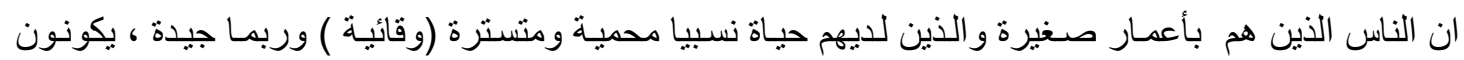
أكثر سذاجة ، فاذا كان كل ماهو معروف لديك آمن ، فأنت سوف تعطي ثقة بدون سؤ ال أو شك، أي أن الناس

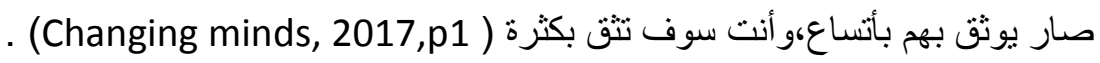

وتشير دراسـات كل من ياماجاثـي (Yamagishi \& et.al 1999) و( (Yamagishi,2001) ودر اسـة كارنر

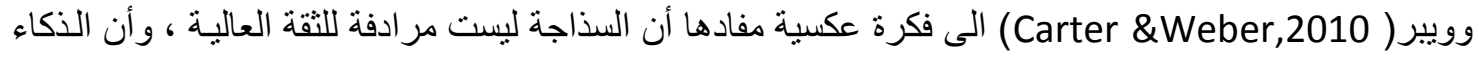

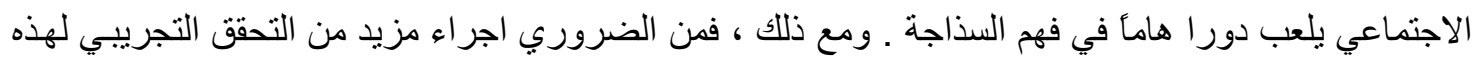

النتائج ( Tennisse,2015,p.16) هاعئ (T)

ويمكن هنا الاشارة الى در اسة جاكوبس وشاين ( Jacobs\&Schin2011) التي أثنار ا فيها الى ان السذاجة يمكن

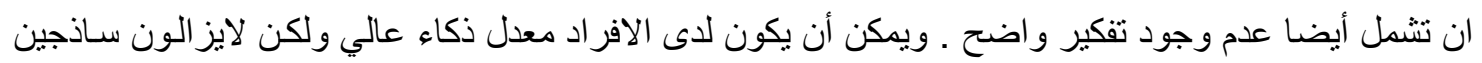

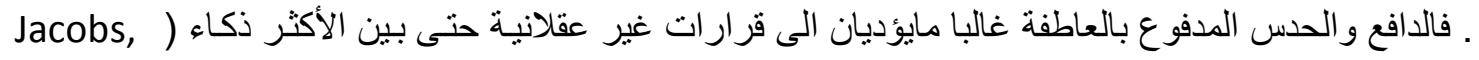

.(schain,.2011,p.41

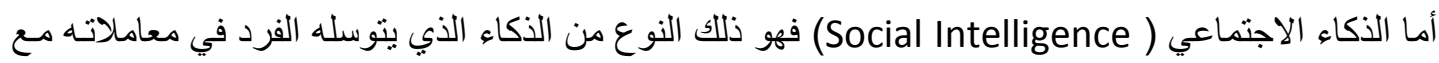

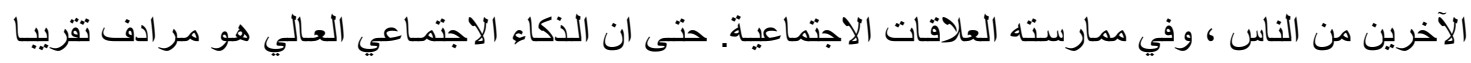

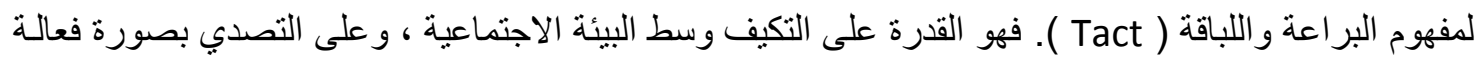

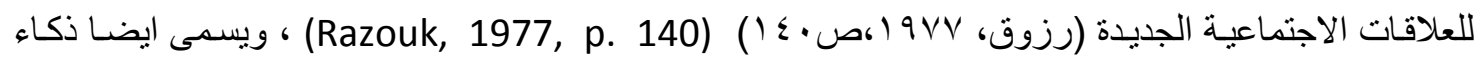

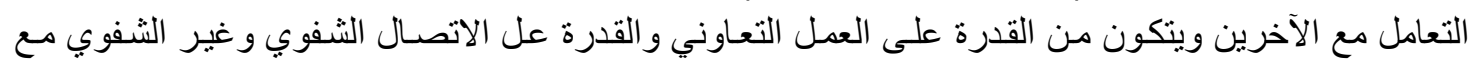

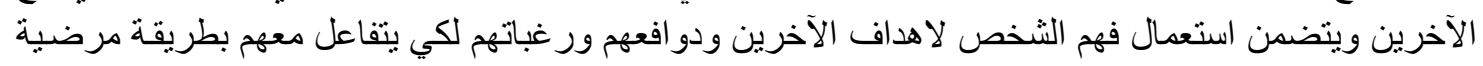

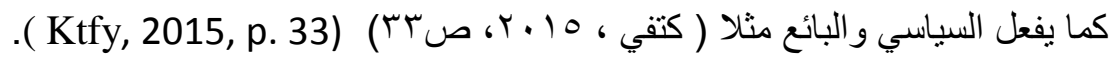

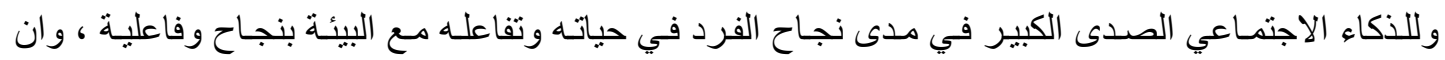

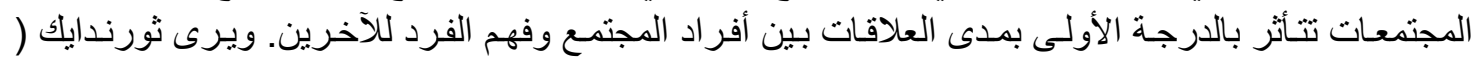
(Thorndik

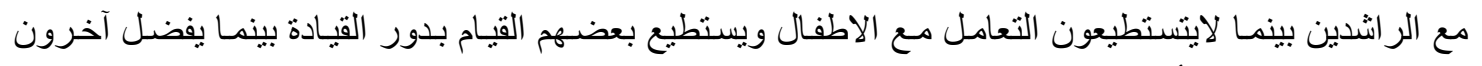

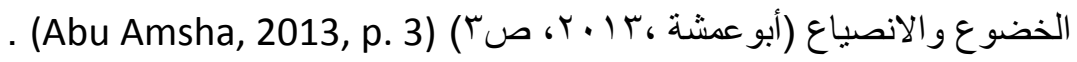
وبناء على ماتقدم تتجلى مشكلة البحث الحالي في التعرف على طبيعة العلاقة بين السذاجة و الذكاء الاجتمـاعي

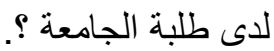

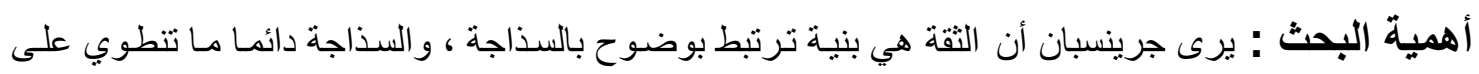

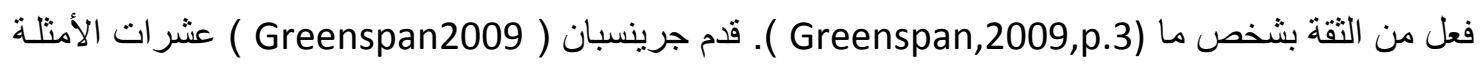

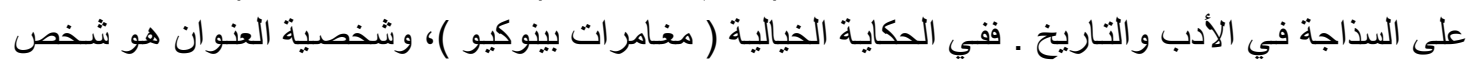




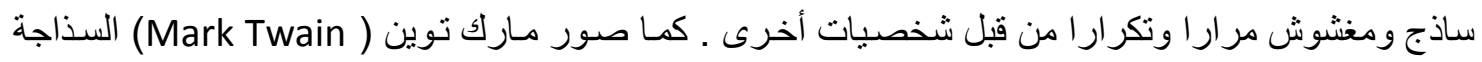

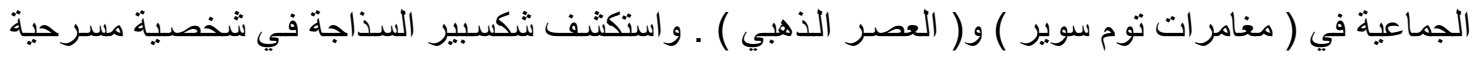

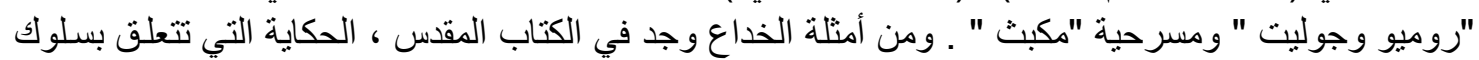
معظم المخدو عين ، مثل "سامسون" في كتاب القضـاة ، و الثخصية التي تتدمر بو اسطة سذاجتها في مواجهة الحب ( p.3, (Wikipedia,2017).

ووجدت دراسة كارير ( Carrier,1963) بأن سذاجة طلبة الجامعة في قبول تحليلات شخصية كاذبة لأنفسهم

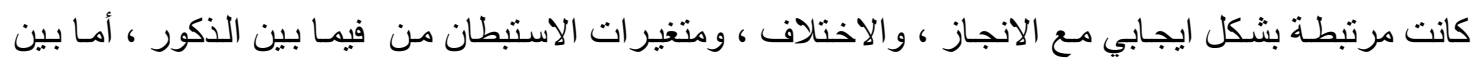

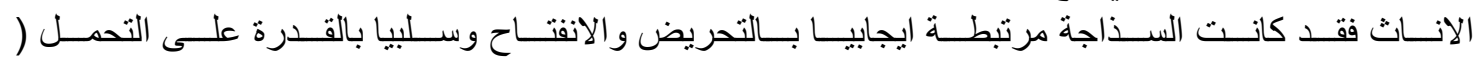

. ( Carrier,1963,p.84

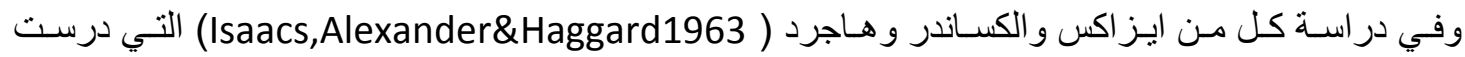

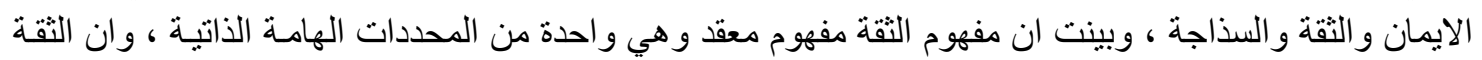

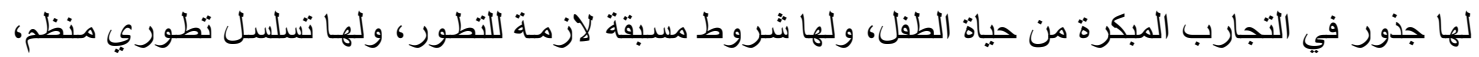

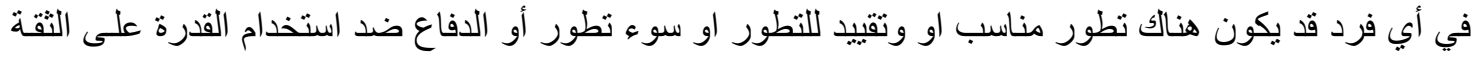

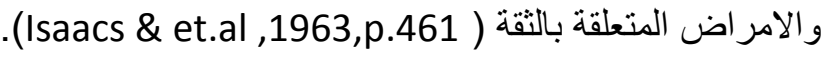

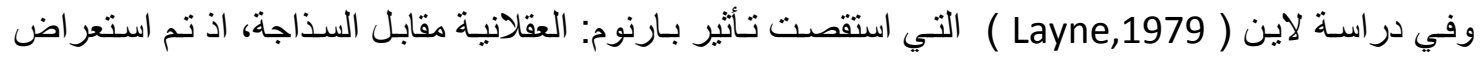

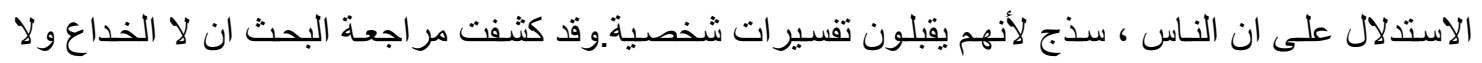

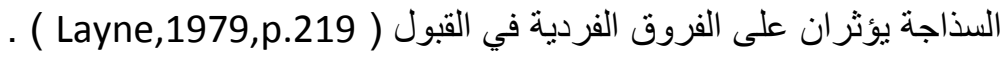

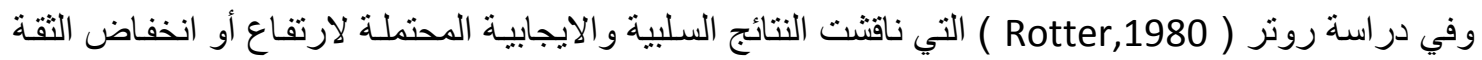

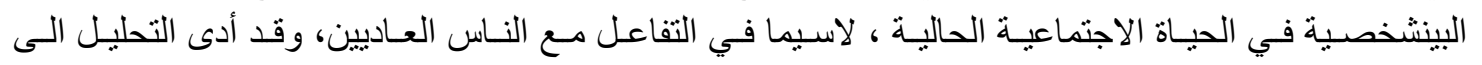

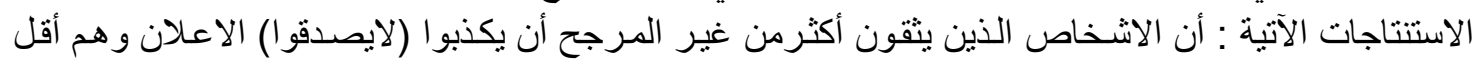

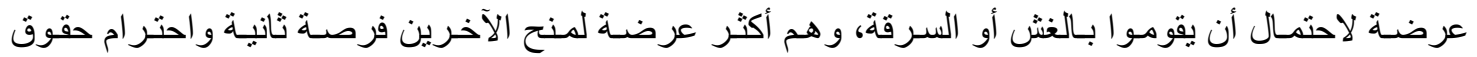

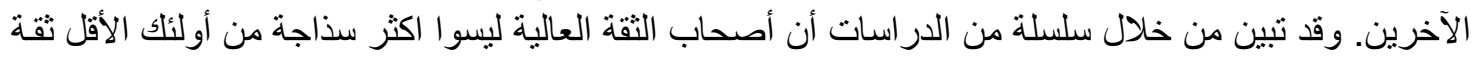

(Rotter,1980,p.1-7)

وفي در اسة بريس وباكستر( Preece\&Baxter,2000 ) التي كانت بعنوان ( الثكوك و السذاجة : المعتقدات

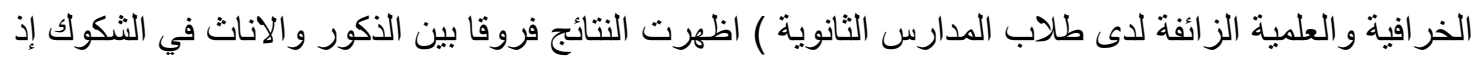

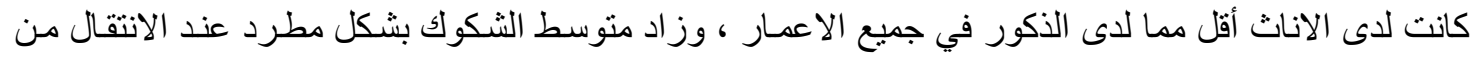

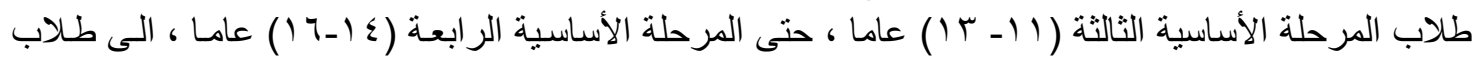

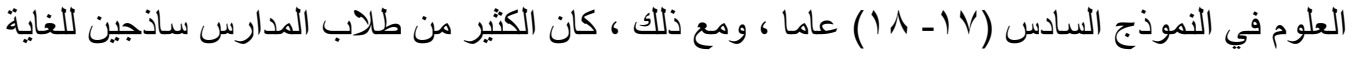

. (Preece\&Baxter,2000,pp.1147- 1156 )

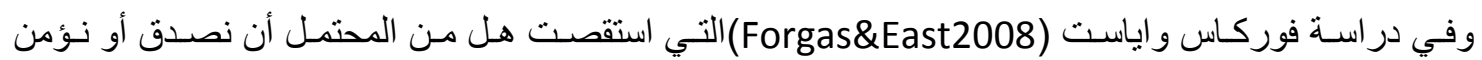

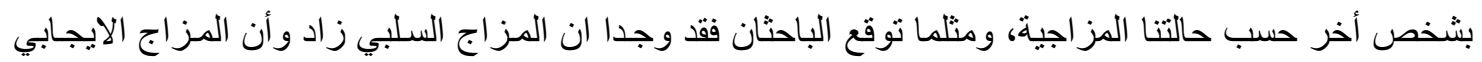

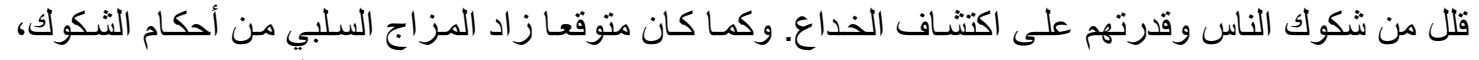

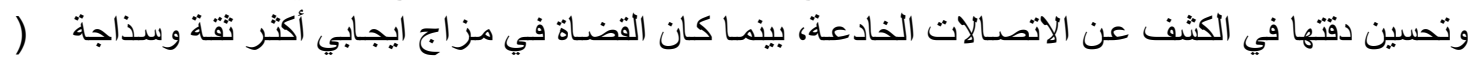

( Forgas\&East,2008,p.1362

وفي دراسة كارتر وويير ( Carter \& weber2010 ) ظهر ان الوثوقين بشكل عالي يتخذون موقفا افتر اضيا

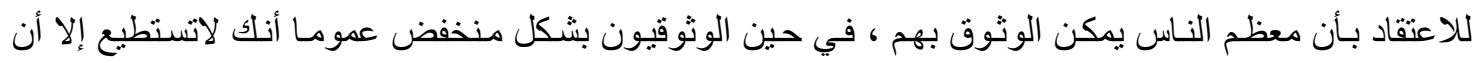




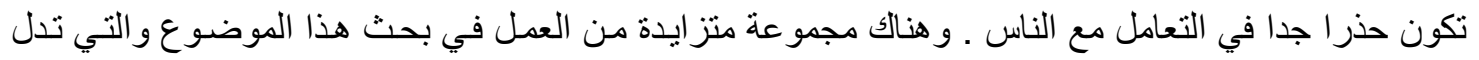

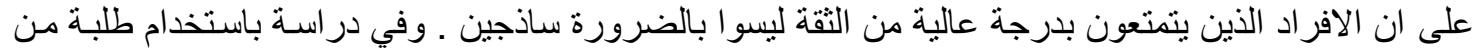

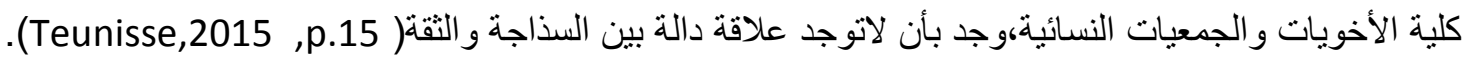

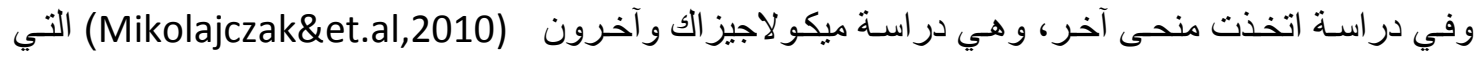

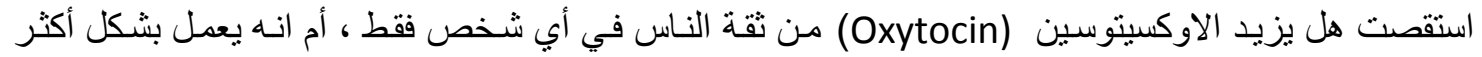

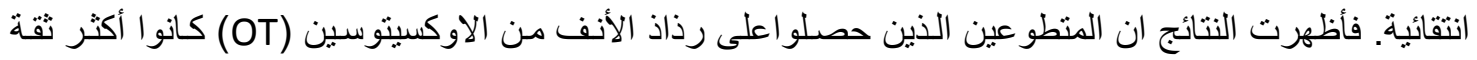

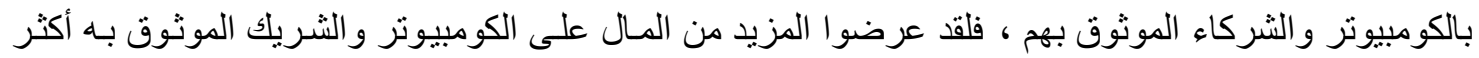

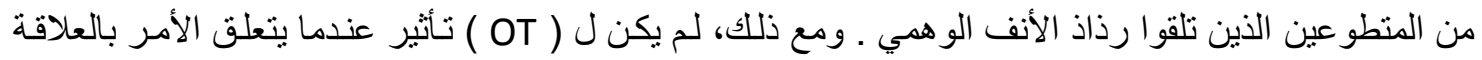

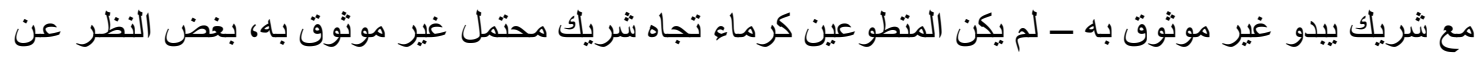

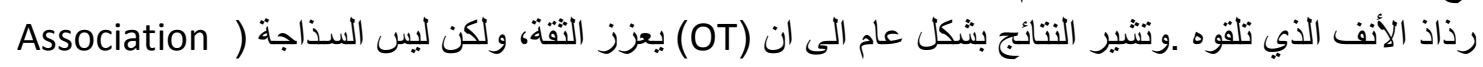

(for psychological science, 2010,p.1

اما الذكاء الاجتماعي ( Social Inteligence)فقد أنشار جولمـان ( Goleman,2006 ) الى أن هناك قدرات

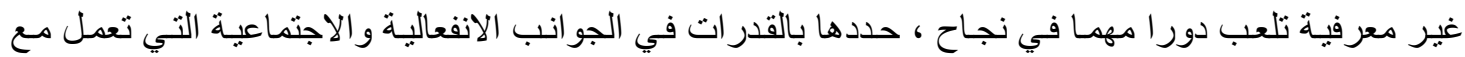

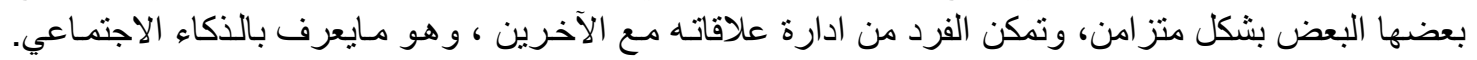

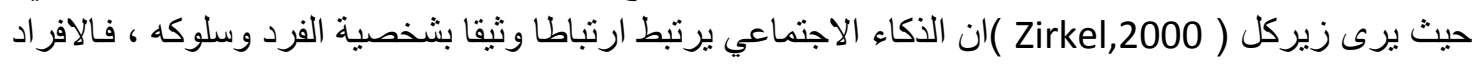

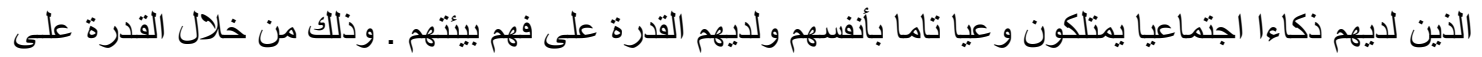

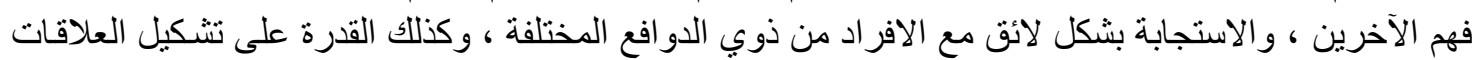

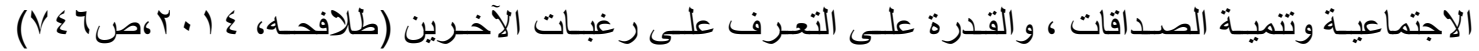

. (Talafah, 2014, p. 746)

ويعد الذكاء الاجتماعي من الجو انب الهامة في الثخصية لكونه يرتبط بقدرة الفرد على التعامل مع الآخرين

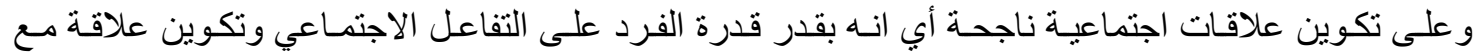

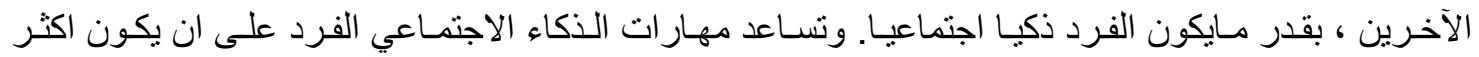

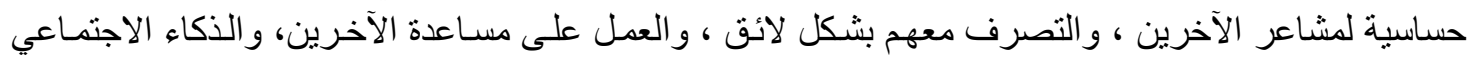

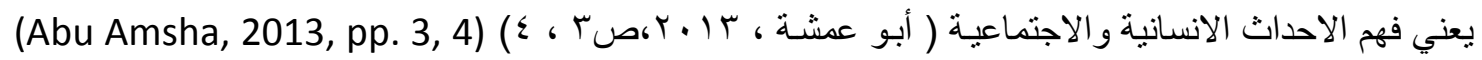

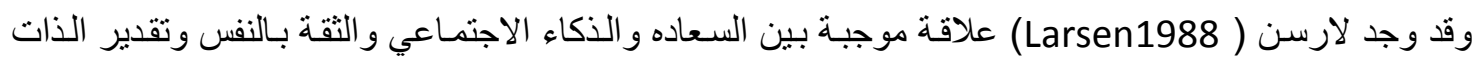

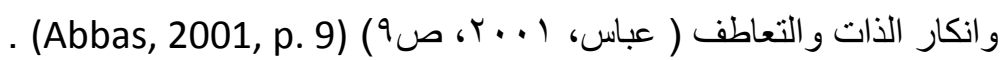

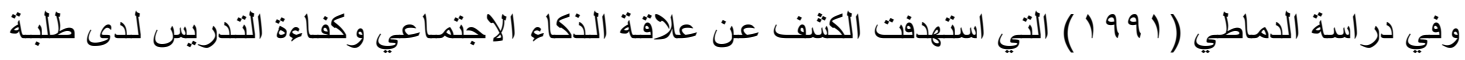

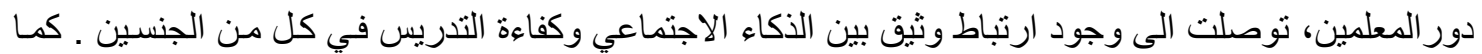

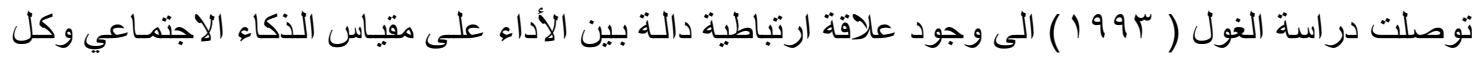

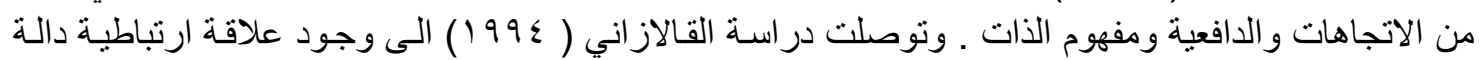

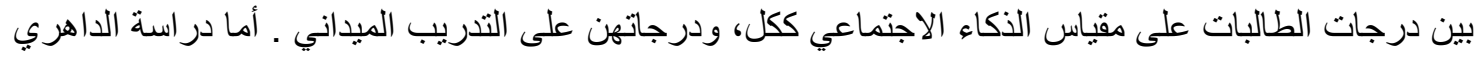

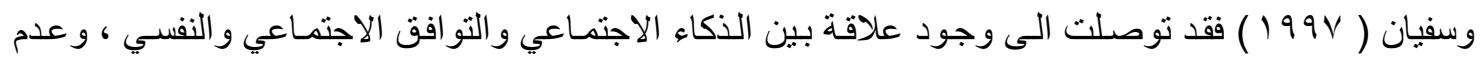

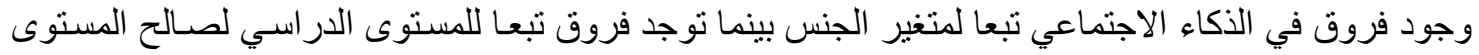

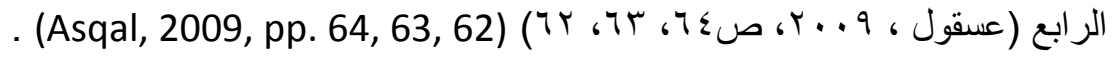

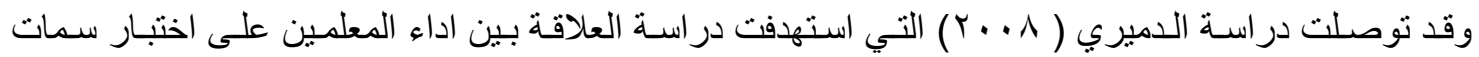

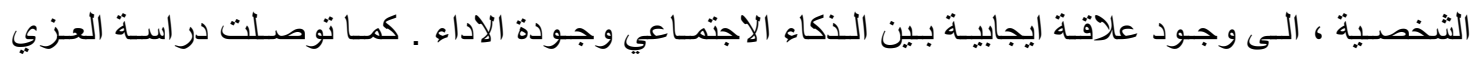

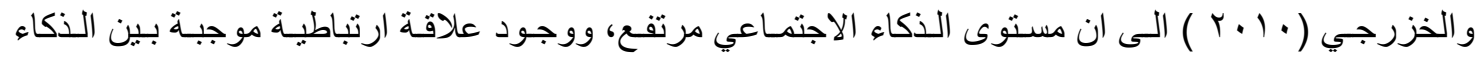

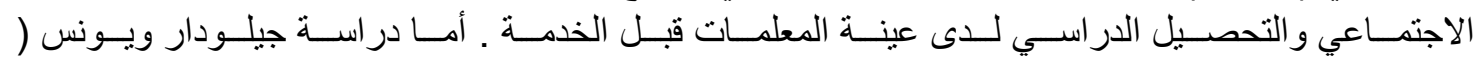




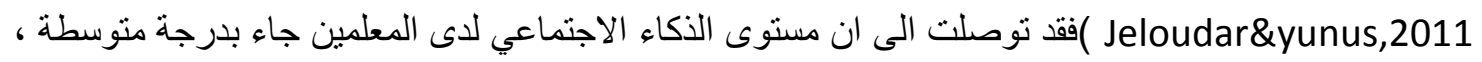

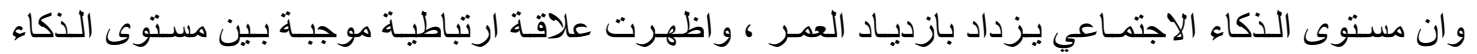

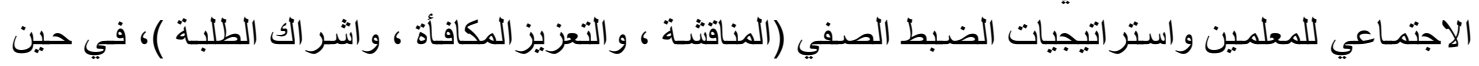

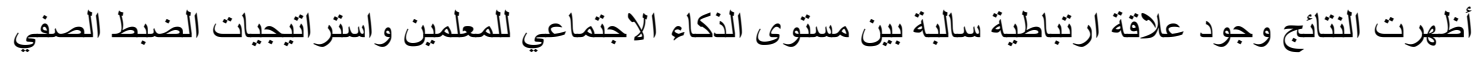

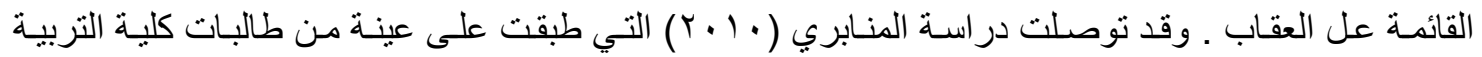

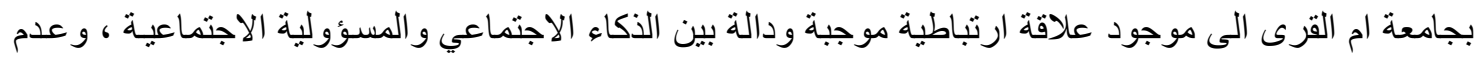

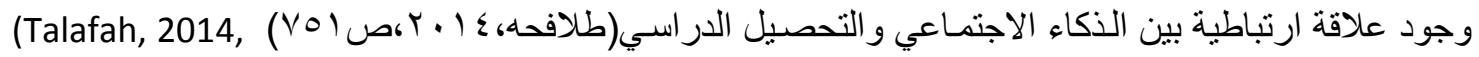

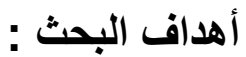

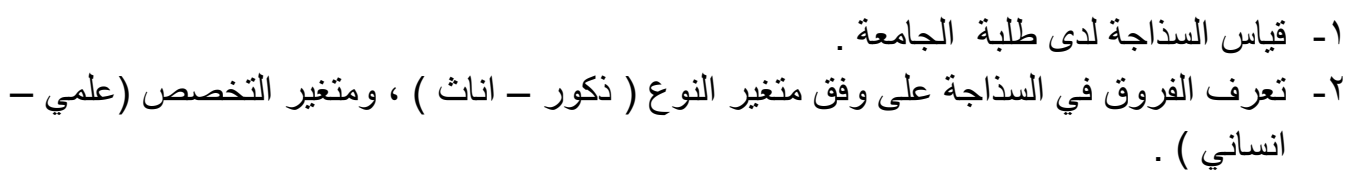

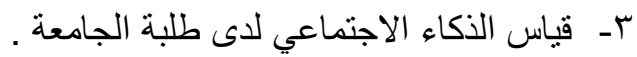
ع- ت تعرف الفروق في الذكاء الاجتماعي على وفق متغير الجئ النوع (ذكور - أناث ) ، ومتغير التخصص (علمي

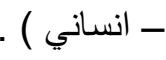
0ـ ايجاد العلاقة بين السذاجة و الذكاء الاجتماعي .

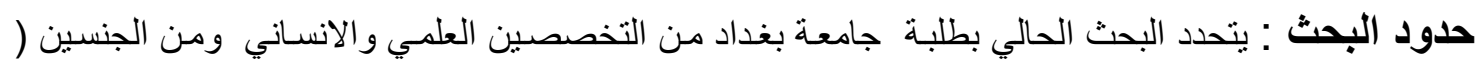

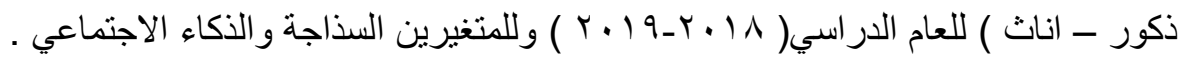

تحديا المصطلحات :

(Gullibility) (أولا- السذاجة

ا - تعريف جرينسبان (Greenspan 2017 ):هي نزعة بعض الناس الذين للايهم ثقة بالناس أكثر من اللازم

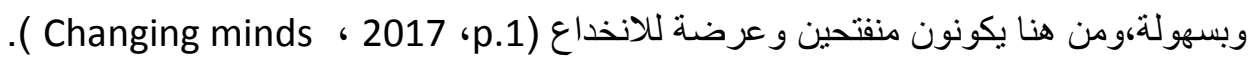

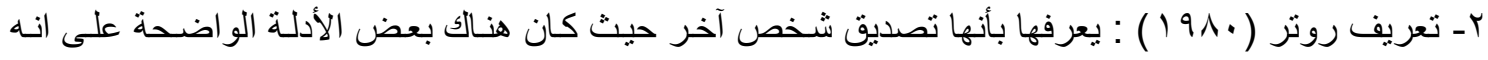

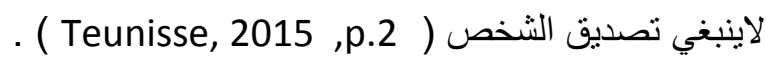

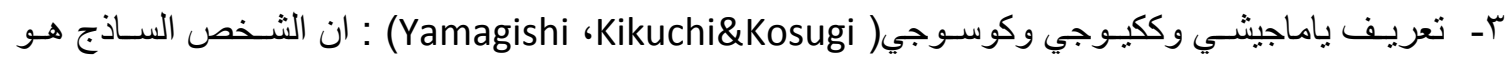

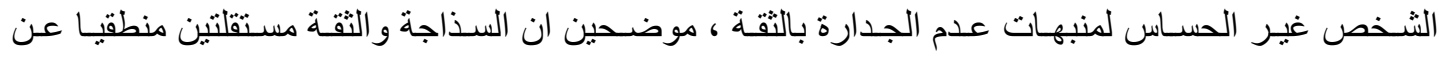

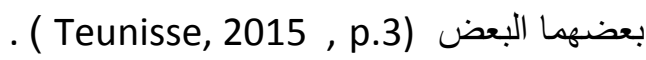

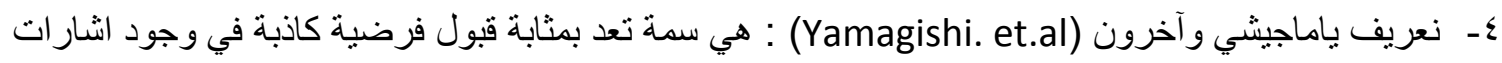

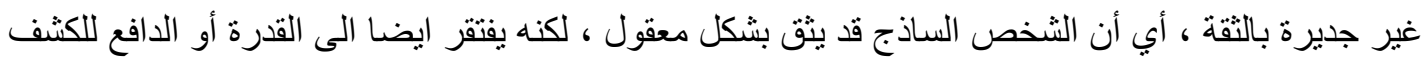

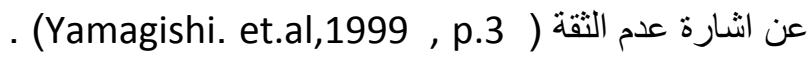

ولم يتبنى الباحث تعربفا محددا وانما تبنى مجمل المنظور المعرفي الذي الذي تنتمي اليه معظم التعريفات السابقة

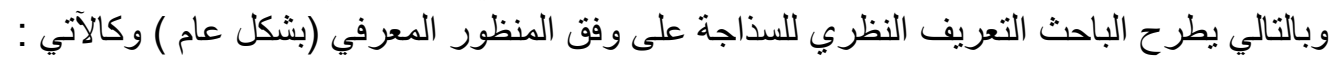

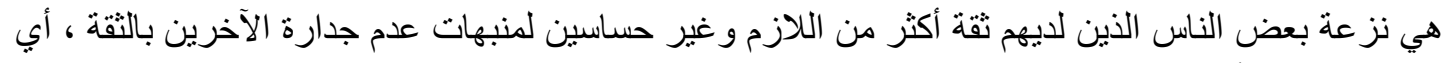

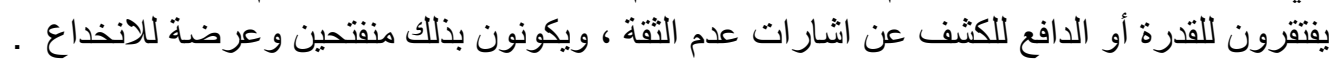

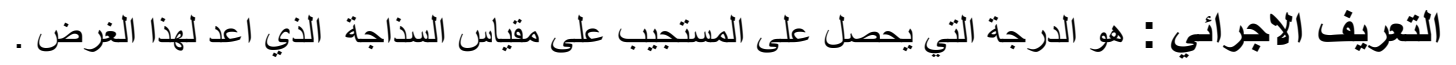




\section{(social Intellagnce ) انيا- الذكاء الاجتماعي}

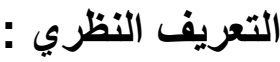

- - تعريف سلفرا واخرون (Silvera\& et.al,2001): هو قدرة الفرد على الدخول و الاستمر ار في علاقات

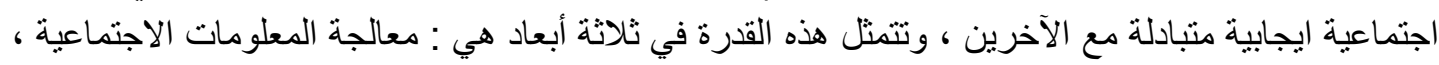

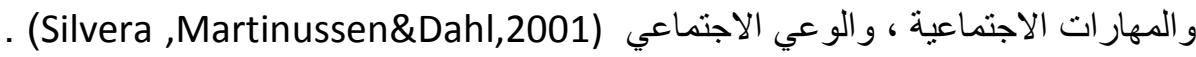

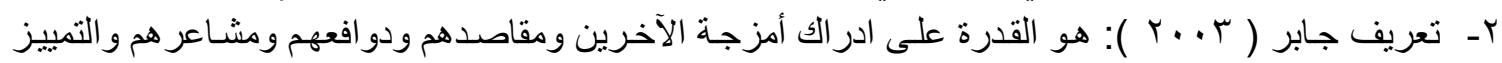

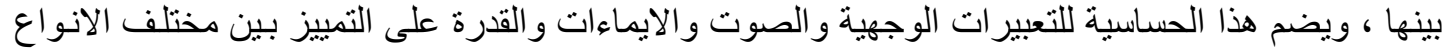

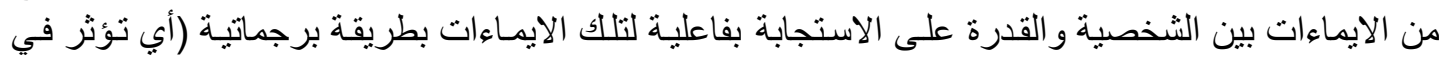

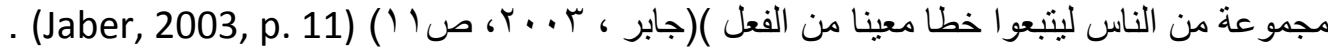
التعريف الاجرائي : هو الدرجة التي يحصل عليها المستجيب على مقياس الذكاء الاجتماعي المعد لهذا

\section{الفصل الثاني / الاطار النظري :القسم الاول - السذاجة :}

أولا- مقدمة : مما يثير الدهشة ان قاموس اللغة الانكليزية الحديثة لايحتوي على كلمة سذاجة ، فالفعل ( gull ) والئل

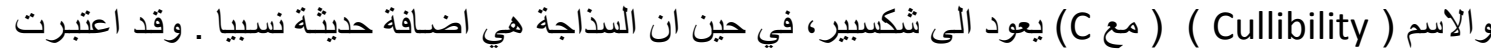

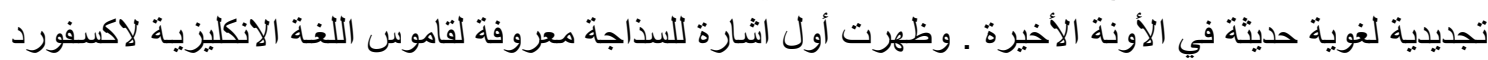

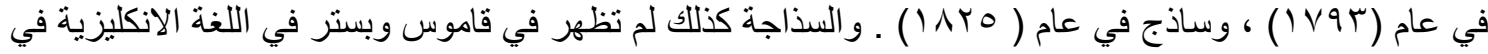

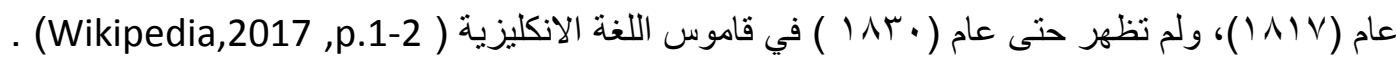

ان الهوموسـابينس (النوع الحسالي من الجنس البشري ) هو من المحتمل أن يكون نو عـا سـاذجا جو هريـا .

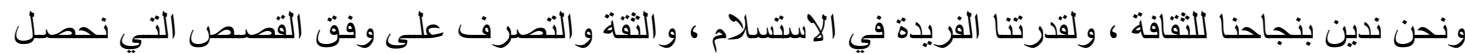

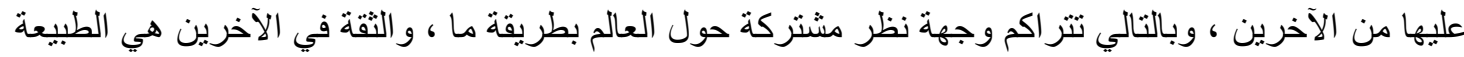

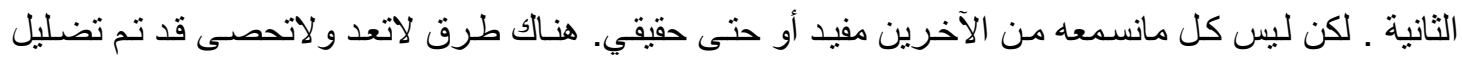

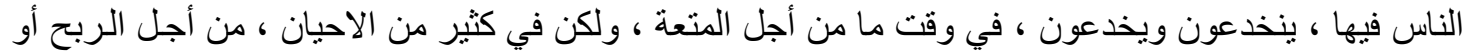

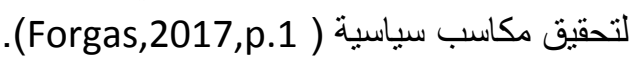

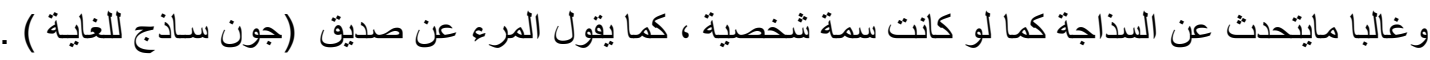

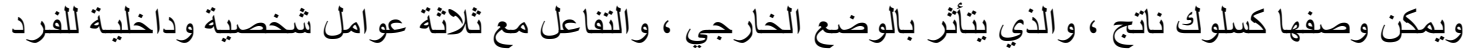

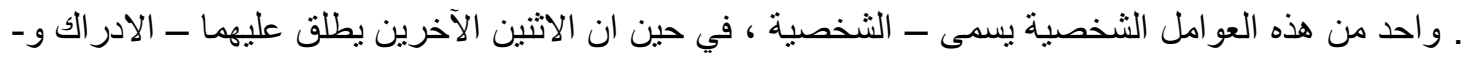

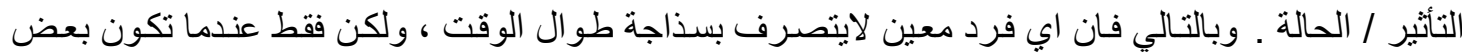

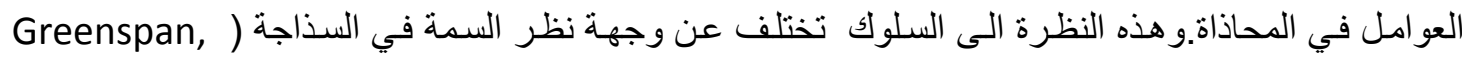

. ( 2009 , p.158

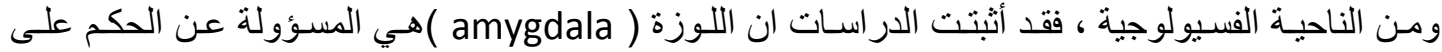

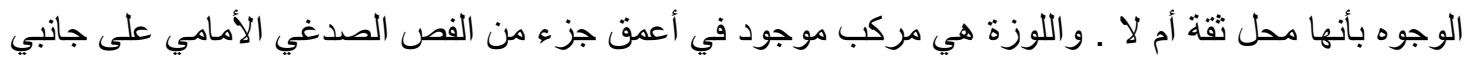

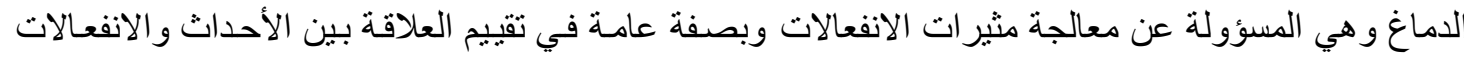

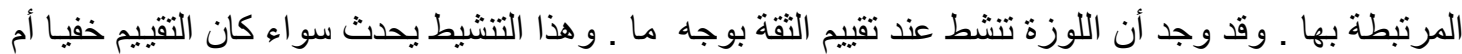

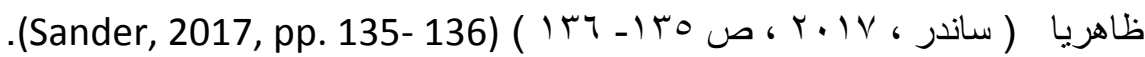

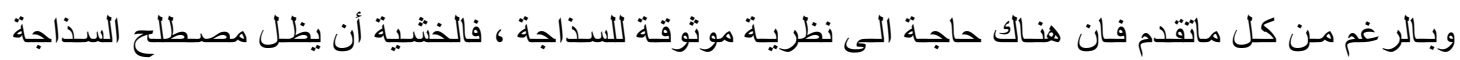

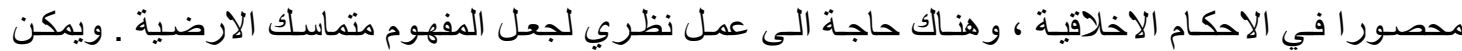

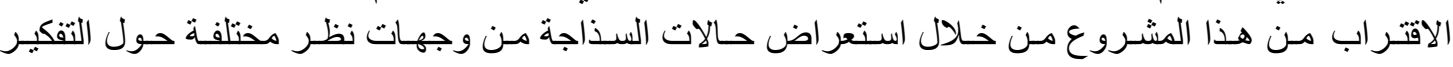




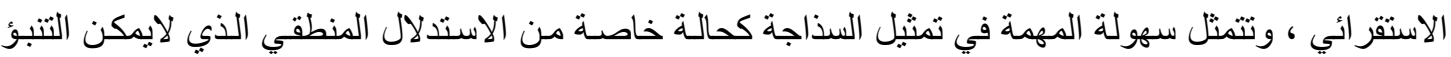

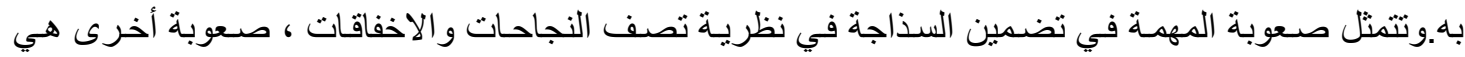

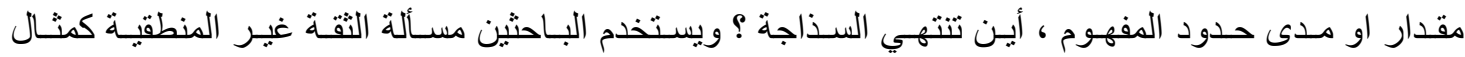

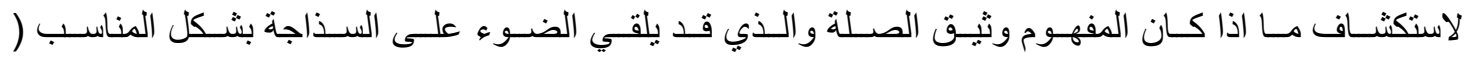

.(Krueger,Haselbacher\&Evanc,2011,p.2

و اذا كان بالامكان الحديث عن شخصية ساذجة ، فانها يمكن ان تمتاز بالآتي :

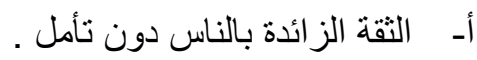

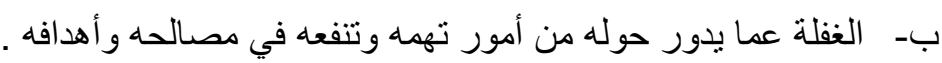

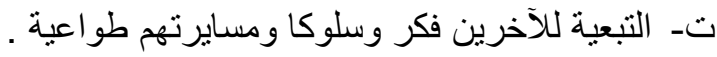

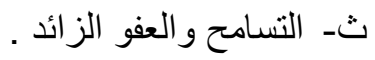

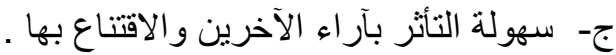

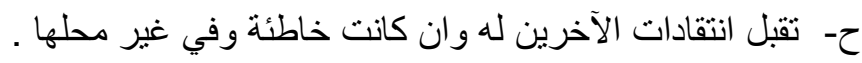

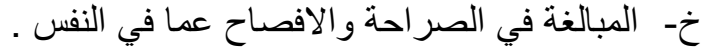

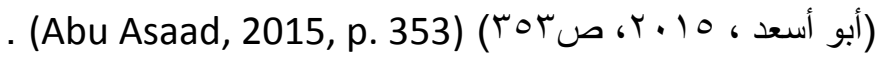

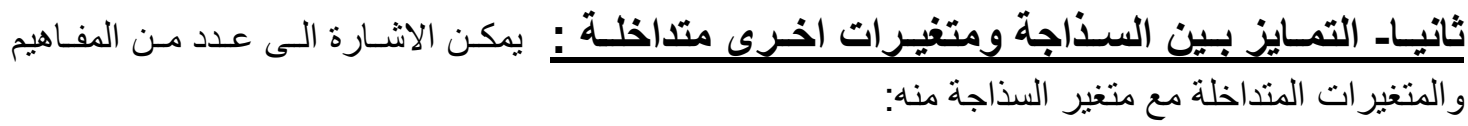

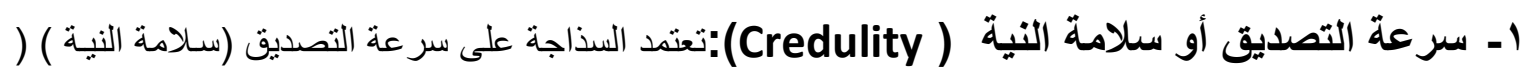
Credulity

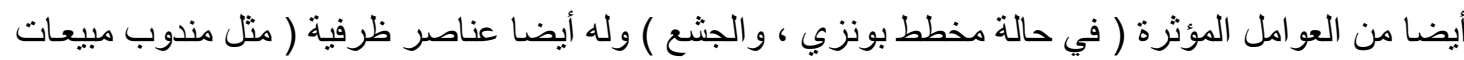

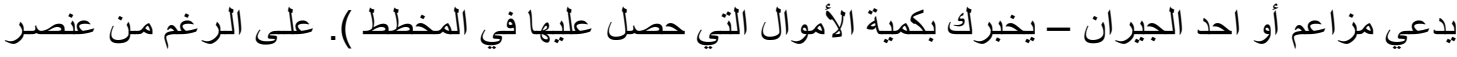

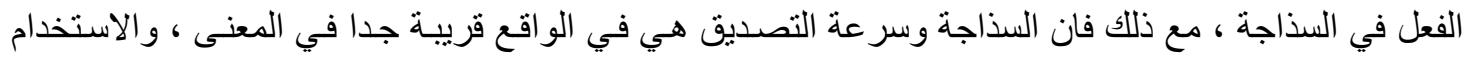

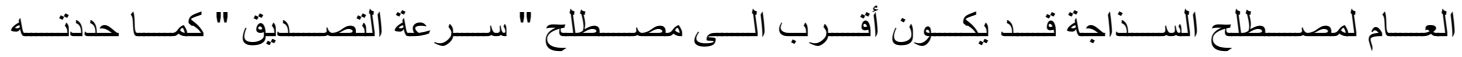

. (Greenspan,2009,p.3)

الكلمات "ساذج " و"سليم النية " ( سريع التصديق ) تكون عادة مستخدمة كمر ادفات ـ و ويرى كويبي وكي (Goepp\&Kay1984)

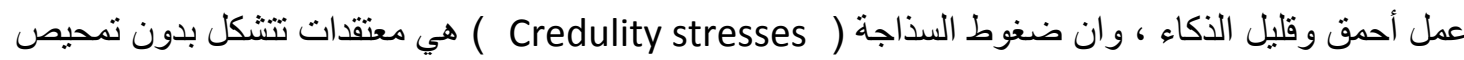

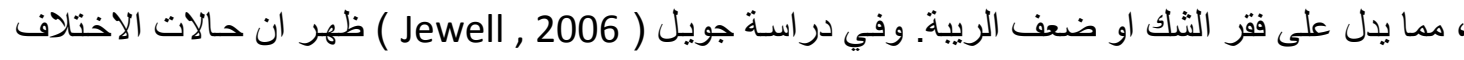

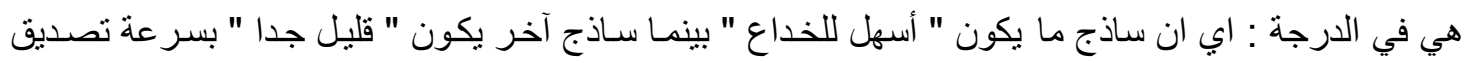

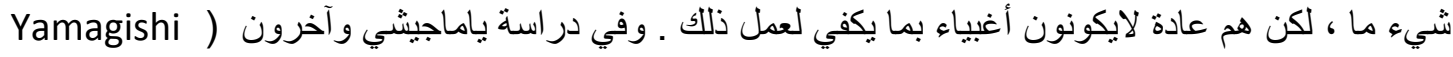
( et.al, 1999

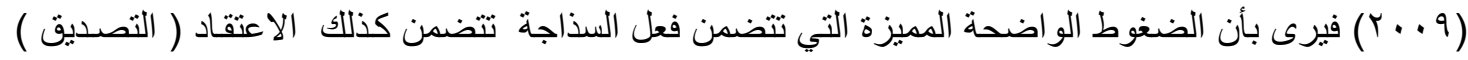

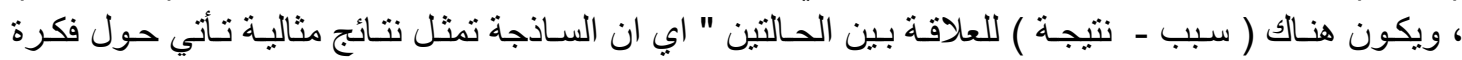

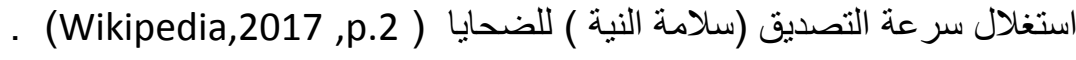

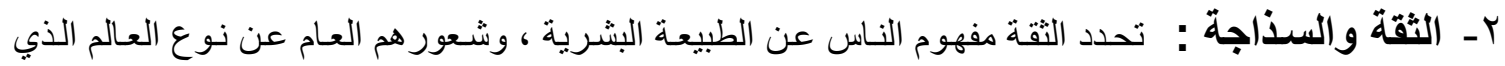

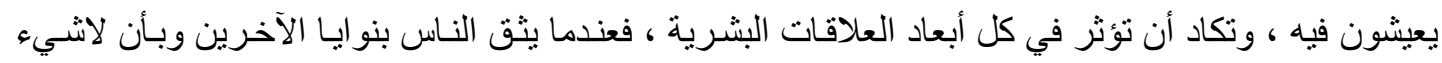

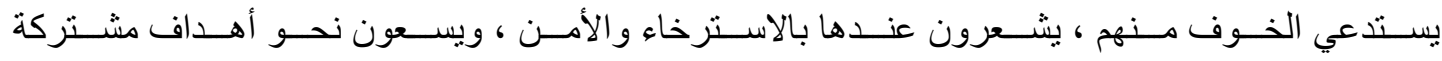

.(Govier,1998,pp.4,1) 


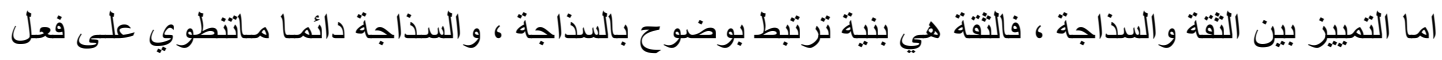
يتضمن الثقة بشخص ما ، والسذاجة فيها بعض التأكيد على ان الثكك غير ملائم وان التقاعس عن الفعل أكثر

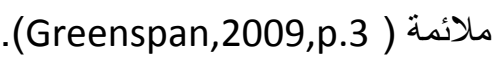

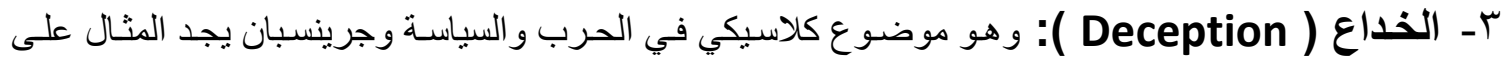

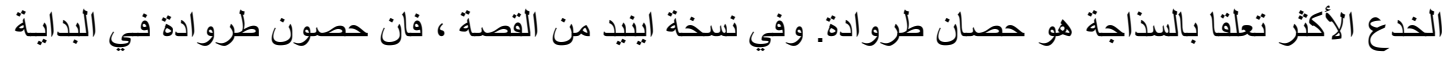

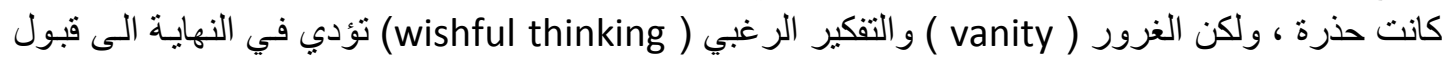

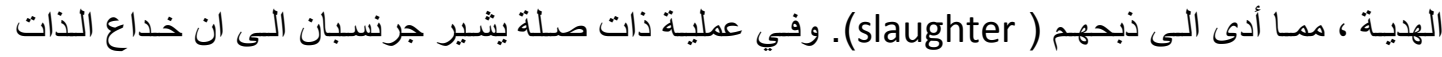

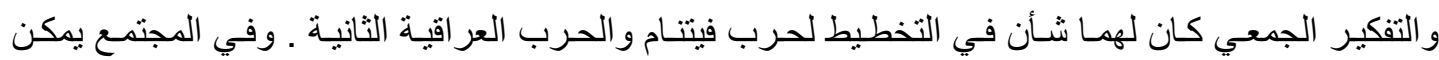
الاشارة الى ظاهرة هوس التوليب او جنون التوليب ( tulipmania) و غير هـا من فقاعات الاستثمار تنطوي

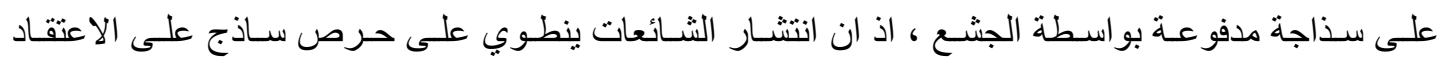
(التصديق) بالثائعة ورو ايتها بشكل أسو أ للناس الآخرين ( p.3, Wikipedia,2017).

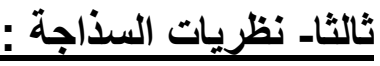

ا-نظرية روتر ( Rotter): الثقة لاى " جوليان روتر" هي ثقة الفرد بـآخرين ممن لايمتلك خبرة شخصية

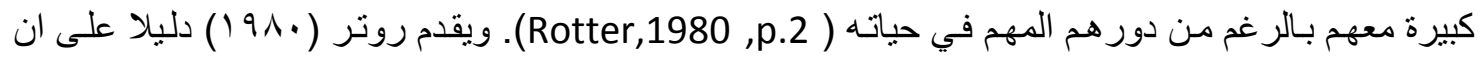

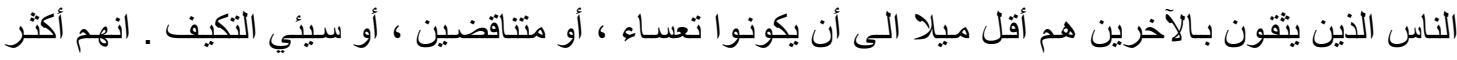

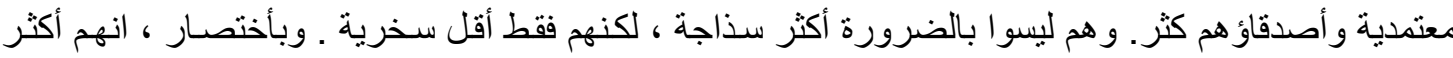

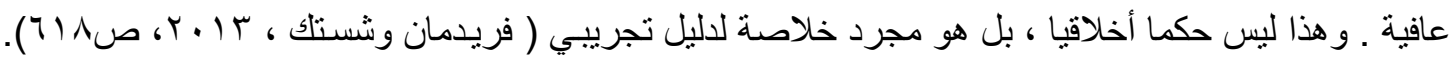
. (Friedman \& Schestek, 2013, p. 618)

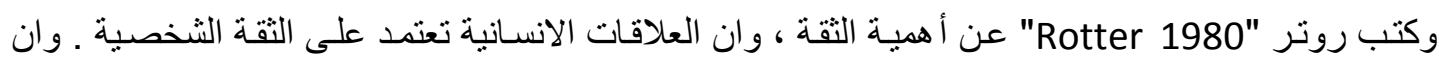

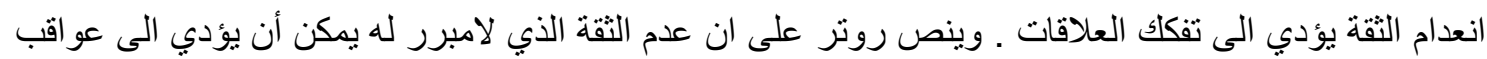

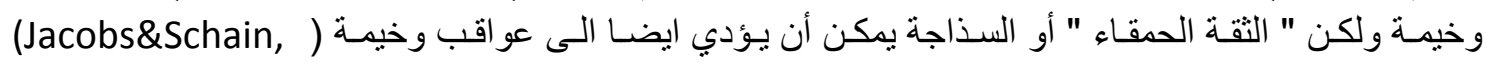
.2011,p.41

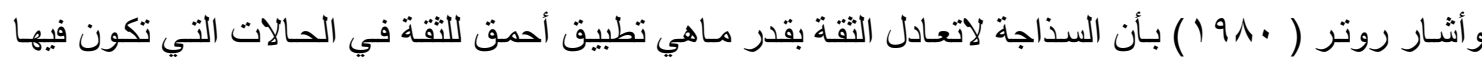

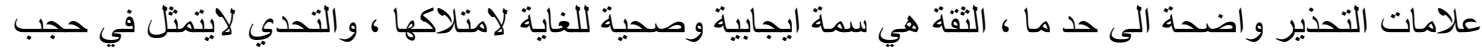

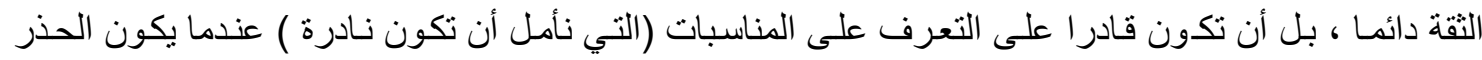

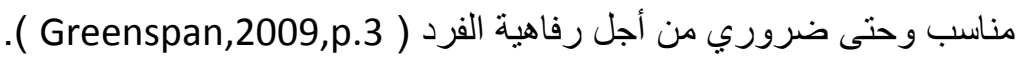

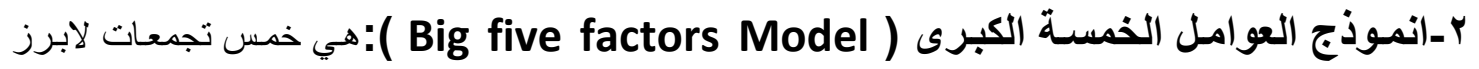

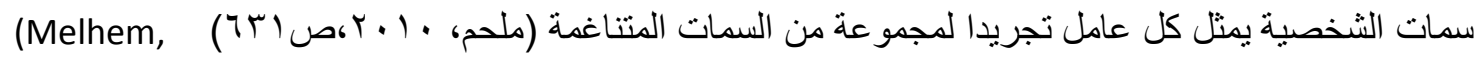

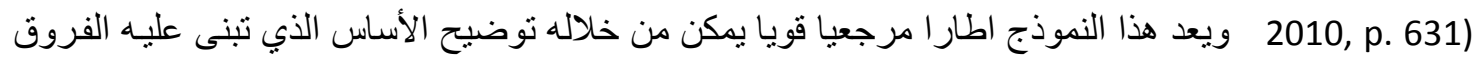

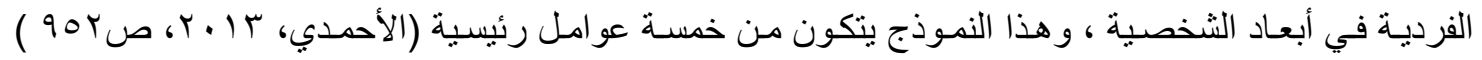

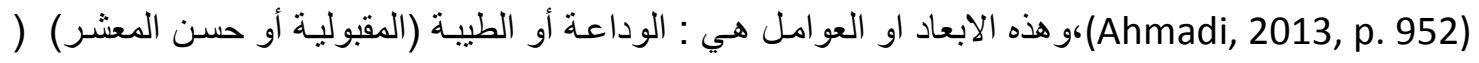

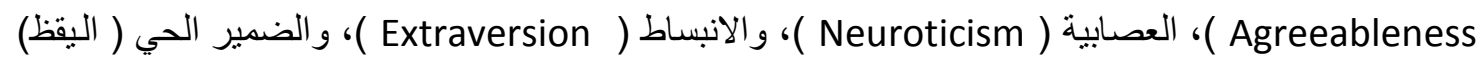

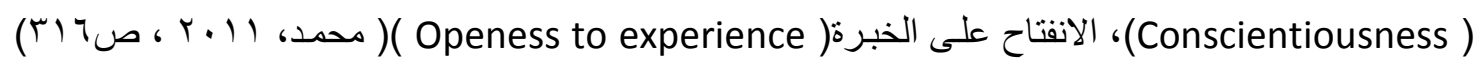
.(Muhammad, 2011, p. 316)

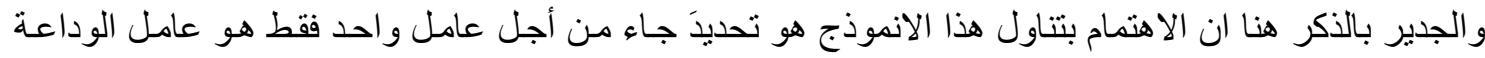

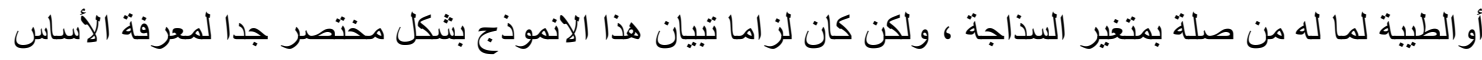

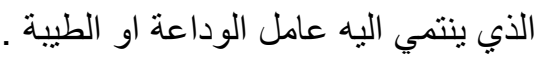


و الوداعة أو الطيبة ( Agreeableness ) هي مجموعة من سمات الثخصية التي تركز على نوعيـة العلاقات

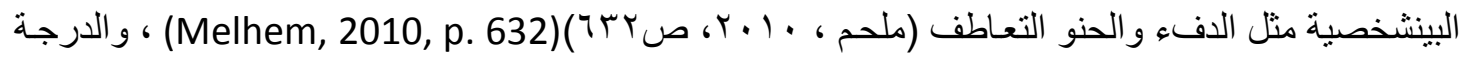

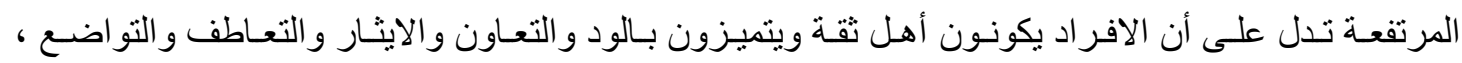

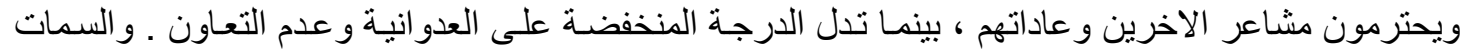

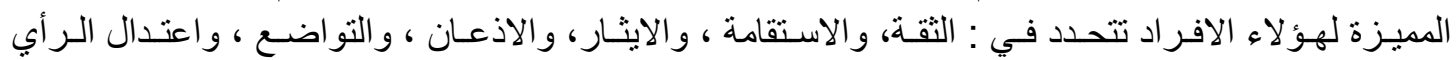

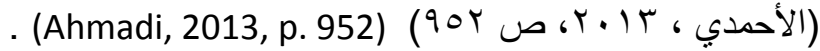

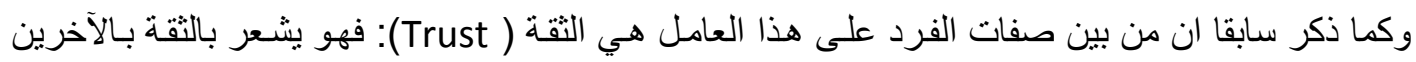

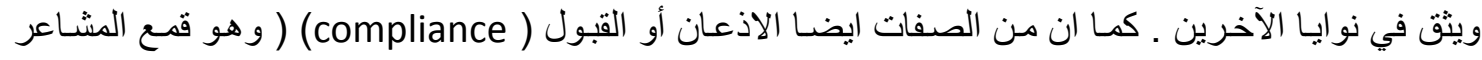

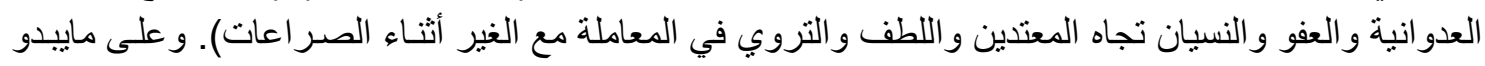

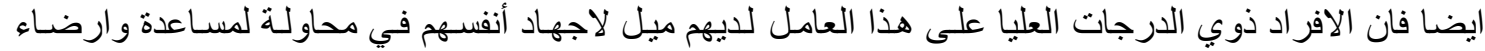

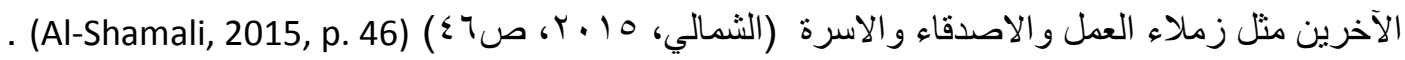

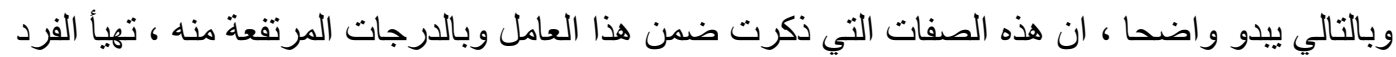

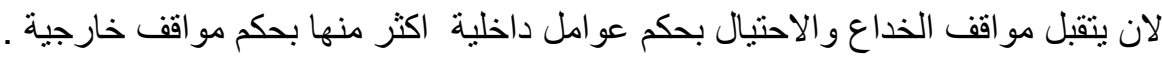
ب-نظرية ياماجيشي ( Yamagishi,1994) :في سلسلة من التجارب التي أجريت في اليابان بو اسطة ياماجيشي

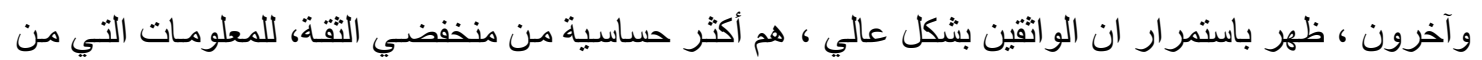

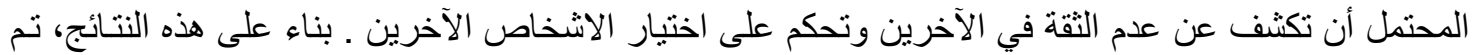

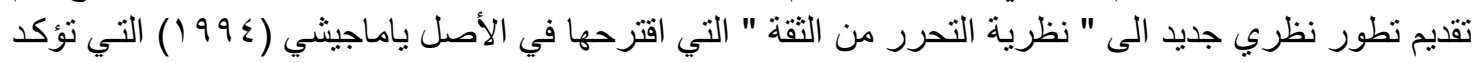

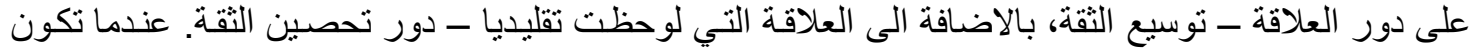

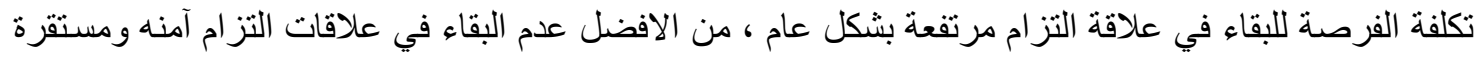

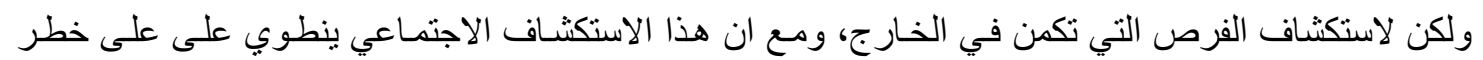

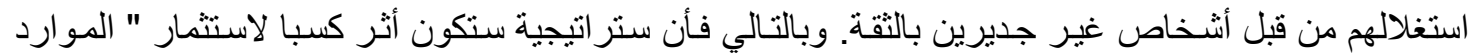

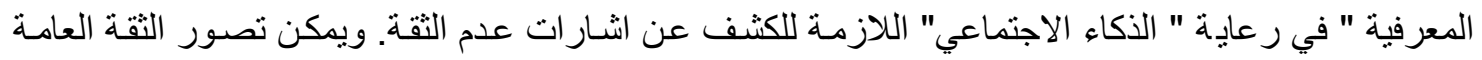

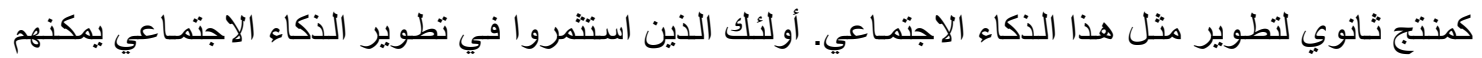

الحفاظ على مسنوى عال من الثقة العامة ( Yamagishi\&et.al ,1999,p.1).

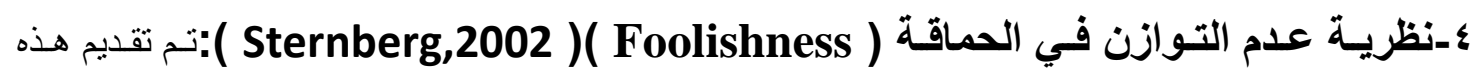

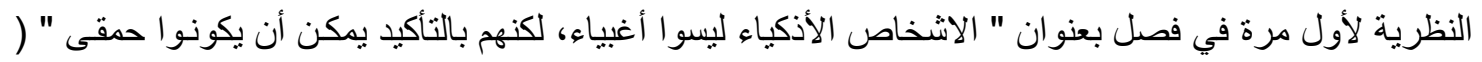

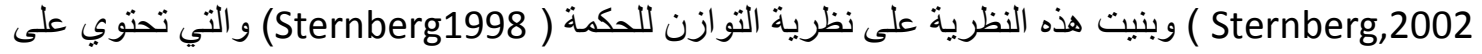

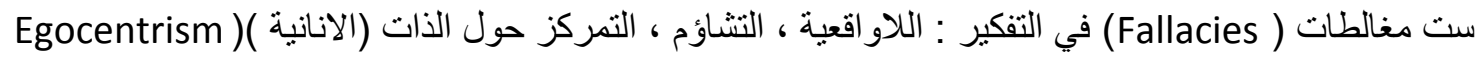

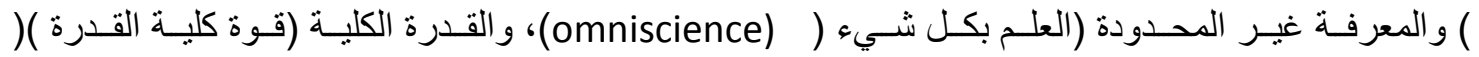

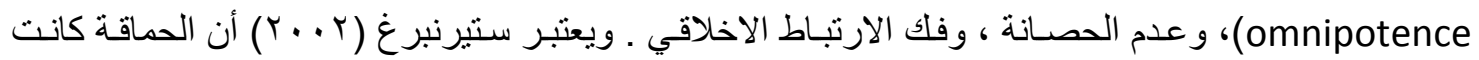

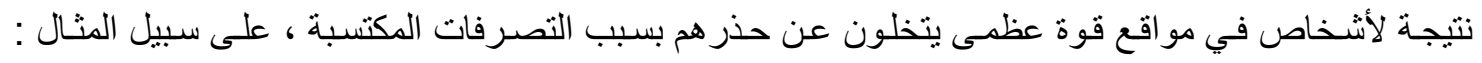

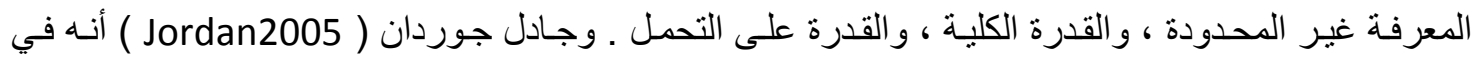
البيئات التنظيمية حيث تحظى السلطة والحالة بتقدير كبير ، و " التركيز على اكتساب و استبقاء السلطة و المكانة

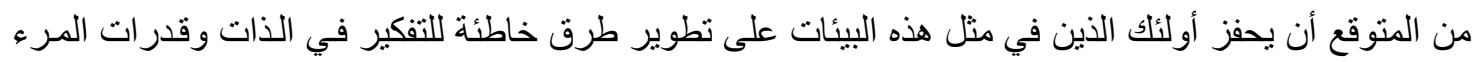

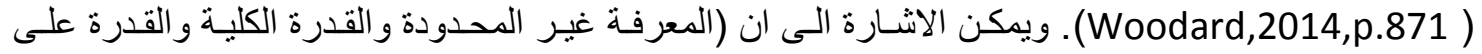

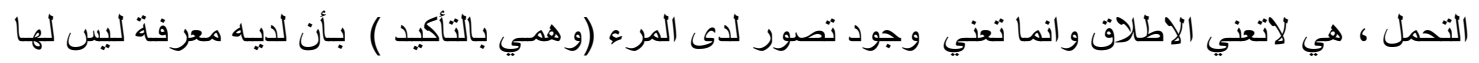
حدود ولديه قوة تمثل كامل القدرة ولديه قدرة على التحمل كبيرة أواستثنائية ) .

هـنظرية جرينسبان (Stephen Greenspan , 2009):دكتور جرينسبان كان مهتم بشكل خاص في مشكلة السذاجة ( النز عة لأن يكون الانسان مخدر او متلاعب به بواسطة واحدة أو أكثر من الوسائل الخادعة 


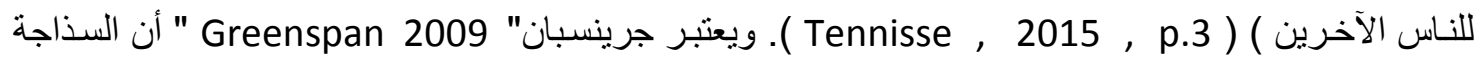

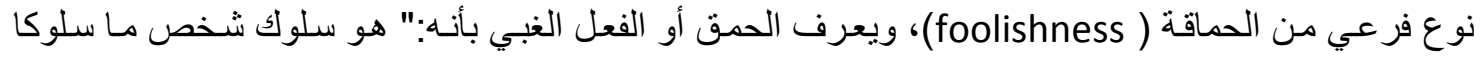

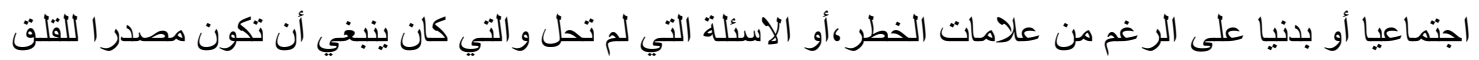
- (Jacobs\&Schain,2011, p40)

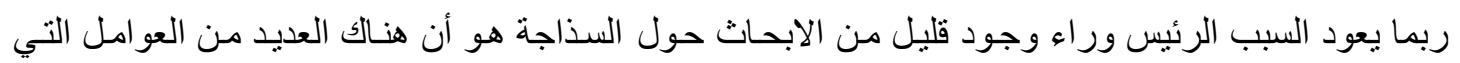

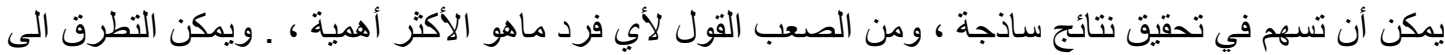

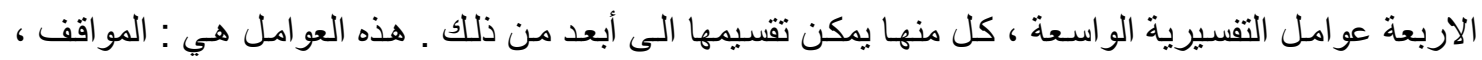

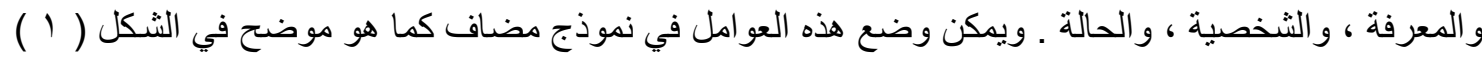

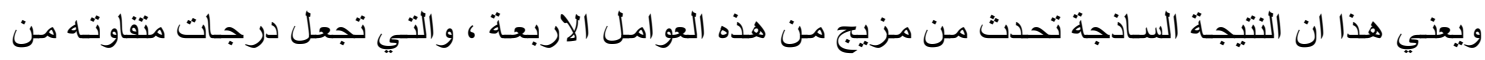

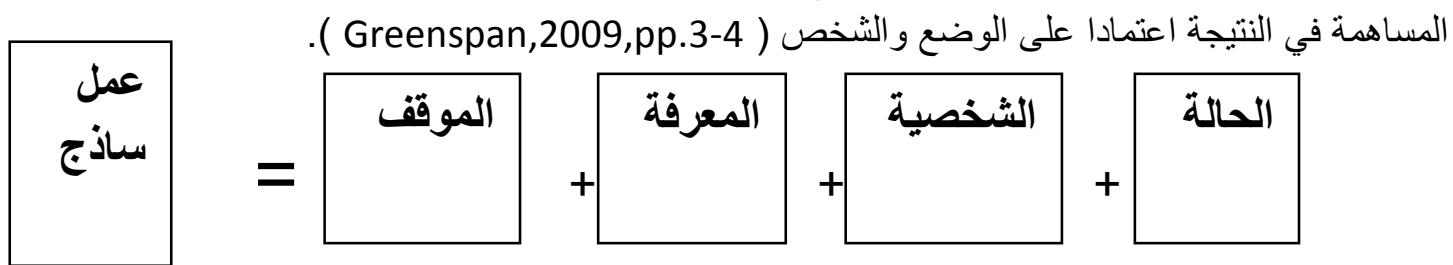

الثكل (1) العو امل التفسيرية الاربعة للسذاجة

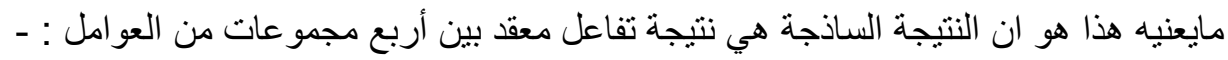

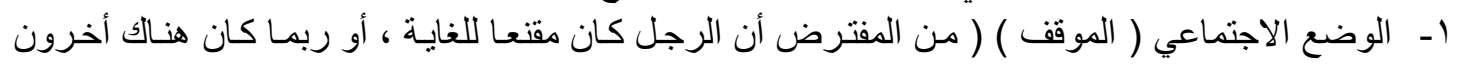

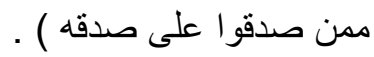
r- العمليات المعرفية ( ربما كانت الضحية سيئة في قر اءة الناس أو ساذجة حول نوع الاستثمار الذي تغطيه عملية الاحتبال ) . r- الثخصية ( ربما كانت الضحية شخصا ) شديد الثقة أو ضعيفا ( لديه صعوبة في قول " لا " ) ) .

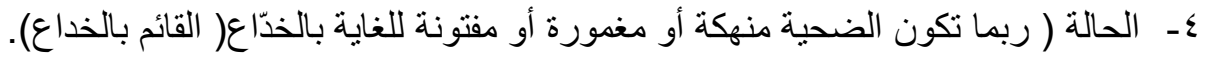

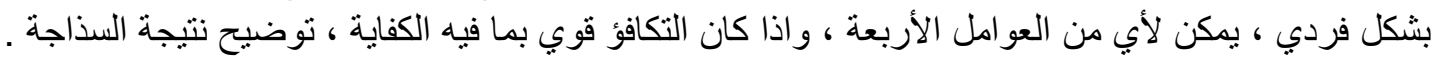

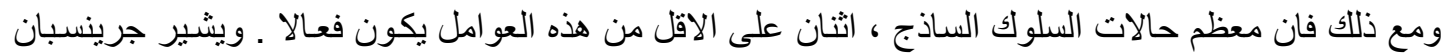

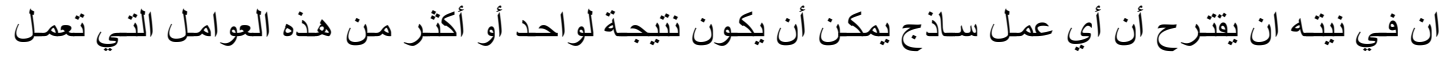

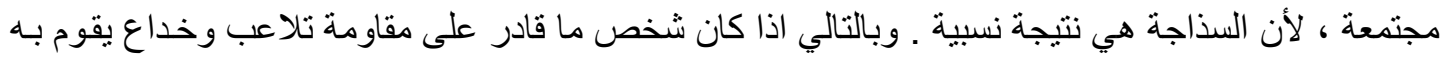

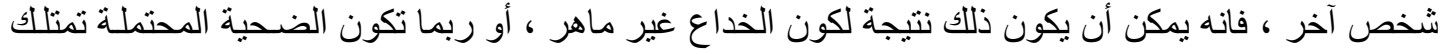

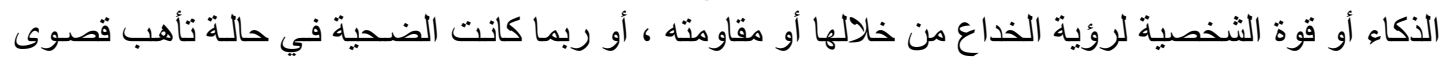

.( Greenspan,2009,pp.4-5 ) 


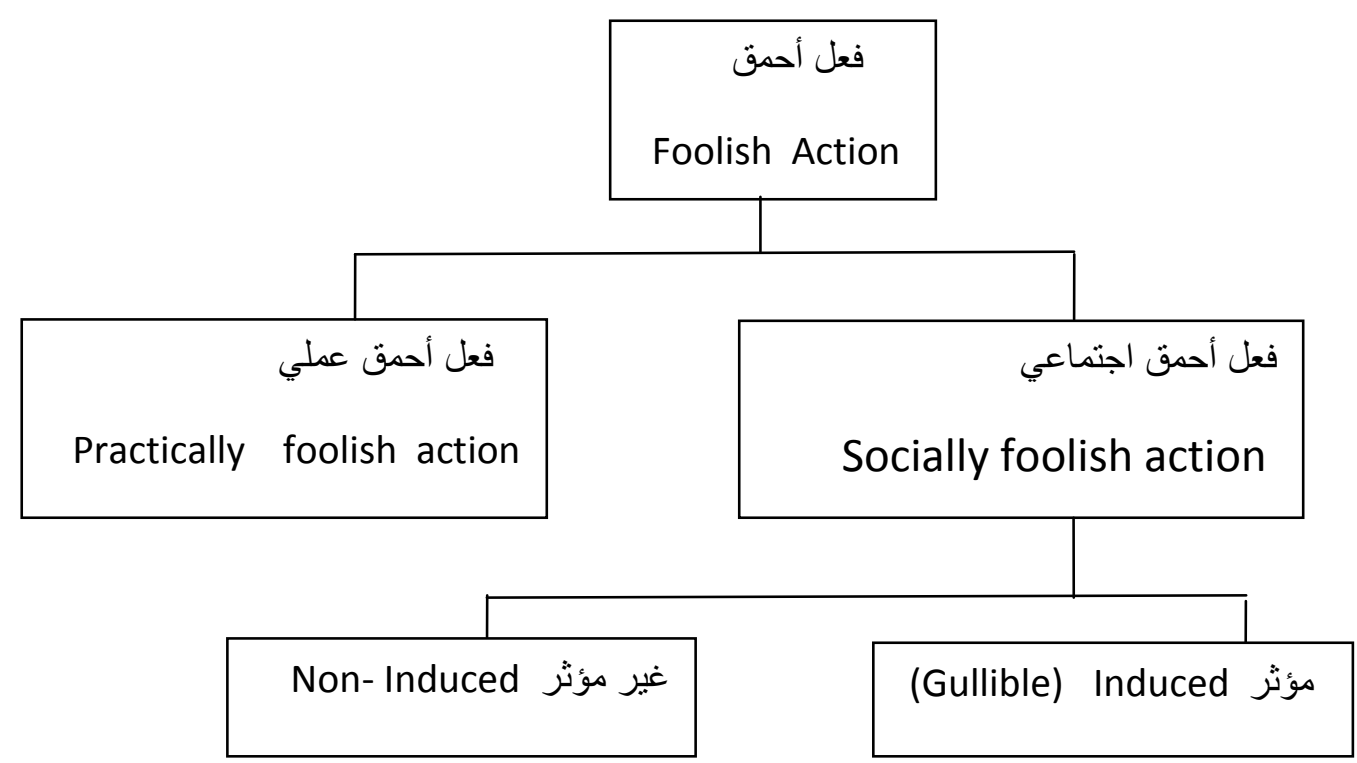

شكل (r) أنواع الفعل الأحمق

القسم الثاني - الذكاء الاجتماعي ( social Intellagnce):-

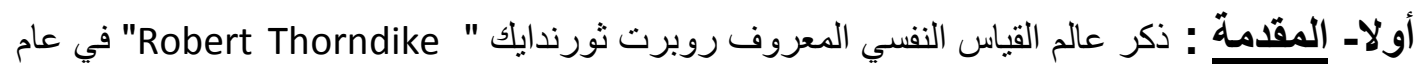

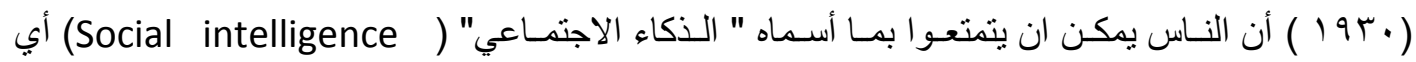
المقدرة على فهم مايدور في داخلهم ودو اخل الآخرين من رغبات وسلوكيات و التصرف طبقا لذلك (سـاندر، . (Sander, 2017, p. 51) (0) ص (T. TV

وفي سبعينات القرن العشرين تميزت هذه الفترة بالنظر للذكاء الاجتماعي على انه تكوين مستقل ومتميز

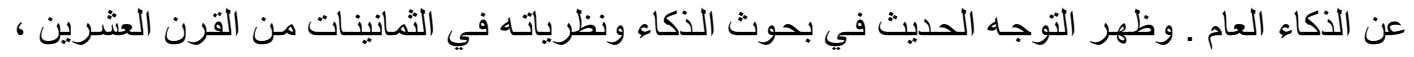

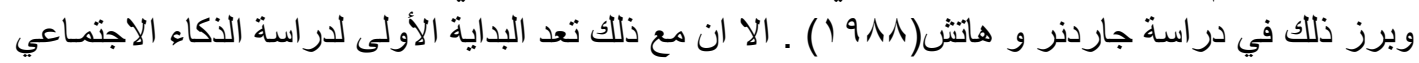

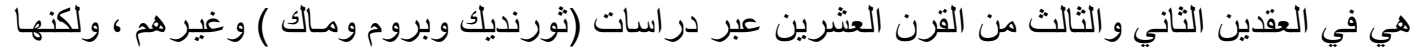

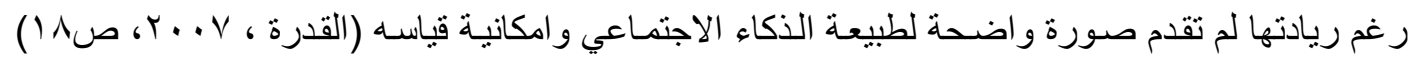

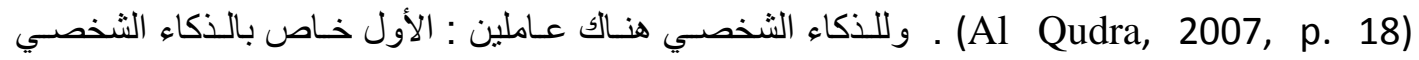

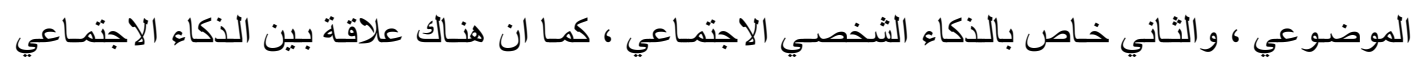

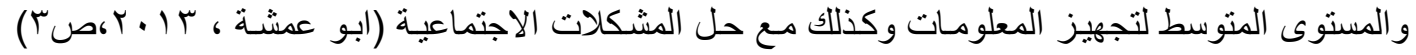
. (Abu Amsha, 2013, p. 3)

\section{ثانيا- نظريات الأكاء الاجتماعى :}

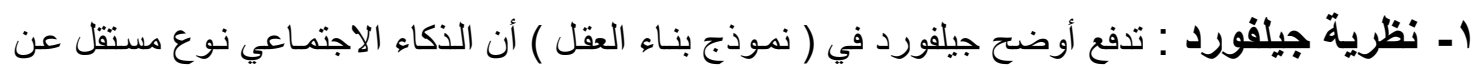

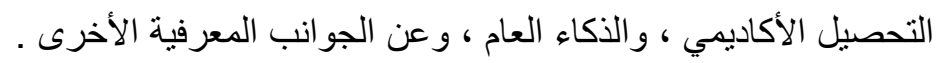

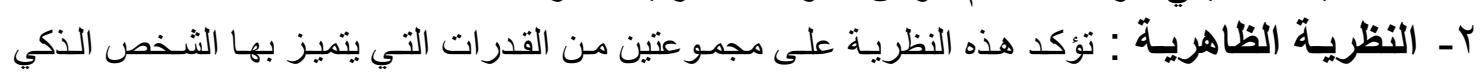

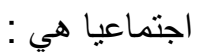

أسهولة التكيف : وتتمثل في القدرة على التكيف مع أي مجموعة بشرية والتأقلم معها. بـ قوة الثخصية : تتمثل في التصرف الجيد في المو اقف الاجتماعية . 
بـ النظرية الضمنية :تشمل أربعة أفكار رئيسة ،تمثل خصال الثخص الذكي اجتماعيا والتي ذكر ها فورد ( (Ford

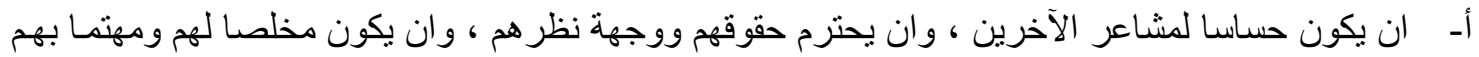

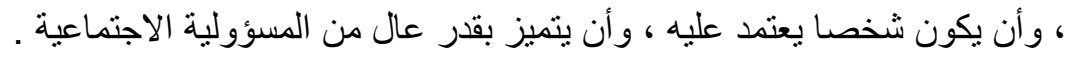

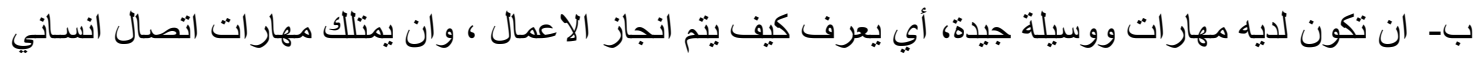

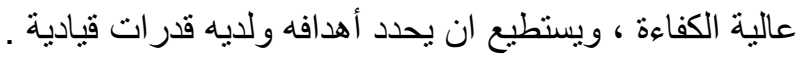

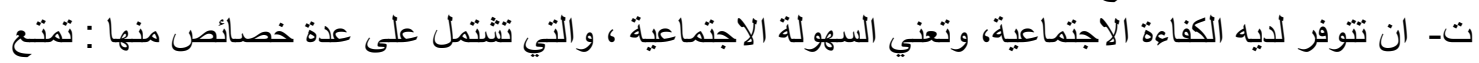

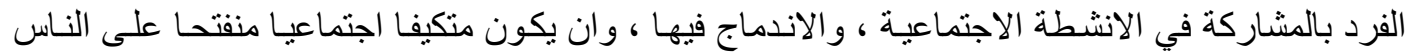
وان يكون سهلا معهم .

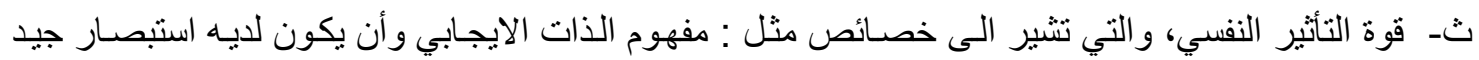

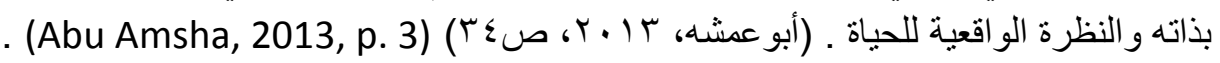

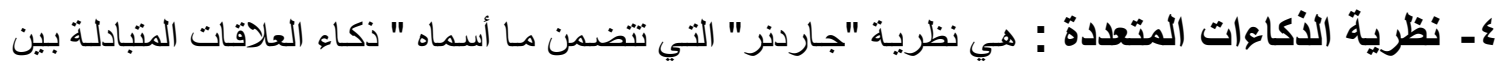

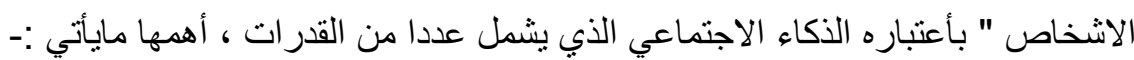

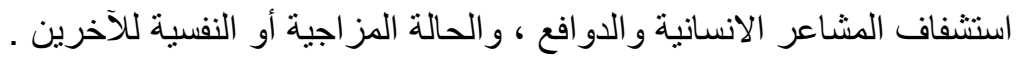

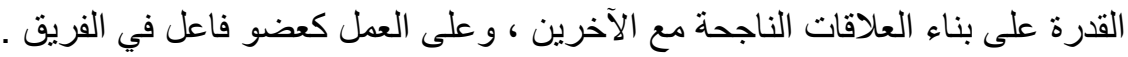

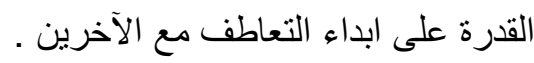

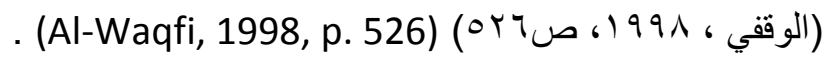

\section{الفصل الثالث / منهجية البحث واجراء(ته}

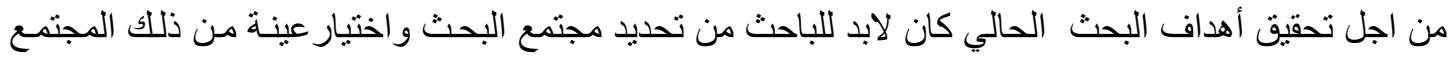

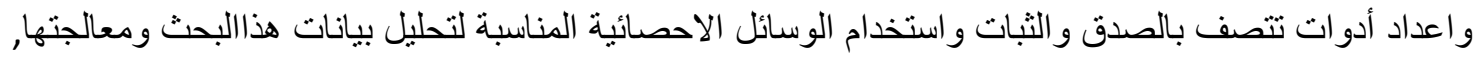

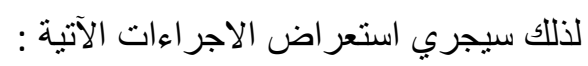

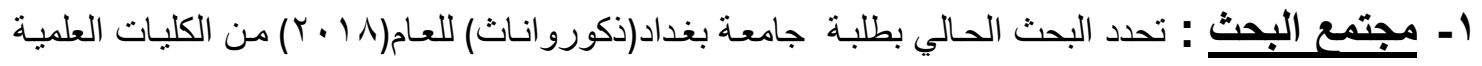

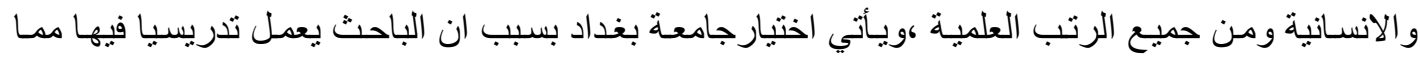
يسهل عملية التطبيق.

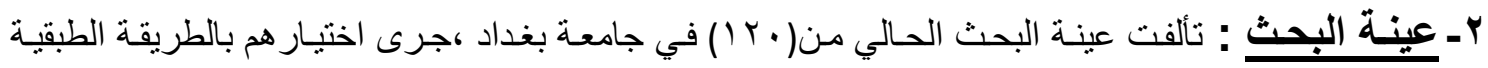
العشو ائية, وذللك باختبار كلية الآداب من الاختصاص الانساني وكلية العلوم لتمثل الاختصاص العلمي وباعداد متساوية. و الجدول( (1) يوضح ذلك. 


\section{جدول ( ) ( )}

توزيع أفر اد العينة على وفق النوع و التخصص والمرحلة

\begin{tabular}{|c|c|c|c|c|c|c|c|c|c|}
\hline \multirow[b]{2}{*}{ المجموع } & \multicolumn{4}{|c|}{ انساني ( كلية الآداب) } & \multicolumn{4}{|c|}{ علمي (كلية العلوم) } & والتخصصلة \\
\hline & رابع & ثالث & ثناني & أول & رابع & ثنالث & ثاني & أول & \\
\hline 7. & v & V & V & V & $\Lambda$ & $\Lambda$ & $\Lambda$ & $\wedge$ & اناث \\
\hline 7. & $\Lambda$ & $\wedge$ & $\wedge$ & $\wedge$ & V & V & V & V & ذ ذكور \\
\hline Ir. & 10 & 10 & 10 & 10 & 10 & 10 & 10 & 10 & المجموع \\
\hline
\end{tabular}

بـأداتا البحث : تتمثل أداتا البحث بمقياسي السذاجة و الذكاء الاجتماعي و على النحو الآتي :-

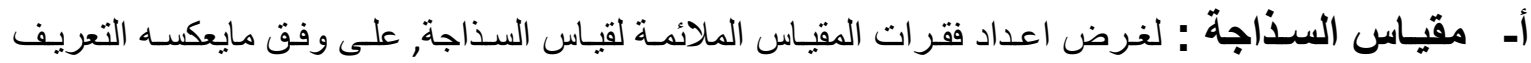

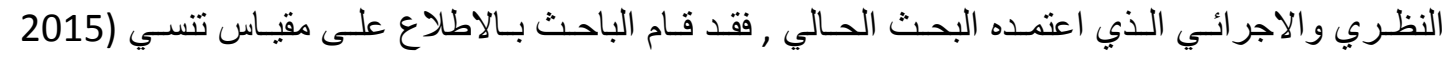
(Tennisse ,2015,p.40) (Tennisse

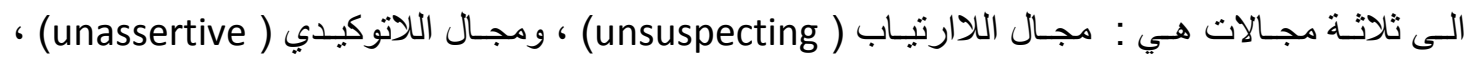

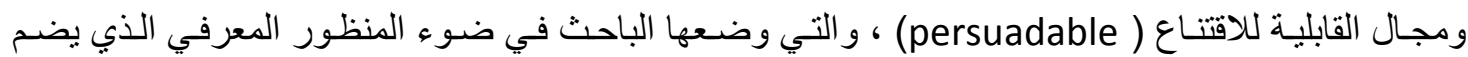
معظم نظريات السذاجة الحديثة .

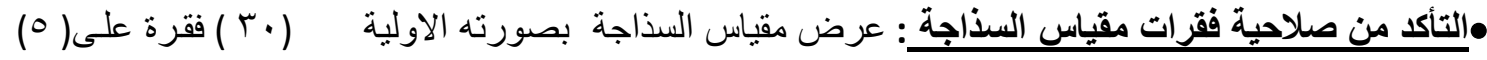

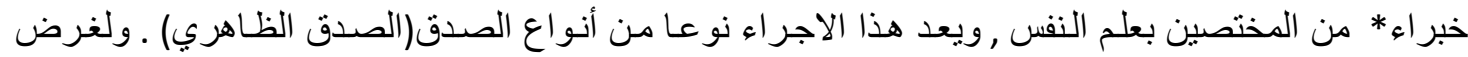

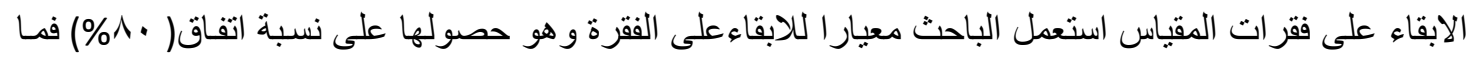

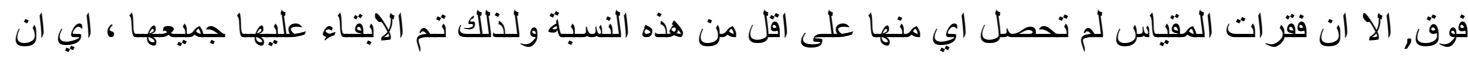

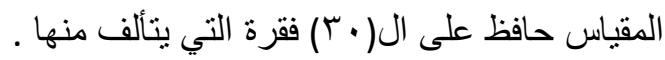

\section{•الإجابة على المقياس :}

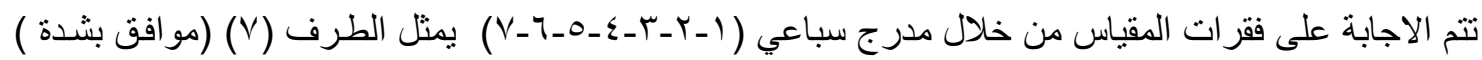

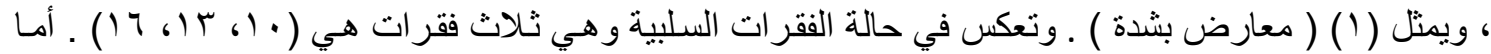

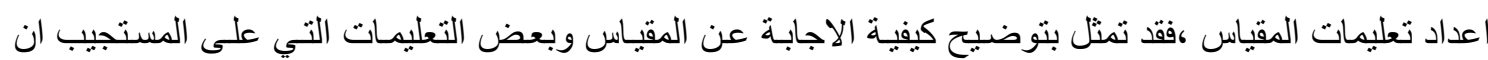
ينتبه اليها.

\section{•تعليل فقزات المقياس:}

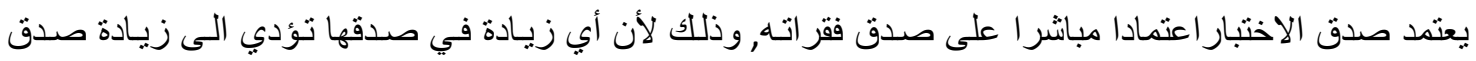

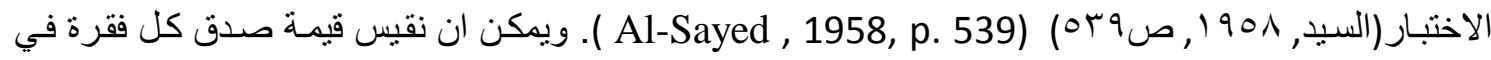

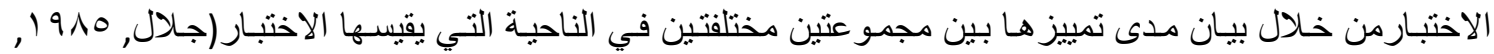

$$
\text { • (Jalal, 1985, p. 37) (rv ) }
$$




\section{1 -ايجاد القوة التمييزية للققرات:}

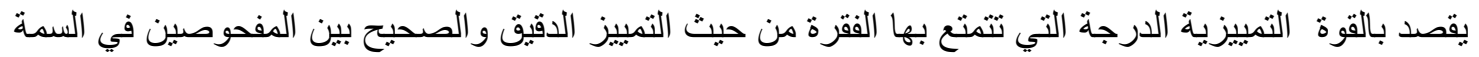

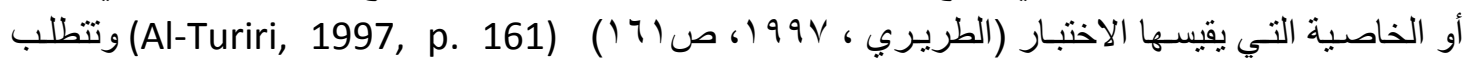

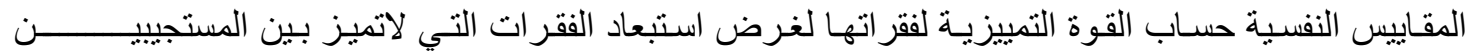

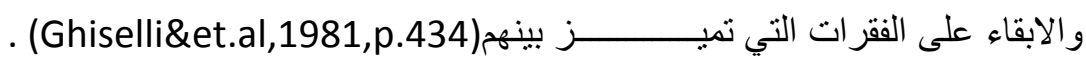

وكان حجم العينة التي حلت درجاتها احصائيا في البحث الحالي عند حساب القوة التمييزية للفقر ات( • ( ) طالبا

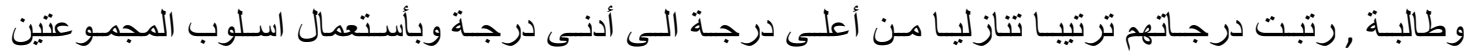

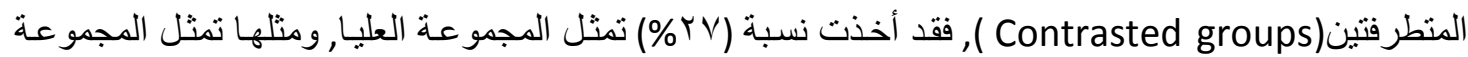

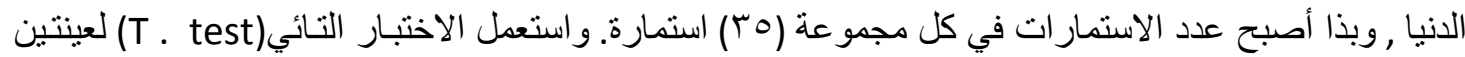

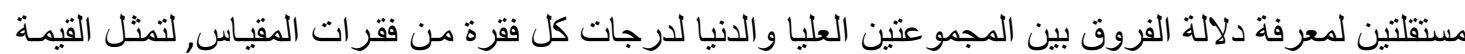

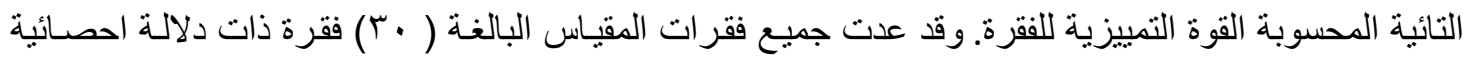

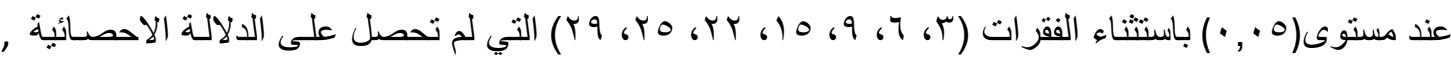

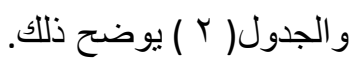




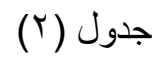

القوة التمييزية لفقر ات مقياس السذاجة

\begin{tabular}{|c|c|c|c|c|c|c|}
\hline \multirow{2}{*}{ النتيجة } & \multirow{2}{*}{ القائية القية } & \multicolumn{2}{|c|}{ المجمو عة الدنبا } & \multicolumn{2}{|c|}{ المجموعة العليا } & \multirow[t]{2}{*}{ ت } \\
\hline & & الانحر اف المعياري & الوسط الحسابي & الانحراف & المعياري الحسابي & \\
\hline دالة دالة & r.99. & $1.0 Y 1 K 1$ & $r . r \leq r \leq$ & $1 \mathrm{~V} 910 \mathrm{~V}$ & $\varepsilon . \wedge \vee \wedge \wedge$ & -1 \\
\hline 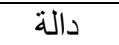 & 7.109 & $1 . r 9491$ & $r .0 \leqslant 00$ & $1 . \Gamma 1 \leqslant 9 \wedge$ & $0.774 \mathrm{~V}$ & $r$ \\
\hline غير دالة &. $.79 \mathrm{~V}$ & $1.097 . \varepsilon$ & $\varepsilon . Y \mid Y)$ & 1.9YYYT & $\varepsilon .010 Y$ & $r$ \\
\hline دالة & $7.7 T \pi$ & $1.7971 \leqslant$ & r.ovon & 1.51709 & $7 . \cdot r \cdot r$ & $\varepsilon$ \\
\hline دالة الة الة & r.707 & 1. rדVqY & r.rq4q & 1.9YKYT & $\Gamma . \varepsilon \wedge \leqslant \wedge$ & 0 \\
\hline غيردالة & $1.7 \%$. & $1 . \leqslant \leqslant Y \cdot T$ & T.VTVT & T.ITVTr & $\varepsilon \leqslant 0 \leqslant 0$ & 7 \\
\hline 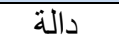 & $r .104$ & $1.09 \leqslant Y 7$ & r.747V & 1.VONTE & $\varepsilon .979 V$ & v \\
\hline دالة د الة & ร.7Tน & 1.rTOOr & $r . r \leq r \leq$ & 1.7100 & $\varepsilon . \wedge \vee \wedge \wedge$ & $\wedge$ \\
\hline غيردالة & 1.809 & $1.0 Y .79$ & $r \ldots . .$. & 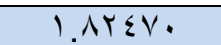 & T.VTVT & 9 \\
\hline 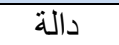 & $0.99 \varepsilon$ & 1. $17 \vee \vee 9$ & דוזעזיז & $I . Y N I \leqslant Y$ & O.VTVY & 1. \\
\hline 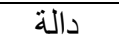 & r.77. & $1 . T T V \leqslant Y$ & r.T.r. & T.VV77T & $\varepsilon \ldots$ & 11 \\
\hline دالة د الة & T.人Tร & $1.1 \mathrm{VON}$ & r.010r & $1 . \leqslant 9 \leqslant 9 \leqslant$ & $\varepsilon . \vee \wedge \vee q$ & $T$ \\
\hline دالة & r..19 & 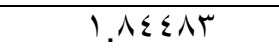 & そ1イ। & $1.07 \ldots \varepsilon$ & 0.9 .7 & $\pi$ \\
\hline 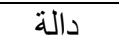 & $V .111$ & $1.50 \wedge \mu q$ & T.VOVT & 1.TYYOY & $0 . \varepsilon \wedge \leqslant \wedge$ & $1 \varepsilon$ \\
\hline غبر داله & $1.0 Y$ & $1.9 . \leqslant \leqslant \varepsilon$ & $\varepsilon .0 \vee 01$ & 1.09 .79 & $0 . T . r$ & 10 \\
\hline داله & $\varepsilon . \vee V \varepsilon$ & 1.0VTrE & $\{. Y|r|$ & $1 . \leqslant \leqslant Y \cdot T$ & $0 . V Y V T$ & 17 \\
\hline 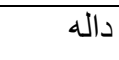 & $r . r \cdot o$ & $1 . \wedge \leqslant r r q$ & r.9.91 & 1.9194 & $\varepsilon .494 q$ & IV \\
\hline داله & $\varepsilon .491$ & 1.0 .119 & $r . \leqslant 0 \leqslant 0$ & T.ITVKr & $0 . \leqslant 0 \leqslant 0$ & 11 \\
\hline داله & Y.ANY & $1 . \leq 9 \leq 9 \leq$ & 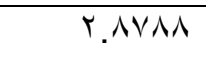 & I.VE.VA & $\varepsilon . \cdot T \cdot r$ & 19 \\
\hline 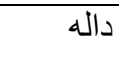 & $r .11 T$ & I.AYYII & $\{.1010$ & $1 . \leqslant 1 \leqslant Y 1$ & $0 . \ldots$ & $r$. \\
\hline داله & $\varepsilon . Y \wedge r$ & $1.0 Y M 11$ & $r .010 Y$ & $1 . \leqslant 7001$ & 0.9 .9 & YI \\
\hline غير دالة & $1 . \wedge \cdot V$ & $1.79 Y K r$ & ร.7นาร & I.VIYAI & 0.4949 & YY \\
\hline دالة & T.7Tr & $.977 r 9$ & r.rqтq & 1.71 .7$. & 纟.7กา & $r \mu$ \\
\hline داله & r.90Y & 1.0 YYOT & $r .0 \leqslant 00$ & $1 . \varepsilon \cdot r \vee \wedge$ & $\varepsilon .979 V$ & $T \xi$ \\
\hline غير داله & 1.110 & 1.OYYOT & $\leqslant \leqslant \leqslant \leqslant 0$ & 1.17999 & 0.1010 & ro \\
\hline 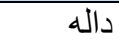 & A.r人T & $1.19 Y A Y$ & T.IYIY & $1 . \Sigma \Gamma \wedge \vee \wedge$ & $0 . \wedge \leqslant \wedge 0$ & T \\
\hline داله & $0.1 \mathrm{TV}$ & I.VTYY. & $T . Y \leqslant Y \leqslant$ & $1.7 V 094$ & 0.4949 & TV \\
\hline داله & 0.20. & 1. rVOOY & T.YVTV & I.9TYYT & $\varepsilon .010 Y$ & $r \wedge$ \\
\hline غير داله & $\cdot . \wedge \cdot 7$ & 1.17999 & $\{.1010$ & Y.IA.Vo & $\leqslant .0 \leqslant 00$ & rq \\
\hline داله & r.Arq & 1.9011. & $r .1 \wedge 11$ & $1 . V \cdot r q \leq$ & $\varepsilon . \wedge \backslash \wedge r$ & r. \\
\hline
\end{tabular}

r ـعلاقة الفقرة بالدرجة الكلية لفقرات مقياس السذاجة : قام الباحث بأستخراج علاقة الفقرة

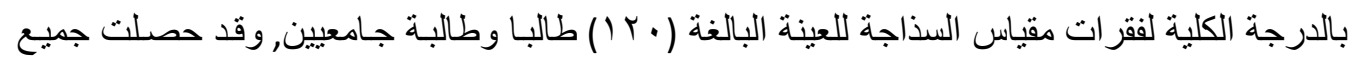

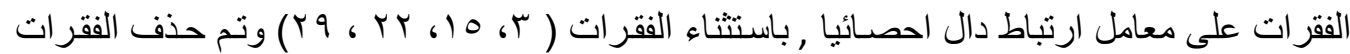

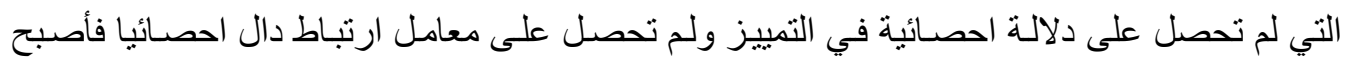


المقياس يتكون من (YrT) فقرة (ملحق ( ) ) و واتفق هذا مع معيار ايبل الذي أكدعلى قبول الفقرة اذا

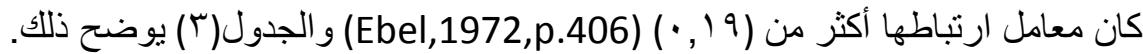

$$
\text { جدول (r) (r) }
$$

علاقة الفقرة بالدرجة الكلية لفقرات مقياس السذاجة

\begin{tabular}{|c|c|c|c|}
\hline قيمة معامل الارتباط & ت & قيمة معامل الارتباط & ت \\
\hline . rAr & -17 & .901 & -1 \\
\hline.$Y q Y$ & $-1 V$ &.$\leqslant 99$ & $-r$ \\
\hline.$\varepsilon r \mu$ & -11 &. $.1 Y$. & $-\mu$ \\
\hline . & -19 & $.0 \mathrm{rV}$ & $-\varepsilon$ \\
\hline .10 & $-Y$. &.$Y 97$ & -0 \\
\hline.$\Sigma \Psi \Lambda$ & -41 &.$Y I \varepsilon$ & -7 \\
\hline$\because 91$ & $-r r$ &.$r V V$ & $-V$ \\
\hline . & חז- & . & $-\Lambda$ \\
\hline$\because \varepsilon \cdots$ & $-Y \xi$ & $. Y T \leqslant$ & -9 \\
\hline .197 & $-r o$ & $.0 . \mu$ & -1. \\
\hline $.09 \varepsilon$ & $-r t$ &. & -11 \\
\hline $.0 . \mu$ & $-Y V$ & .0 .7 & $-1 Y$ \\
\hline.$\leqslant 9 \wedge$ & $-Y \Lambda$ & .194 & -14 \\
\hline$\because 9 V$ & $-4 q$ & $.0 T \varepsilon$ & $-1 \varepsilon$ \\
\hline ו וTM & -r. & $\because 1 \leqslant V$ & -10 \\
\hline
\end{tabular}

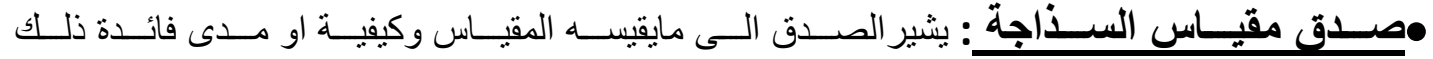

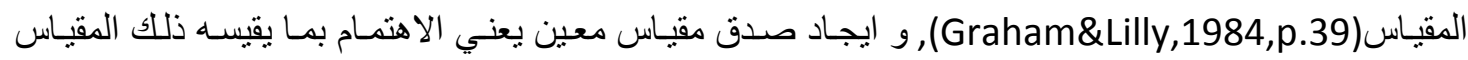
ومدى كفايته في تحقيق ذلك(Anastasi,1988,p.139) , اتخذ في البحث الحالي اجر اء التمييز وعلاقة الفقرة

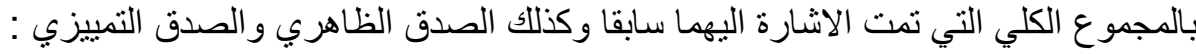

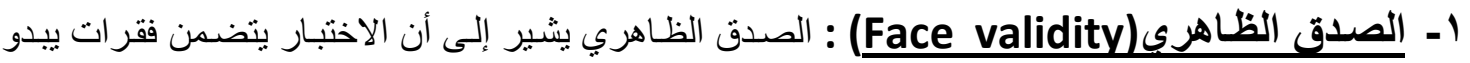

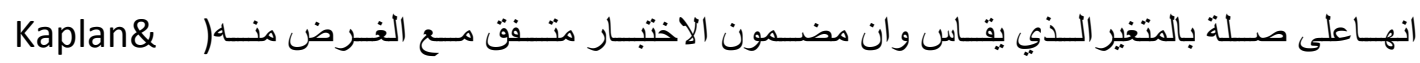
(Saccuzzo,1982,p.113)ويشير اييل(Ebel) الـى انـه في حالـة استخدام الصـدق الظـاهري فـأن الوسيلة

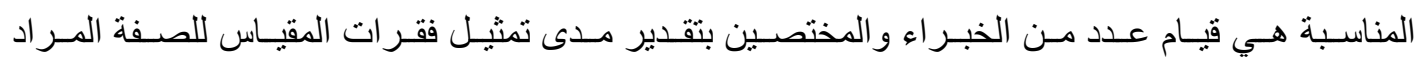
قياسها(Ebel,1972,pp.5,7). وقد تم عرض هذا الاجر اء في خطو ات اعداد مقياس السذاجة .

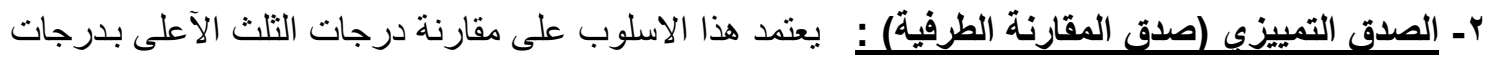

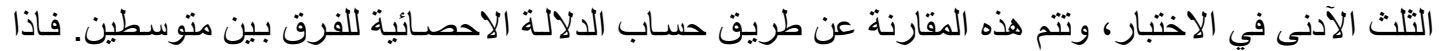

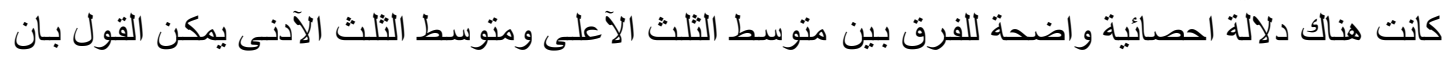

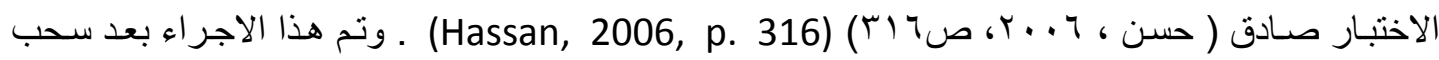

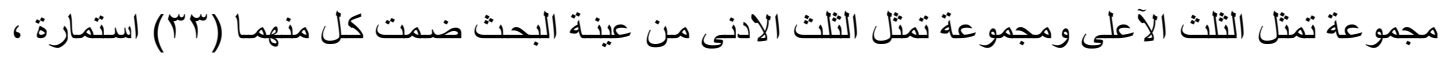
و الجدول (ع ) يوضح ذللك . 
جدول(๕)

يوضح المجموعتين العلياو الدنيا للصدق التمبيزي لمقياس السذاجة

\begin{tabular}{|c|c|c|c|c|c|}
\hline درجة الحرية & القيمة التائية & الانحر اف المعياري & الوسط الحسابي & العدد العد & المجمو عة \\
\hline $7 \varepsilon$ & 19.11 & 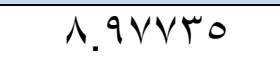 & $11 \cdot r \cdot r$. & سץ & العليا \\
\hline & & А.Y人MII & $79 . \wedge \vee \wedge \wedge$ & سT & الدنيا \\
\hline
\end{tabular}

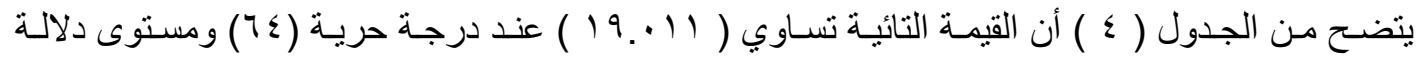

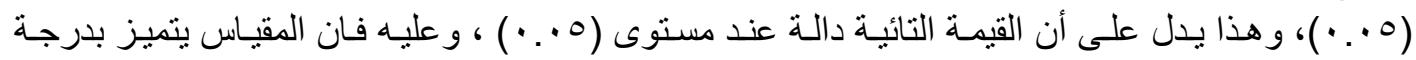

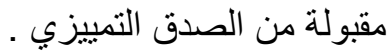

•ثبات مقياس السذاجة: تشير انستازي الى ان الثبات هو الاتساق في الدرجات التي يحصل عليها مـن نفس الافراد بتطبيق نفس الاختبار ـ ومن الناحية العملية يعرّف الثبات بأنه الى اي درجة يمكن الاعتماد علـى المقاييس لاعطاء معلومات منسقة وغير غامضة وبحيث تعكس الخصائص الحقيقية للصفة أو الخاصية المقاسة

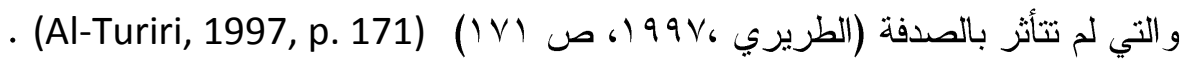
ويعد ثبات معامل ألفــا (م ) أحد اجر اءات الاتسـاق الداخلي (Elliot\&Stewart,1984,p.61). ويرى ننللي (Nunnally) مشكلة قياسه ثانية و البدء ببناء اختبار جديد (Nunnally,1978,p.230) ـ وبناء على ماتقدم فأن (معامل ألفا ) الذي تحقق في البحث الحالي لمقياس السذاجة بواسطة معادلة ألفا-كرونباخ (Y9, • ) يعد جيد على وفق المدى المذكور أعلاه . - إي

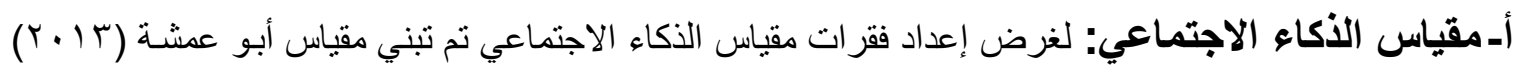

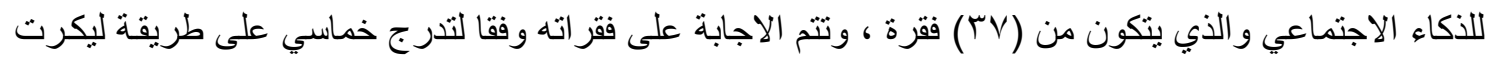

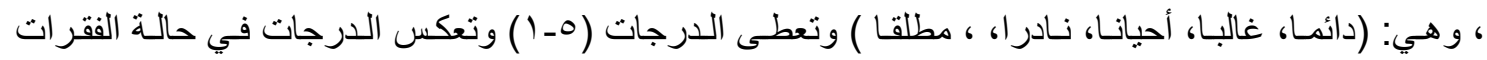

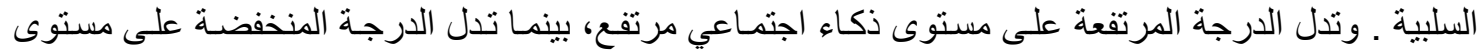

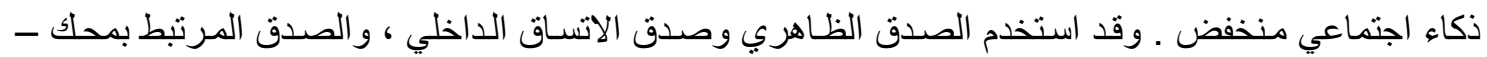

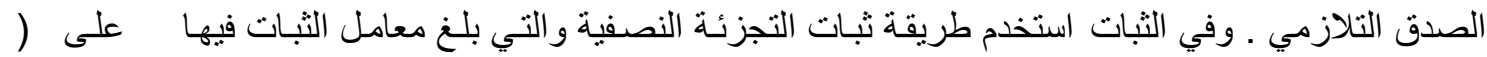

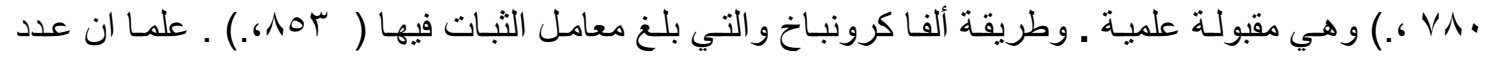

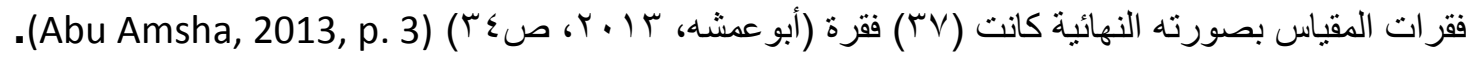

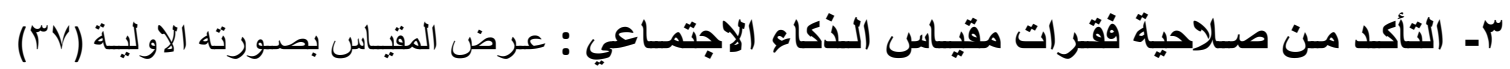

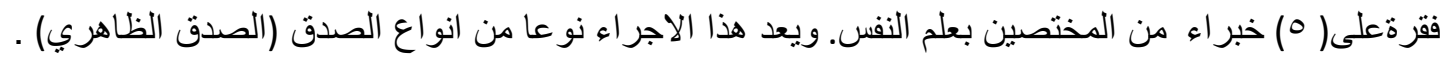
عـ تحليل فقرات المقياس:- في تحليل الفقرات تم استخدام طريقتي المجمو عتين المتطرفتين و علاقة الفقرة بالمجموع الكلي و على النحو الآتي : ع علئ 
أـايجـاد القوة التمييزيـة للفقرات: كان حجم العينـة التي حلت درجاتها احصـائيا في البحث الحالي عند

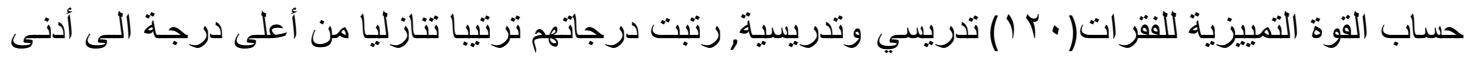

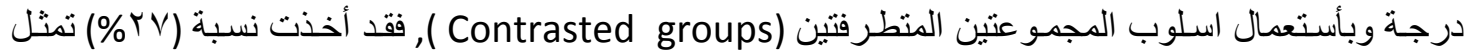

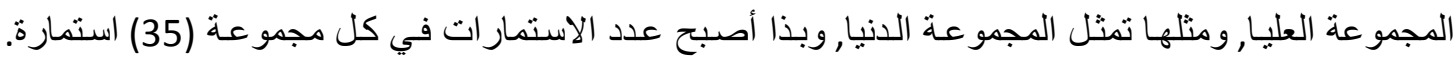

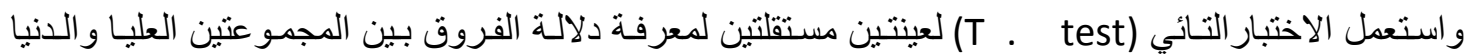

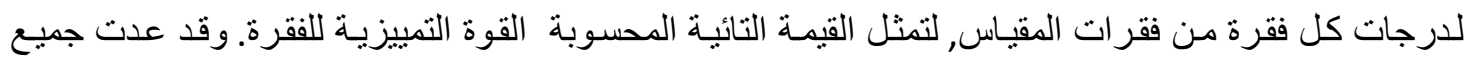

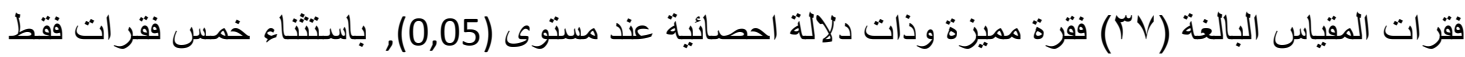

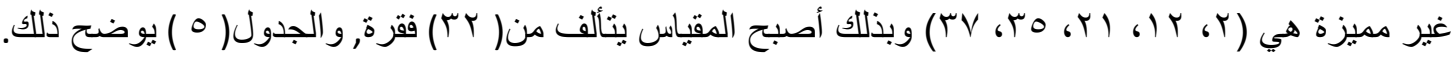

جدول (0)

القوة التمييزية لفقرات مقياس الذكاء الاجتماعي

\begin{tabular}{|c|c|c|c|c|c|c|}
\hline \multirow{2}{*}{ النتيجة } & \multirow{2}{*}{ القيمة التائية } & \multicolumn{2}{|c|}{ المجمو عة الدنيا } & \multicolumn{2}{|c|}{ المجمو عة العليا } & \multirow[t]{2}{*}{$ت$} \\
\hline & & الانحراف المعياري & الوسط الحسابي & الانحر اف المعياري & الوسط الحسابي & \\
\hline دالة & $r .1 \wedge V$ & $.901 \leqslant V$ & r.79V. & $\cdot \wedge \leq 711$ & $\varepsilon .1 \wedge 1 \wedge$ & -1 \\
\hline غير دالة & $1 . \leqslant 9 V$ & $\cdot V \odot r V A$ & $\varepsilon .0 \leqslant 00$ & $.0 \leqslant O r$. & $\varepsilon . \vee \wedge \vee q$ & -4 \\
\hline دالة & $\Gamma . \wedge \wedge q$ & 1.18 .99 & r.qrq\& & 1.18 .99 & 8.7 .7 & r \\
\hline دالة ل & r.qYY & $.9 r 4 \leq r$ & $r . \varepsilon Y \leqslant Y$ & 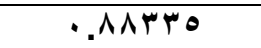 & $\varepsilon . \mu \cdot r$. & $-\varepsilon$ \\
\hline دالة & $\varepsilon .0 Y \wedge$ & $1 . r q \vee ० \wedge$ & r.rqrq &. $.101 Y 4$ & $\varepsilon .0 \vee \bullet \Lambda$ & -0 \\
\hline دالة & $r .1 \wedge q$ & $1.1 Y \wedge 10$ & 5.9 .9 & 1.Y & r.VYVY & -7 \\
\hline دالة & \&.VTY & .99 .199 & 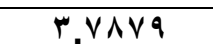 & $.0 Y q \leq \varepsilon$ & $8.79 \mathrm{~V}$ & $-V$ \\
\hline دالة & $0.9 \wedge r$ & $.9 \vee Y 10$ & $r .010 r$ & $.0 \wedge 0 \leqslant 9$ & $\varepsilon .79 V$. & $-\Lambda$ \\
\hline دالة & 0.091 & $1.10 \% .7$ & Y.YVYV &. .71799 & $\varepsilon .0 \leqslant 00$ & -9 \\
\hline دالة & $7 . r 09$ & $1 . \cdot 7 \leqslant Y r$ & $\Gamma . \varepsilon \wedge \leqslant \Lambda$ &. .24019 & $\varepsilon . \vee 0 \vee 4$ & -1 \\
\hline دالة & r.VI. & $1.1 \leq 7 \leq V$ & $r . \varepsilon Y \leqslant Y$ &.$\wedge 170$. & E.MrMr & -11 \\
\hline غير دالة & $\cdot . \leqslant 0 \leqslant$ & $1 . \cdot 7 \varepsilon r r$ & $Y . \wedge \leqslant \wedge \theta$ & $1.1 .10 \varepsilon$ & Y. $979 \mathrm{~V}$ & $-1 Y$ \\
\hline دالة & 0.871 & 918.1. & $r . \wedge \backslash \wedge r$ &. $.4917 V$ & $\varepsilon . \wedge \backslash \wedge Y$ & -14 \\
\hline دالة & 7.909 & $.99 \vee 991$ & $\varepsilon .9 .9$ &. $.4917 V$ & $\varepsilon . \wedge \backslash \wedge r$ & $-1 \leq$ \\
\hline دالة & $\varepsilon . \cdot \leq \varepsilon$ & 1. roro & צ.7. & $. V I Y \leq \varepsilon$ & $\varepsilon .010 Y$ & -10 \\
\hline دالة & $0.9 \leq \leq$ & 1.4179 & r.V०VY & $\cdot r \mu \mid \leqslant r$ & $\varepsilon . \wedge \vee \wedge \wedge$ & -17 \\
\hline دالة & $r .9 r V$ & $.9 r 4 \leq r$ & Y.VOVY & $1.11 \wedge \wedge \wedge$ & r.VOVY & $-1 V$ \\
\hline دالة & $r .911$ &.$\wedge 170$. & r &.$\wedge 199 V$ & $\varepsilon .1 Y I Y$ & -11 \\
\hline دالة & \&.YTY &.$\neg \wedge \curlyvee \diamond \wedge$ & $r .|\wedge| \wedge$ & $\cdot \wedge \neg 7 \cdot r$ & $\varepsilon \ldots$ & -19 \\
\hline دالة & $1.11 \mathrm{r}$ & $1.10 . \varepsilon$ & $r . r \cdot r$ & $1.19 .4 \leq$ & r.Mrr & $-Y$. \\
\hline غير دالة & $.0 \leqslant \Lambda$ & .9 q qr & Y.7TY & -.ATVIr & Y.V०VY & $-Y_{1}$ \\
\hline دالة & 7.115 & $. .9 . \leqslant 0 \%$ & $r .0 \leq 00$ & $.0 \leq \ldots 7$ & $\varepsilon .777 V$ & $-Y Y$ \\
\hline دالة & 0.071 & $1 .+r r \varepsilon$. & $\Gamma . \wedge \vee \wedge \wedge$ & $.4919 \leq$ & 8.9 .91 & Tr- \\
\hline دالة & Y.00V & I. MIVI & Y.IYIY & 1.1AYYY & 4.9 .91 & $-Y \varepsilon$ \\
\hline دالة & $\varepsilon . \mu \wedge$. & 1.10 .5 & $\mu$ & $1 . \cdot 7 \leqslant r r$ & $\$ .1010$ & -YO \\
\hline دالة & r.OHO & I. MYOVE & $r .1010$ & $.949 \leq 7$ & $\varepsilon .1010$ & $-Y Y$ \\
\hline دالة & Y.YVI & $\cdot \vee \wedge \wedge \mid \vee$ & 7.9 .7 & $1 . r 1 \leqslant 9 \wedge$ & r. 7778 & $-r V$ \\
\hline دالة & $0 . r V_{1}$ & $\cdot \Lambda \mu \cdot r \cdot$ & r.०V०A & $.070 \vee 0$ & $\varepsilon .010 Y$ & $-r \Lambda$ \\
\hline دالة & $0.59 V$ & $\cdot V \leq V \leq V$ & $\varepsilon .9 .7$ &. .21010 & $\varepsilon . \wedge \vee \wedge \wedge$ & -19 \\
\hline دالة & V.A7q & $\cdot \Lambda \leqslant \vee Y Y$ & $r . \mu \cdot r$ & .21111 & $\varepsilon .0 \leq 00$ & r. \\
\hline دالة & 0.879 & $1.1 \vee r \leqslant 1$ & r.०V०ᄉ &.$r q 17 V$ & $\varepsilon . \wedge \backslash \wedge r$ & ו ו \\
\hline
\end{tabular}




\begin{tabular}{|c|c|c|c|c|c|c|}
\hline دالة & r. roq &. $.9 \wedge 90 \%$ & س & . VYAYY & $\varepsilon . \mu \cdot r$ & \\
\hline دالة & $0.19 \varepsilon$ & $1.1 \leqslant \wedge 90$ & 1.1010 & $\cdot V I Y \leqslant \varepsilon$ & $\varepsilon .010 Y$ & سז- \\
\hline دالة & $7 . \leqslant Y 0$ & •.人YqI & r..... & $\cdot \wedge 04 q 1$ & E.MTH & $-T \leq$ \\
\hline غير دالة & $1.7 \wedge r$ & 1.9100 & $Y . Y \leq Y \leq$ & 1.110. & r. $79 \mathrm{~V}$. & $-r o$ \\
\hline دالة & $\varepsilon .874$ & .97 Yry & r. &. $.770 \mathrm{VY}$ & $\varepsilon .0 \leqslant 00$ & -ry \\
\hline غير دالة & 1.490 & I.ror.r & $r . \leqslant \Lambda \leqslant \wedge$ & $1 . r \mid \wedge 0 \leq$ & 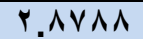 & $-r V$ \\
\hline
\end{tabular}

ملاحظة: الصفوف المظلله تدل على الفقرات التي حذف من المقياس .

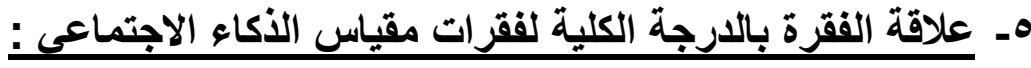

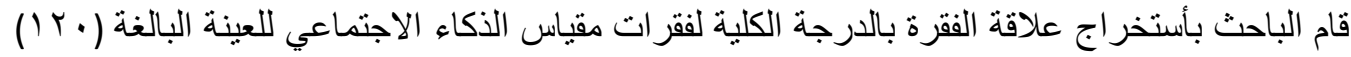

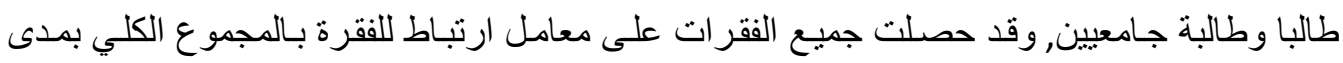

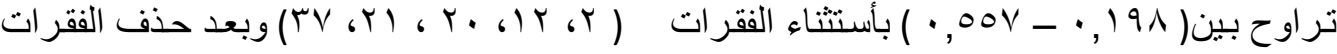

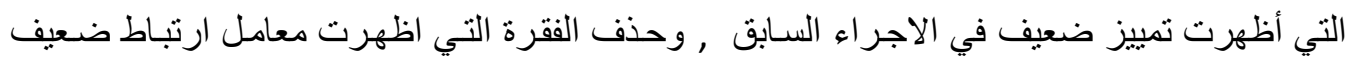

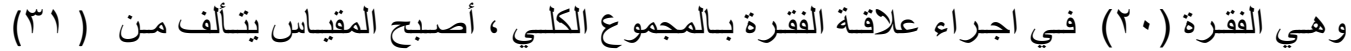

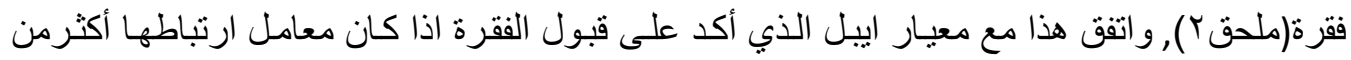

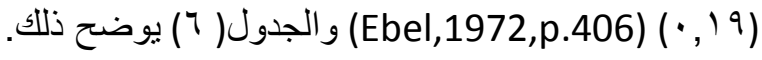

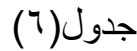

علاقة الفقرة بالدرجة الكلية لفقرات مقياس الذكاء الاجتماعي

\begin{tabular}{|c|c|c|c|}
\hline قيمة معامل ارتباط & ت & قيمة معامل ارتباط & ت \\
\hline $.17 \pi$ & $-Y$. & .191 & -1 \\
\hline$\because \cdot r$ & $-Y_{1}$ & $.1 \vee \varepsilon$ & $-Y$ \\
\hline $.0 . \varepsilon$ & $-Y Y$ & . YTE & $-r$ \\
\hline .0 .1 & $-Y T$ &.$r 9 r$ & $-\varepsilon$ \\
\hline$. r 0 \leqslant$ & $-Y \leq$ & .291 & -0 \\
\hline$\because \varepsilon \cdot r$ & $-Y O$ &.$Y I Y$ & -7 \\
\hline . & $-Y T$ & .011 & $-V$ \\
\hline. YVA & $-Y V$ & .049 & $-\Lambda$ \\
\hline $.0 . \varepsilon$ & $-r \wedge$ & $.00 \mathrm{~V}$ & -9 \\
\hline.$\leqslant 0 V$ & $-r q$ & .019 & -1. \\
\hline .049 & $-r$ &. rov & -11 \\
\hline $.0 \leqslant 1$ & ו ו & .119 & $-1 Y$ \\
\hline$\cdot r \cdot v$ & - & .001 & $-1 T$ \\
\hline $.01 \pi$ & L &.$r \Lambda T$ & $-1 \leq$ \\
\hline $.0 \% 1$ & $-r \leq$ & .970 & -10 \\
\hline.$Y 09$ & ס ס & $.00 \pi$ & -17 \\
\hline$\because \Sigma V Y$ & - & $\because \leqslant 19$ & $-1 V$ \\
\hline $.1 \mathrm{H}$ & $-r V$ & . rqr & -11 \\
\hline & & .907 & -19 \\
\hline
\end{tabular}


ملاحظة : الفقرات المضلله هي الفقرات التي حذفت من المقياس . .

\section{•صدق مقياس الأكاء الاجتماعى :}

لتحقيق الصدق لمقياس الذكاء الاجتماعي فأن البحث الحئ فاعلي لجأ الى ثلاثة مؤشرات للصدق هما :

$$
\text { أ_الصدق الظاهري(Face validity) : عرض في خطوات اعداد مقياس السذاجة . }
$$

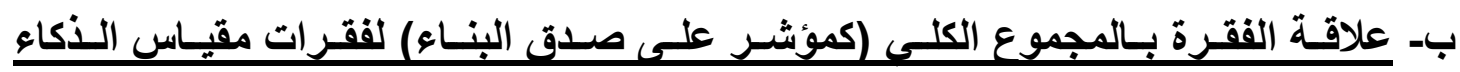

الاجتماعى: عرض هذا الاجر اء في خطوات اعداد مقياس الذكاء الاجتماعي .

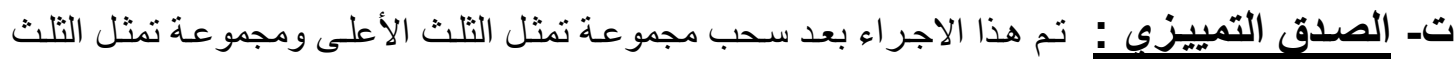

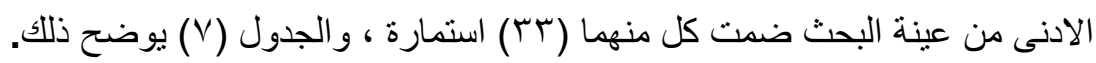

$$
\text { جدول (v) }
$$

\begin{tabular}{|c|c|c|c|c|c|}
\hline درجة الحرية & القيمة التائية & الانحر اف المعياري & الوسط الحسابي & 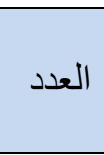 & المجمو عة \\
\hline $7 \varepsilon$ & 18.977 & 0.0794 & $1 M 7.0 \vee 01$ & r & العليا \\
\hline & & $1 . \leqslant 971$. & 1.0 .7 .71 & سT & الدنبا \\
\hline
\end{tabular}

يوضح المجمو عتين العليا والدنيا للصدق التمبيزي لمقياس الذكاء الاجتماعي

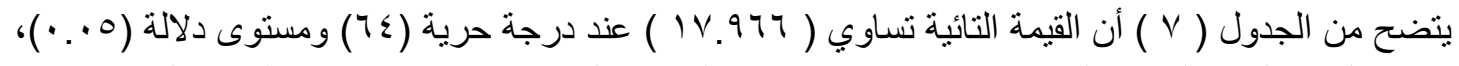

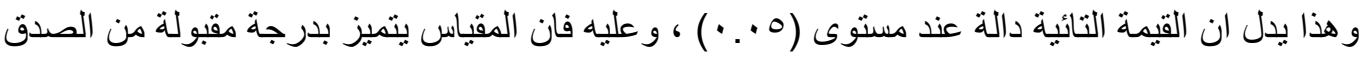

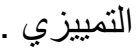

• ثبات مقبـاس الذكاء الاجتمـاعى: بناء على استخدام طريقة الاتساق الداخلي ، فأن (معامل ألفا ) الـذي تحقق في البحث الحالي لمقياس الذكاء الاجتماعي بواسطة معادلة ألفا-كرونباخ (عی, •) • ويعد هذا المعامـلـل جيد على وفق ماأنشار اليه ننلاي( Nunnally 1978 ) المشار اليه في ثبات مقياس السذاجة .

$$
\text { الوسائل الاحصائية : لمعالجة بيانات البحث الحالي, تمت الاستعانة بمايأني : }
$$

ا- الاختبار التائي(t-test) لعينتين مستقلتين(Edwards,1957,p.152) استعمل لاستخر اج القوة التمييزيـة

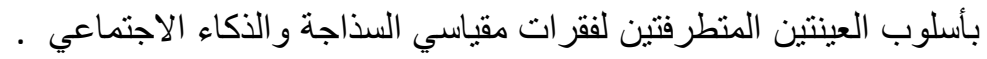

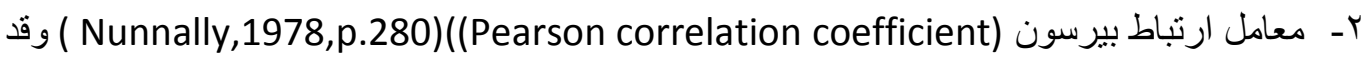
استعمل لأيجاد العلاقة بين كل فقرة والدرجة الكلية في كلا كلا المقياسيين .

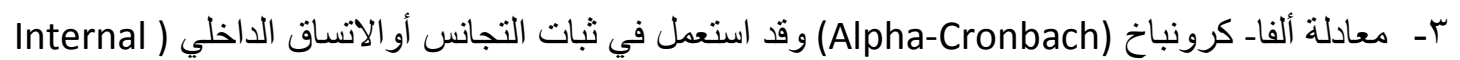

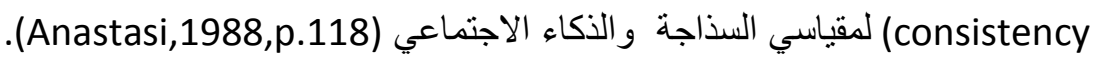

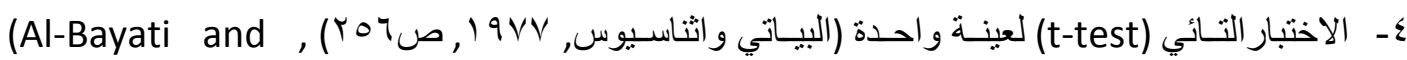

وقد استعمل لقياس السذاجة و الذكاء الاجتماعي للعينه بأكملها.

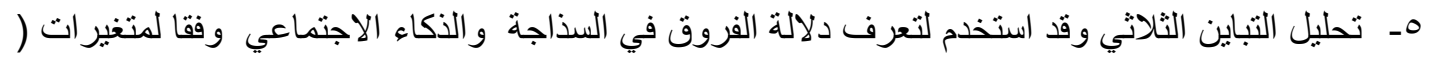




\section{الفصل الرابع - النتائج ومناقشتها وتفسير ها}

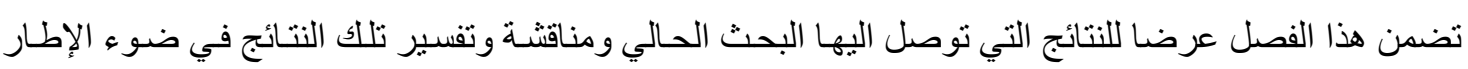
النظري المعتمد في البحث الحالي و الخروج بتوصيات ومقتر النترحات و على النحو الآتي:

أولا - عرض النتائج ومناقثتها وتففيرها:

ا ـ قياس السذاجة للدى طلبة الجامعة : كان الوسط الحسابي لدرجات عينة طلبة الجامعة على مقياس

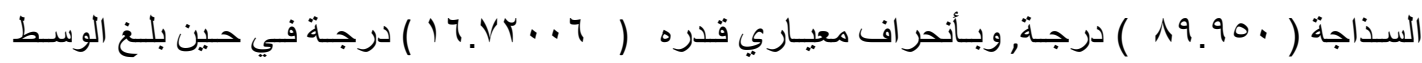

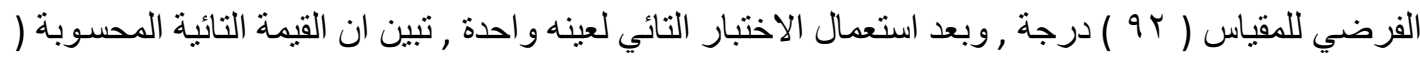

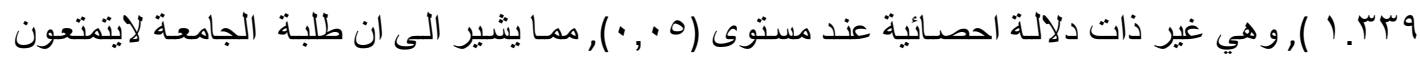

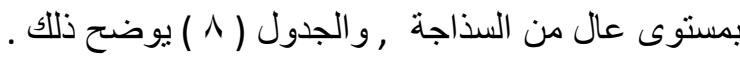

$$
\text { جدول(^) }
$$

الاختبار التائي لعينة واحدة لمقياس السذاجة لاى طلبة الجامعة

\begin{tabular}{|c|c|c|c|c|c|c|c|}
\hline النتيجة & مستوى & القيمسة التائية & الفرضي & الانعياري اف & الحسابي & الحرية & العدد \\
\hline غالة & .0 & q & $q Y$ & $17 . V Y \ldots 7$ & 19.90. & 119 & $1 \%$. \\
\hline
\end{tabular}

\section{علما ان القيمة التائية الجدولية هي 97.}

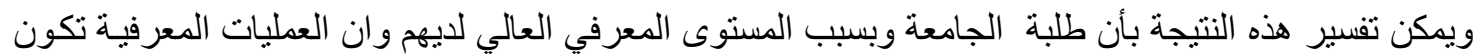

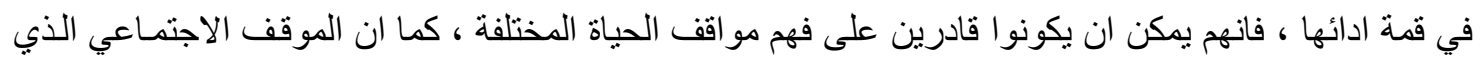

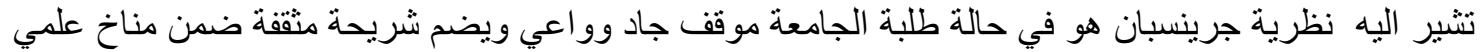

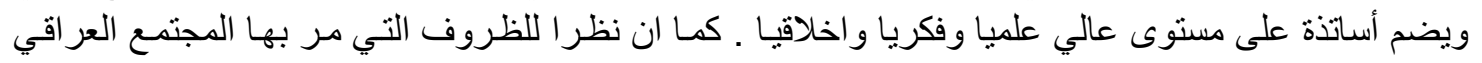

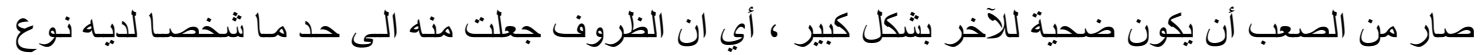

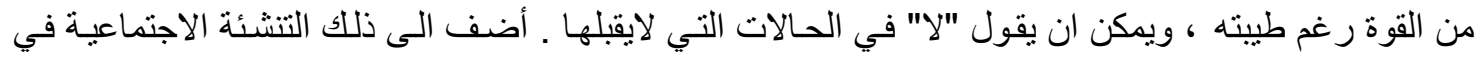

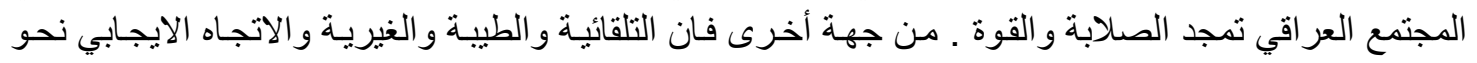

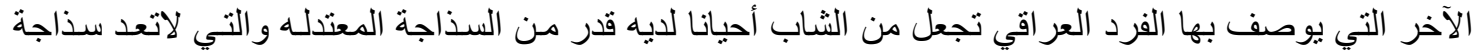

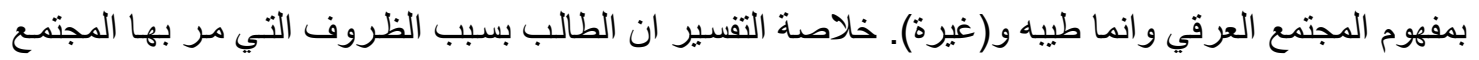
وكذلك التنشئة تكون لديه عناصر قوة تشده نحو اللاسذاجة ، وبالمقابل لديه تلقائية وثقة تشده نحو السذاجة أحيانا .

\section{r- تعرف الفروق في السذاجة على وفق متغيرات التخصص (علمى ـ انسانى ) و الجنس ال}

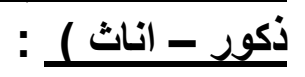

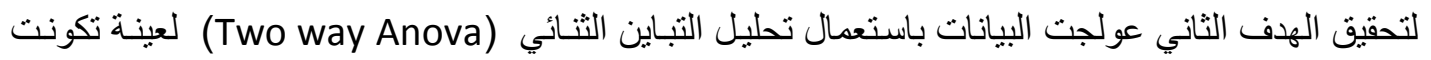

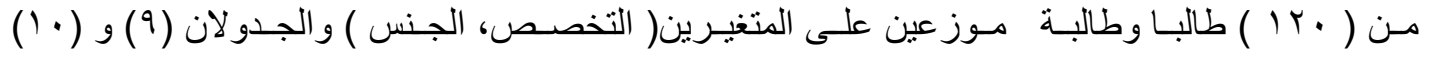
يوضحان ذلك . من ( 


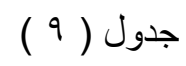

تحليل التباين الثنائي لتعرف دلالة الفروق في السذاجة تبعا لمتغيري التخصص و الجنس

\begin{tabular}{|c|c|c|c|c|}
\hline العدد & الانحر اف المعياري & المتوسط الحسابي & التخصص & الجنس \\
\hline$r$. & IV.YVIT & 9r.rצדV & كي & \multirow{3}{*}{ ذكور } \\
\hline r. & I & $\Lambda \vee . \vee \ldots$ & ني & \\
\hline 7. & $17 . \cdot 87.7$ & זسז. . 9 & المجمو ع & \\
\hline$r$. & IV.r...Aq & $\wedge q . \mu \ldots$ & علمي & \multirow{3}{*}{ اناث } \\
\hline$r$. & $1 V .9 Y 7 \leq 0$ & & انساني & \\
\hline 7. & IV. $\leqslant \vee O \wedge T$ & 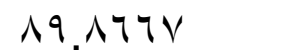 & المجمو ع & \\
\hline 7. & $I V . Y \cdot A V O$ & q. & علمي & \multirow[t]{2}{*}{ المجموع } \\
\hline 7. & r. & $19 . \cdot 77 \vee$ & انساني & \\
\hline $1 \%$. & $17 . V Y \ldots 7$ & $19.90 \ldots$ & المجموع & \\
\hline
\end{tabular}

$$
\text { جدول (1) }
$$

تحليل التباين الثنائي لتعرف دلالة الفروق في السذاجة تبعا (الجنس،و التخصص) و التفاعل بينها

\begin{tabular}{|c|c|c|c|c|}
\hline القيمة الفائية & المربعات & درجة الحرية & مجموع المربعات & مصدر التباين \\
\hline . & r. & 1 & r. & التخصص \\
\hline 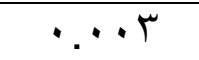 & •.AMT & 1 & •.ATM & الجنس \\
\hline \multirow[t]{3}{*}{$\cdot . \wedge \wedge 9$} & ror.r.. & 1 & ror.r.. & التخصص* الجنس \\
\hline & rᄉr.A. I & 117 & rrqu.qr & الخطأ \\
\hline & & Ir. & $1 \ldots \leqslant 1 \wedge \wedge \ldots$ & المجموع \\
\hline
\end{tabular}




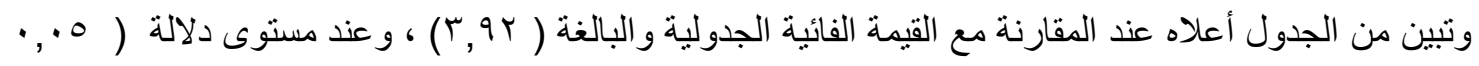

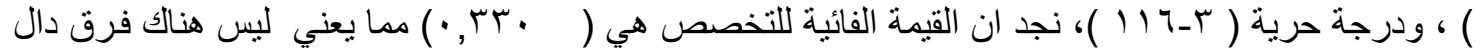

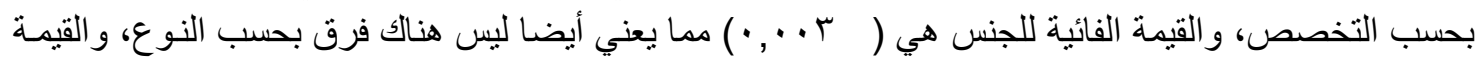

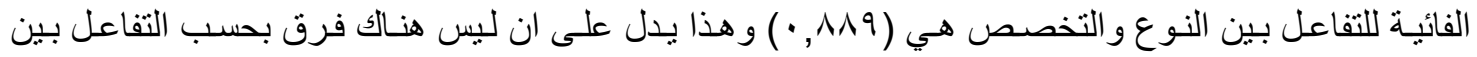

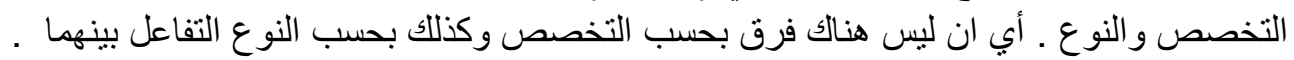

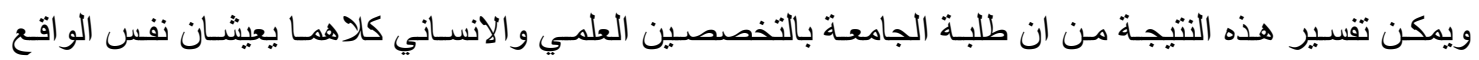

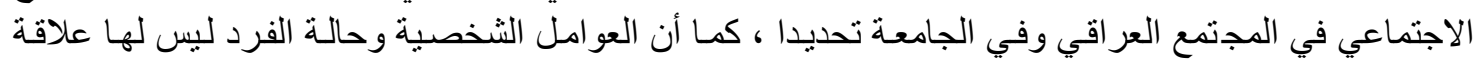
بالتخصص هنا فيما يخص السذاجة حصر ا ، كما ان العو امل المعرفية على الرغم دن اختلافها الريا بين التخصصين

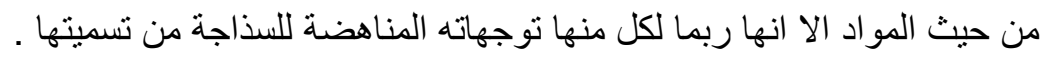

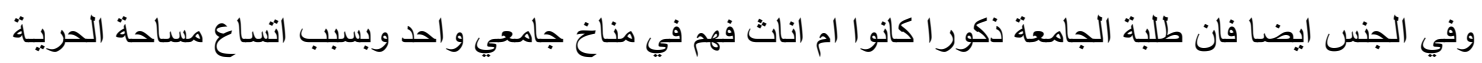

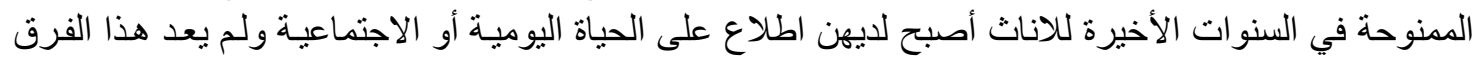

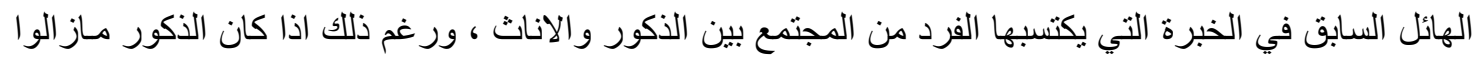

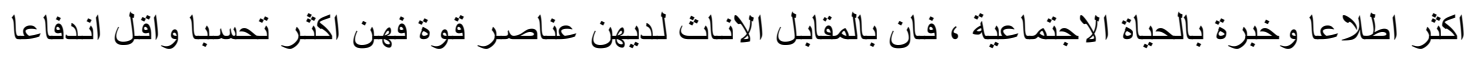

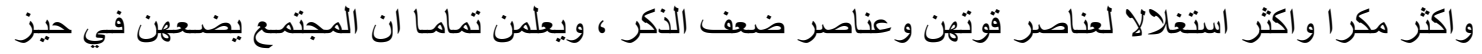

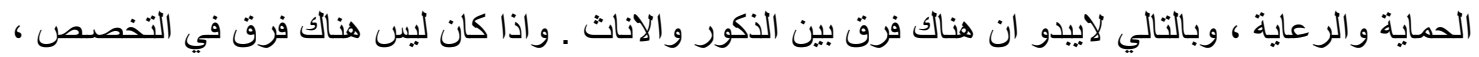

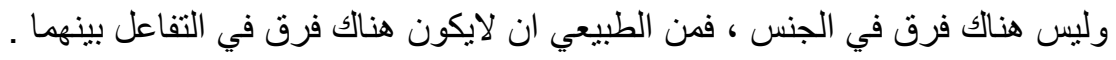

الهلف الثالث : قياس الأكاء الاجتماعى لاى طلبة الجامعة : كان الوسط الحسابي لدرجات عينة

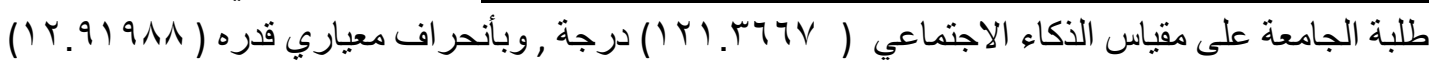

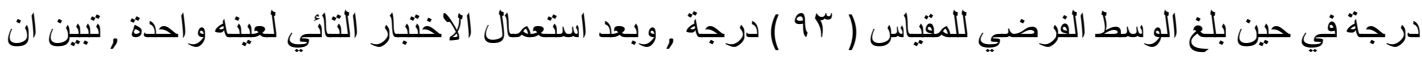

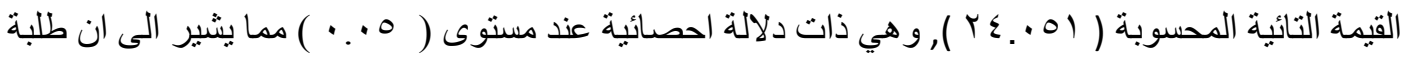

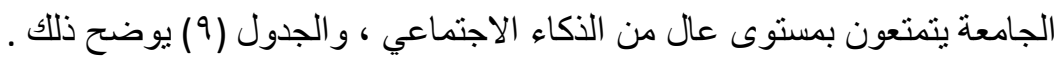

جدول (1)

الاختبار التائي لعينة واحدة لمقياس الذكاء الاجتماعي لدى طلبة الجامعة

\begin{tabular}{|c|c|c|c|c|c|c|c|}
\hline النتيجة & الدلالة & المِيمة التائية & الفرضي & الأنحر اف & الوسط الحسابي & درجة الحرية & العدد \\
\hline دالة & $\therefore 0$ & $Y \varepsilon .01$ & 94 & $14.919 \wedge 1$ & IYI.TצV & 119 & 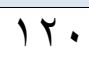 \\
\hline
\end{tabular}

علما ان القيمة التائية الجدولية هي 97.

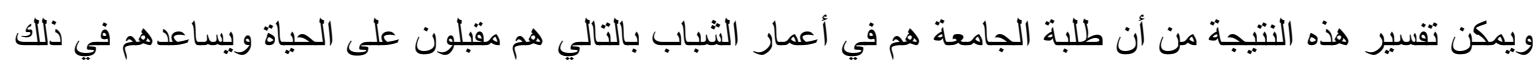

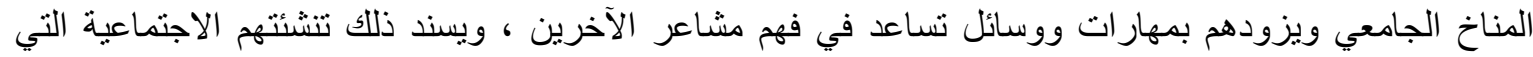

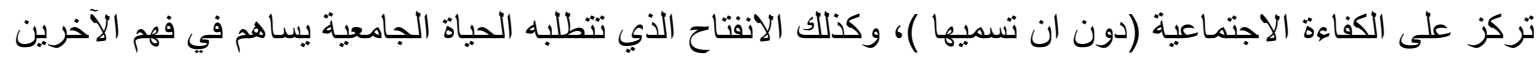

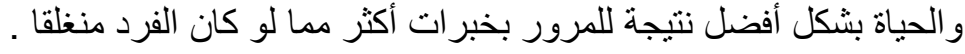

•الرابع ـ تعرف الفروق فى الذكاء الاجتماعى على وفق متغيرات التخصص والجنس : 


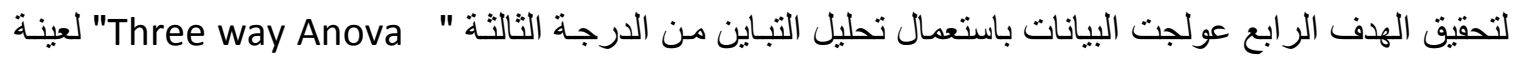

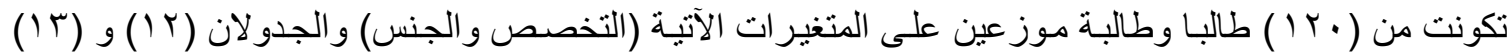
يوضحان ذلك.

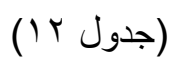

تحليل التباين الثنائي لتعرف دلالة الفروق في الذكاء الاجتماعي تبعا التخصص و الجنس

\begin{tabular}{|c|c|c|c|c|}
\hline العدد & الانحر اف المعياري & المتوسط الحسابي & التخصص & الجنس \\
\hline r. & $1 \leqslant . \wedge 90 \wedge 0$ & $111.9 \ldots$ & علمي & \multirow{3}{*}{ ذكور } \\
\hline r. & 1. & 141.9778 & انساني & \\
\hline 7. & IT. TONA & سTrE. • & المجموع & \\
\hline r. & 11.9 Y人R & IY.V... & علمي & \multirow{3}{*}{ اناث } \\
\hline r. & q & . . . . & انساني & \\
\hline 7. & 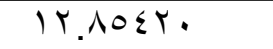 & ITY..... & المجموع & \\
\hline 7. & $1 \% . \varepsilon .91 \varepsilon$ & $119.1 \ldots$ & علمي & \multirow{2}{*}{ المجموع } \\
\hline 7. & 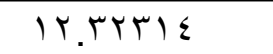 & משזq. אזו & انساني & \\
\hline IY. & $1 r .919 \wedge 1$ & ITI.T & المجمو ع & \\
\hline
\end{tabular}

$$
\text { جدول ( 1T) }
$$

\begin{tabular}{|c|c|c|c|c|}
\hline القيمة الفائية & متوسط المربعات & دالحرية & مجموع المربعات & مصدر التباين \\
\hline 1.200 & rqะ.OTr & 1 & rqะ.0Tr & التخصص \\
\hline TrT & $1 . \varepsilon .0 T r$ & $T$ & $1 . \varepsilon .0 T r$ & الجنس \\
\hline$\because \cdots 1$ & 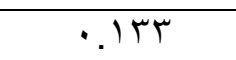 & 1 & . & التخصص * الجنس \\
\hline & 178.899 & 117 & $19 \leq 7 \leq .77 V$ & الخطأ \\
\hline & & IT. & IVA $\vee \leqslant \varepsilon \wedge . \cdots$ & المجموع \\
\hline
\end{tabular}

تحليل التباين الثنائي لتعرف دلالة الفروق في الذكاء الاجتماعي تبعا لمتغيري التخصص و الجنس و التفاعل بينهما 


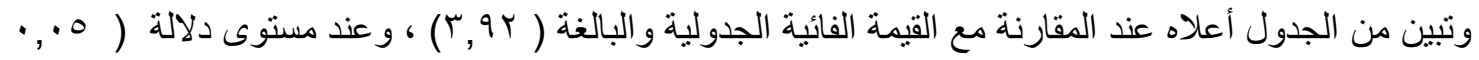

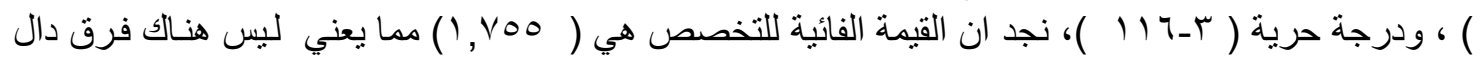

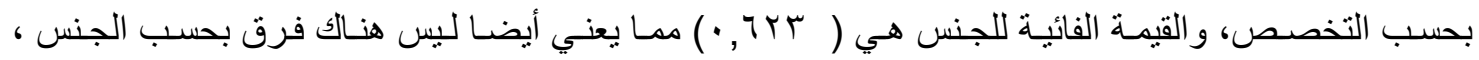

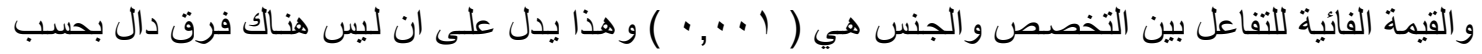

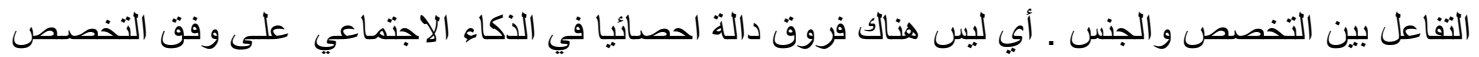

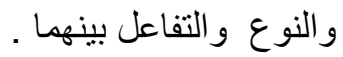

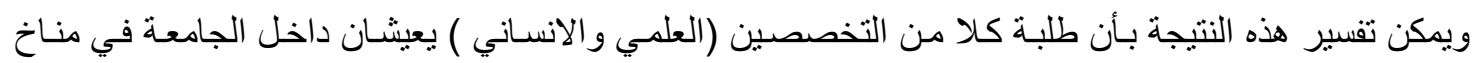
اجتماعي متثابه وكما ان الذكاء الاجتماعي يعتمد على ما اكتسبه الفرد من خبر ات تمكنه من فهم مشاعره

ومشاعر الآخرين وانفعالاتهم و هذا الأمر لايتعلق بالتخصص فالخبرات التي أنشرنا اليها تم اكتسـاب الكثير منها

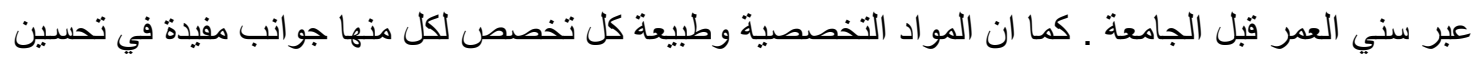

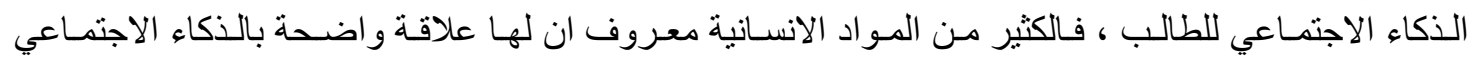
(كالفلسفة مثلا ) ، اما في التخصص العلمي فان وجود المختبرات وقضاء أوقات طويلة فيها يمكن يحسن التفاعل

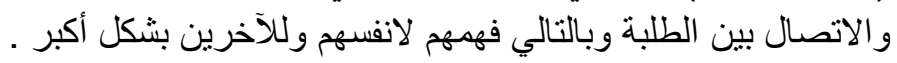

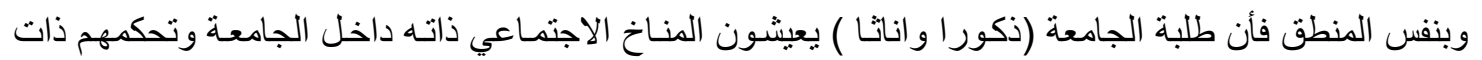

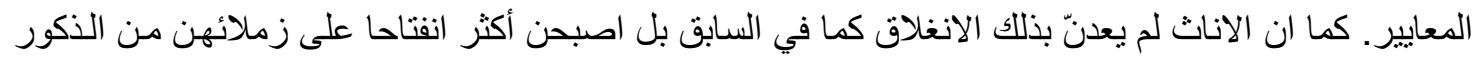

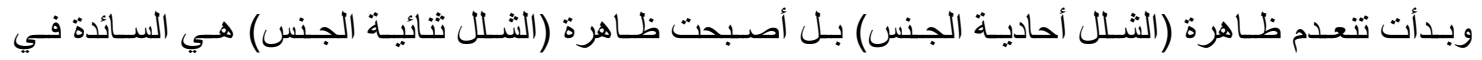
الجامعة،و هذا يجعل الخبرات التي تتعلق بالذكاء الاجتماعي سواء لدى الذكور او لدى الاناث تكون متقاربة .

\section{الهذف الخامس - ايجاد العلاقة بين السذاجة والأكاء الاجتماعي :}

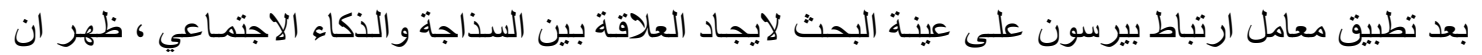

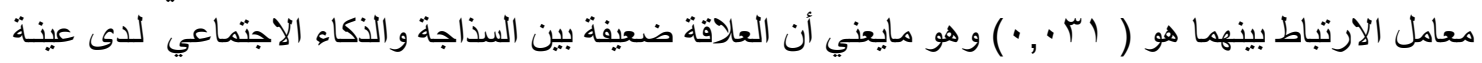
البحث .

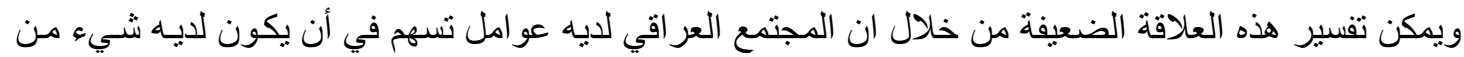

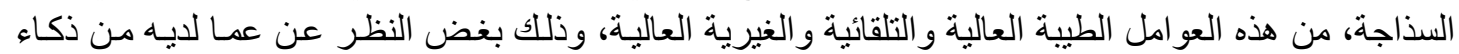

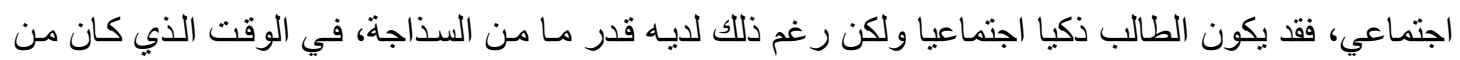

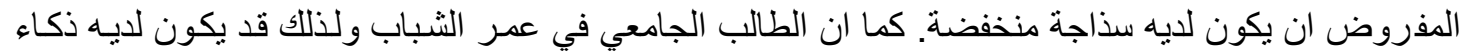

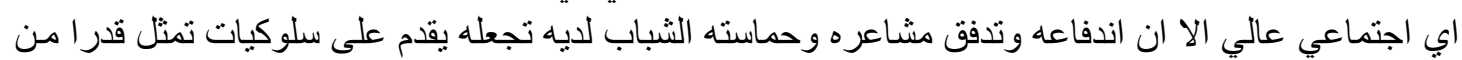
السذاجة . و لاشك ان المجتمعات في كثير من المتغيرات تكون لها فيها خصوصية ما وبالتالي تكون النكون مختلفة عن

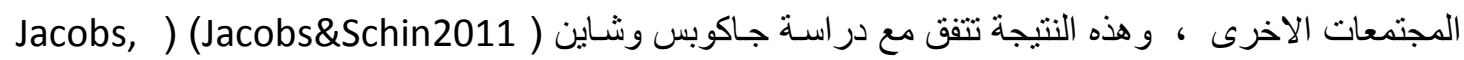

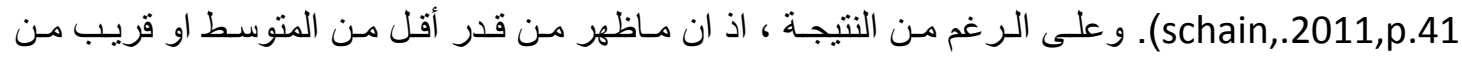

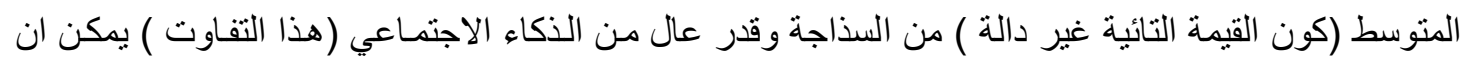

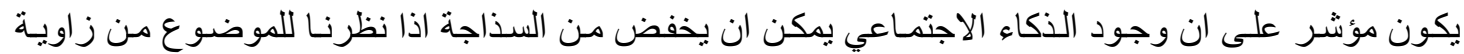

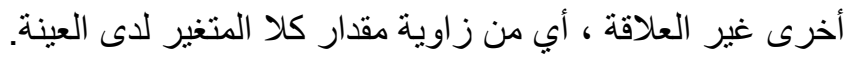

ثانيا- التوصيات : خرج البحث الحالي بعدد من التوصيات و على النحو الآتي :-

ا-ضرورة قيام وحدات الارشاد في الجامعة بمحاولة عقد ندوات أو ورش بحثية لمكافحة هذا المستوى المعتدل من السذاجة، كونه رغم انه معتدل ، ألا انه مؤشر خطير على المدى البعيد ويشير الى نتائج كامنه خطيرة . 
r-ضرورة قيام وسائل الاعلام بالتركيز على هذه الظـاهرة و اعطائها الأولويـة كونها تمثل خطر ا مستقبليا لان

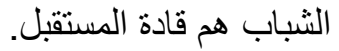
ب- ضرورة قيام المعنيين بوضـع المنـاهج (في وزارة التربيـة ) أو حتى وزارة التعليم العـالي و البحث العلمي،أن يضمنو ا في مناهجهم مو ادا تساعد على مكافحة السذاجة.

ع -توجيه مر اكز البحوث في الجامعات الى التركيز على علاج هذه الظاهرة واجر اء الندوات و المؤتمرات العلمية

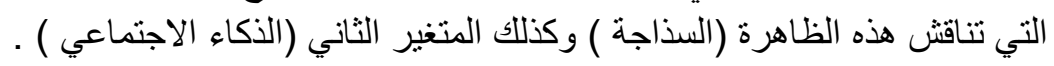
ثالثاـ المقترحات :خرج البحث الحالي بعدد من المقترحات :ا ـاجر اء بحث لدر اسة السذاجة لدى شر ائح أخرى ، كالمسنين ، و المتفوقين در اسيا ، و المبدعين ب-اجر اء بحث لدر اسة الذكاء الاجتماعي لدى شر ائح أخرى كالموظفين و العمال مثلا . r-اجر اء بحث لدر اسة علاقة السذاجة بمتغير ات أخرى كالثقة وتتظيم الذات و الذكاء العام والانتباه و اليقظة

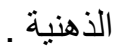

ـ ـاجر اء بحوث لدر اسة مقارنة في الذكاء الاجتماعي بين عمال وموظفي القطاع الخاص و عمال وموظفي القطاع العام . ماء هـاجر اء بحث لدر اسة العلاقة بين متغيري البحث لدى شر ائح أخرى . جـاجر اء بحث لدراسة علاقة السذاجة بالمتغير ات الآتية : الطيبة ، النقاء ، البراءة ، التفكير الرغبي ، الرومانسية أو العاطفية العالية .

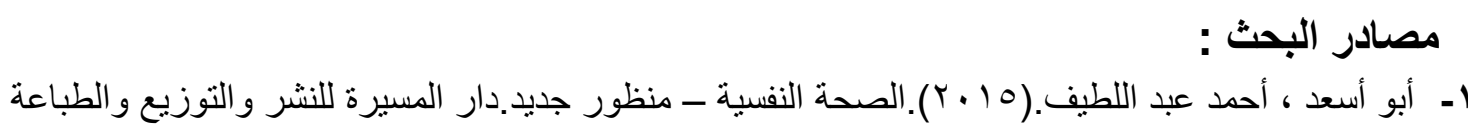

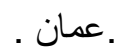

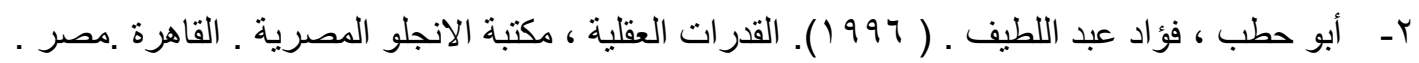

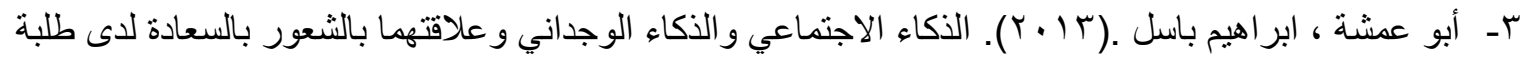

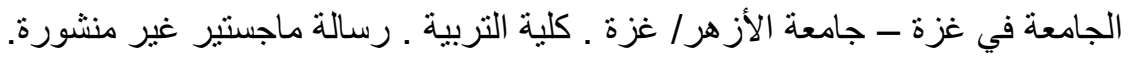

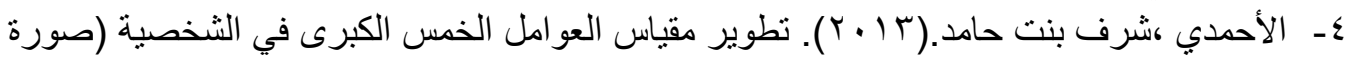

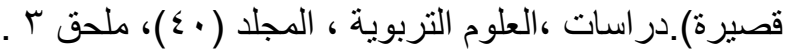

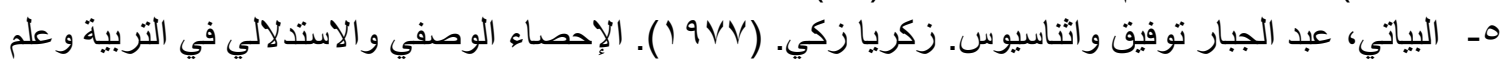
النفس. بغداد. الجامعة المستتصرية.

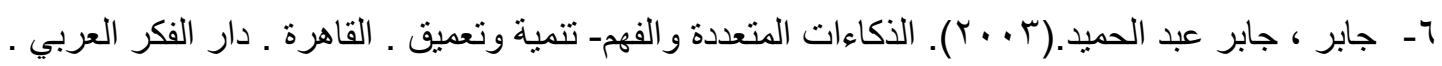

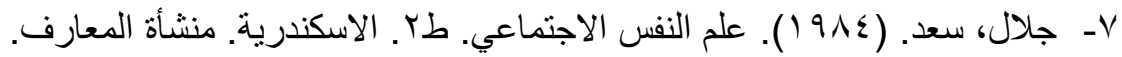

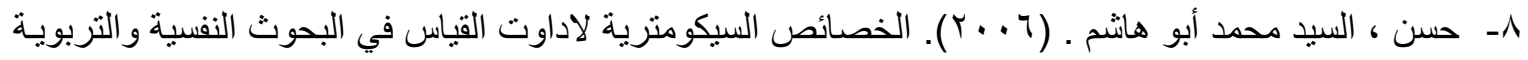

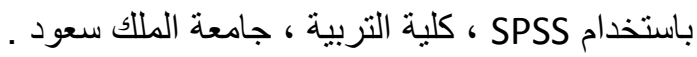

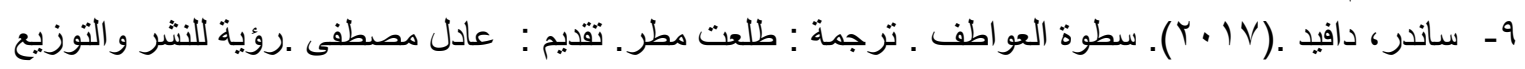

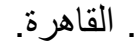
• 1ـ السيد ، فؤاد البهي (1901) ) . علم النفس الإحصائي وقياس العقل البشري ، طا ، دار الفكر العربي . 


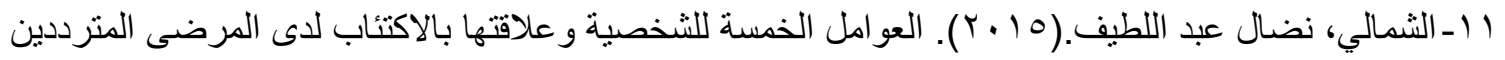

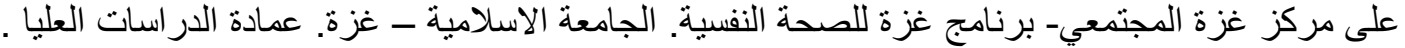

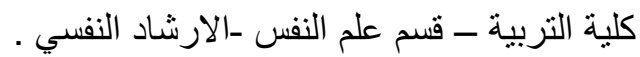

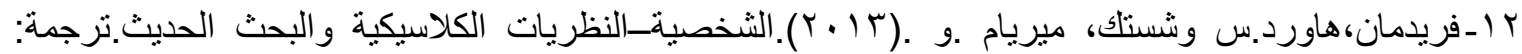

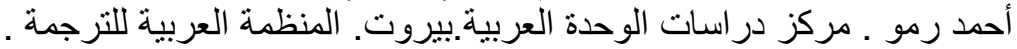

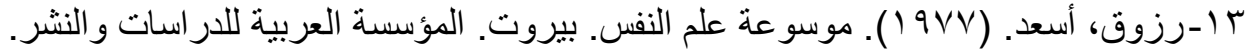

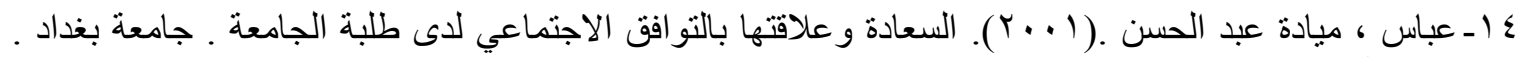

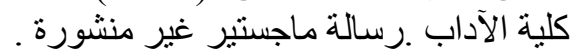

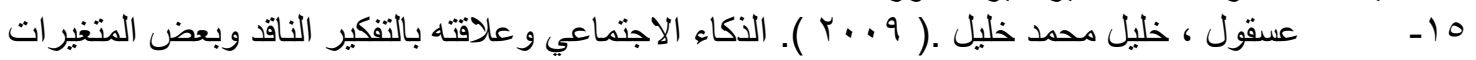

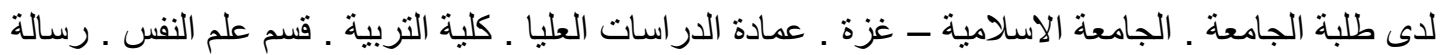

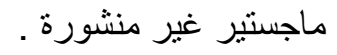

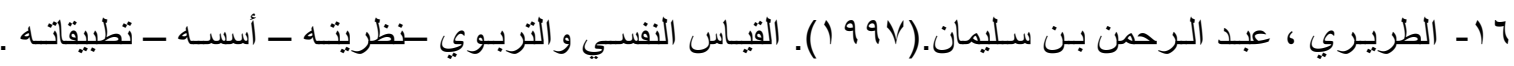

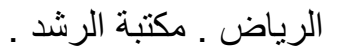

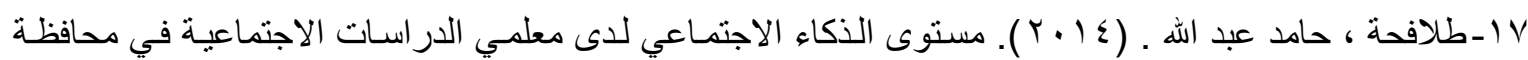

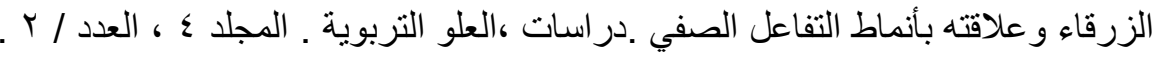

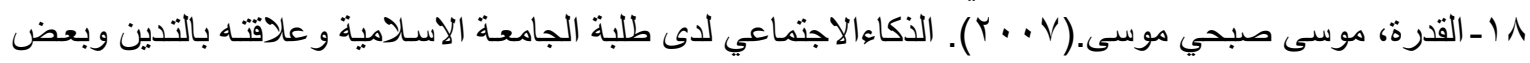

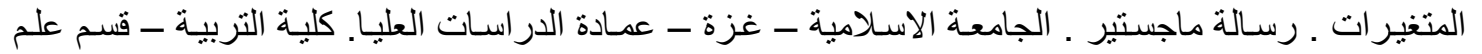
النفس .

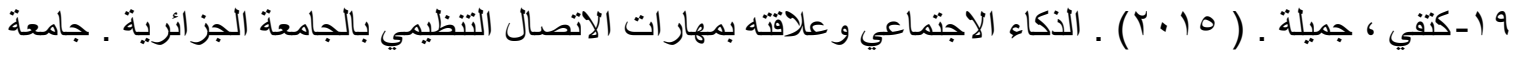

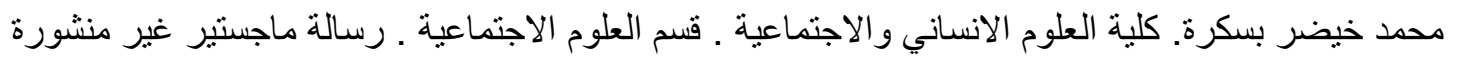

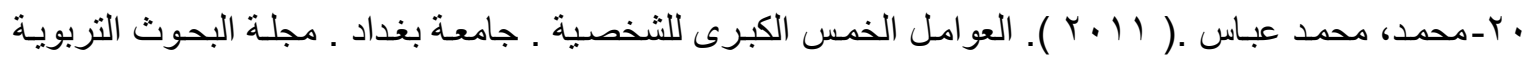

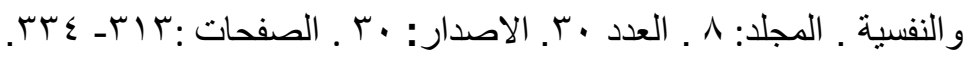

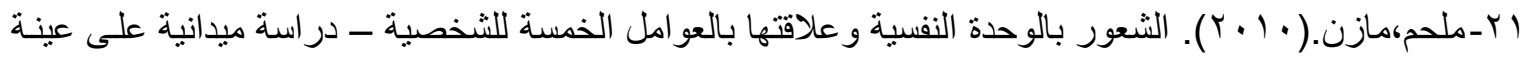

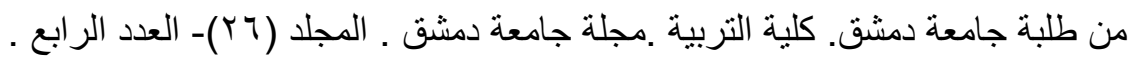

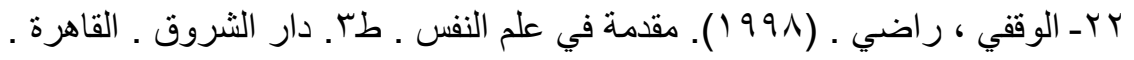

\section{References :}

23-Anastasi, A. (1988 ).Psychological Testing . New York. MacMillan Publishing Company.

24-Association for psychological seience .(2010). Study suggests Oxytocin makes people trusting, but not gullible. https://www.psychological science.org/. 25-Brodziak, Andrzej ; zlotkowska, Renata\&Myrta, Alicia-Rozyk .(2018).Assessment of Gullibility of older patients is important for their safety and health. Journal of gerontology\& geriatric research.Vol.(7)Doi:lo.4172/2167-7182.1000462.Issue 1.1000462.

26-Carrier,N.A.(1963). Neede correlates of "gullibility " . The Journal of Abnormal and social psychology ,66(1). 84-86.http://dx.doi.org/10.1037/. 27-Changing minds.(2017). Gullibility. Convert from Doc to pdf,pDf to Doc simply with the free on - line Appl Go to fromdoctopdf. Com . http://changing minds . org/techniques/con_tricks/gullibility . 
28- Ebel, R. L. (1972). Essential of educational measurement, New Jeresy, Englewood cliffs, prentice- Hall.

29- Edwards,A.L.(1957). Technigues of attitude scale construction. New York croets, Inc.

30-Elliot , A. W. \& Stewart , B. J. (1984) . Assessing individuals . Psychological and Educational. Tests and measurements, Boston, Little, Brown \& Company .

31-Forgas, Joseph p. \& East, Rebekah . (2008). On being happy and gullible : Mood effects on skepticism and the detection of deception .Journal of Experimental social psychology. 44. 1362-1367.

32-Forgas, Joseph Paul. (2017). Why are some people more gullible than others ? The conversation. Http://theconversation. Com / .

33- Ghiselli , E. E. \& et. Al. (1981) . Measurement Theory for Behavioral Sciences . San Francisco, W. H. Freeman \& Company .

34-Govier,T.(1998).Dilemma of trust (chapter 1) . Canada : McGill-Queen University press . In: Internet,pp.1-15 .

35-Graham, J. R. \& Lilly, R. S. (1984) . Psychological Testing . New Jersey . Prentice - Hell , Inc., Englewood Cliffs .

36-Greenspan, Stephen.(2009). Annals of Gullibility-why we get duped and how to avoid it .foreword by Donald S. Connery. British Library Cataloguing in publication Data is available. An imprit of Greenwood publishing Group, Inc . Westport, Connecticut, London. WWW.praeger.com .

37- Isaacs , Kenneth. S ; Alexander, James. M \& Haggard, Ernest. A .(1963). International Journal of psycho-Analysis, 44. 461- 469.

38- Jacobs , Pearl; Schain , Linda .(2011). The never ending attraction of the Ponzi scheme . Journal of comprehensive Research , 9, 40- 46 . Https: //digitalcommons.sacredheart.edu/ej-fac.

39-Kaplan , R. M. \& Saccuzzo , D. P. (1982) . Psychological Testing Principles , Applications, and Jssues, Brooks . California . Cole Publishing Company Monterey .

40- Krueger, Joachin . L.,Haselbacher, Claudia Vogrincic \& Evans , Anthony M.(2019). We need a credible theory of gullibility . prepared for Forgas , J.p.\& Baumeister,R .F. (2019). Homo credulous. The social psychology of gullibility (The $20^{\text {th }}$ Sydney Symposium on social psychology ). New York : Taylor\& Francis .

41- Layne,C.(1979). The Barnum effect: Rationality versus gullibility . Journal of consulting and clinical psychology , 47 (1) , 219- 221. http;//dx, doi,org / .

42 - Nunnally , J. G. (1978). Psychometric theory. New York, McGraw-Hill , Book Company.

43- Preece,peeter .F.w\&Baxter, John. H.Baxter.(2000). Scepticism and gullibility : the superstitions and pseudo - scientific beliefs of secondary school students . International Journal of science education .Vol.22. Issue.11.

44- Rotter,J.B.(1980).Interpersonal trust, trustworthiness, and gullibility. American psychologist, 35(1),1-7. http;//dx.doi.org/10.1037/. 
45- Silvera,D.,Martinussen,M. and Dahl,T.( 2001). The Tromso social Intelligence scale , a self - report measure of social Intelligence, Scandinavian Journal of psychology , 42, 313-319.

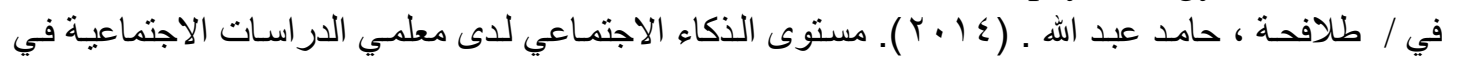

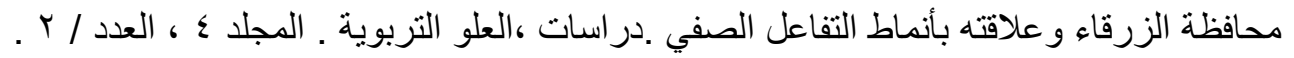

46- Teunisse , Alessandra . (2015). Gullibity: A review of the literature and devising a self- report measure. Department of psychology, Macquarie University . Submtted on the $8^{\text {th }}$ October, 2015, in partial fulfillment of requirements for the degree of master of research Macquarie University .

47- Wikipedia, the free encyclopedia.(2017).Gullibility. https://en.wikipedia.org/. 48- Woodard, Melvin J.(2014).Constructing an assessment for the Imbalance theory of foolishness. Journal of Business and Economics,ISSN 2155-7950,USA. June2014,Volume5.No.6,PP.871-895.Academic star publishing company .2014. http://www.academicstar.as .

49- Yamagishi, Toshio;Kikuchi,Masako;Kosugi,Motoko.(1999). Trust,Gullibility,and social Intelligence. Asian journal of social psychology. Vol.2, Issue1.pages 145-161. http://onliuelibrary.wiley.com/. المصادر العربية التي ترجمت الى الانكليزية (References): 1- Abu Asaad, Ahmed Abdel-Latif. (2015). Mental Health - A New Perspective. Dar AlMasirah Publishing, Distribution and Printing. Amman.

2- Abu Hatab, Fouad Abdel Latif. (1996). Mental capabilities, the Anglo-Egyptian Library. Cairo Egypt .

3- Abu Amsha, Ibrahim Basil. (2013). Social intelligence and emotional intelligence and their relationship to a sense of happiness among university students in Gaza - AlAzhar University / Gaza. Faculty of Education . A magister message that is not published.

4-Al-Ahmadi, Sharaf Bint Hamed. (2013). Development of the scale of the five major factors in personality (short picture). Studies, Educational Sciences, Volume (40), Appendix 3.

5-- Al-Bayati, Abdul-Jabbar Tawfiq and Athanasius. Zakaria Zaki. (1977). Descriptive and inferential statistics in education and psychology. Baghdad. Mustansiriya University.

6- Jaber, Jaber Abdul Hamid. (2003). Multiple intelligences and comprehension development and deepening. Cairo . Arab Thought House.

7- Jalal, Saad. (1984). Social Psychology. 2nd floor. Alexandria. Knowledge facility. 8- Hassan, Sayed . Muhammad Abu Hashem. (2006). Psychometric properties of measurement tools in psychological and educational research using SPSS, College of Education, King Saud University.

9- Sander, David. (2017). The power of emotions. Translation: Talaat Matar. Presented by: Adel Mostafa. Vision for publication and distribution. Cairo.

10- Al-Sayed, Fouad Al-Bahi (1958). Statistical Psychology and Measurement of the Human Mind, 1st Floor, Dar Al-Fikr Al-Arabi.

11- Al Shamali, Nidal Abdul Latif. (2015). The five factors of personality and its relationship to depression in patients attending the Gaza Community Center - Gaza 
Mental Health Program. Islamic University of Gaza. Deanship of Graduate Studies. College of Education - Department of Psychology - Psychological Counseling. 12- Friedman, Howard S. \& Schestek, Myriam. (2013). Personality - Classical Theories and Modern Research. Translated by: Ahmad Rimu. Center for Arab Unity Studies, Beirut. Arab Organization for Translation.

13- Razuq, Asaad . (1977). Encyclopedia of Psychology. Beirut. Arab Institution for Studies and Publishing.

14- Abbas, Mayada Abdel Hassan. (2001). Happiness and its relationship to social harmony among university students. Baghdad University . College of Arts, unpublished Master Thesis.

15- Ashqul, Khalil Muhammad Khalil (2009). Social intelligence and its relationship to critical thinking and some variables among university students. Islamic University of Gaza . Deanship of Graduate Studies. Faculty of Education . Department of Psychology . A magister message that is not published .

16- Al-Turiri, Abdul Rahman bin Suleiman. (1997). Psychological and educational measurement - theory - foundations - its applications. Riyadh. Al-Rushd Library. 17- Talafhah, Hamed Abdullah. (2014). The level of social intelligence among social studies teachers in Zarqa Governorate and its relationship to patterns of class interaction. Studies, educational highs. Volume 4, Issue / 2.

18- Al Qudra, Musa Sobhi Musa. (2007). Social intelligence among students of the Islamic University and its relationship to religiosity and some variables. Master Thesis . Islamic University - Gaza - Deanship of Graduate Studies. College of Education Department of Psychology.

19- Ktfy , jmela. (2015). Social intelligence and its relationship to organizational communication skills at the Algerian University. Muhammad Khader University in Biskra. College of Humanities and Social Sciences. Department of Social Sciences. A magister message that is not published .

20- Muhammad, Muhammad Abbas. (2011). The five biggest factors of personality. Baghdad University . Journal of Educational and Psychological Research. Volume: 8. Issue 30. Issue: 30. Pages: 313-334.

21- Melhem, Mazen. (2010). Feeling of psychological loneliness and its relationship to the five factors of personality - a field study on a sample of Damascus University students. College of Education, Damascus University Journal. Volume (26) - Fourth Issue.

22- Al-Waqfi, Radhy,. (1998). Introduction to Psychology. 3rd floor. Sunrise House. Cairo .
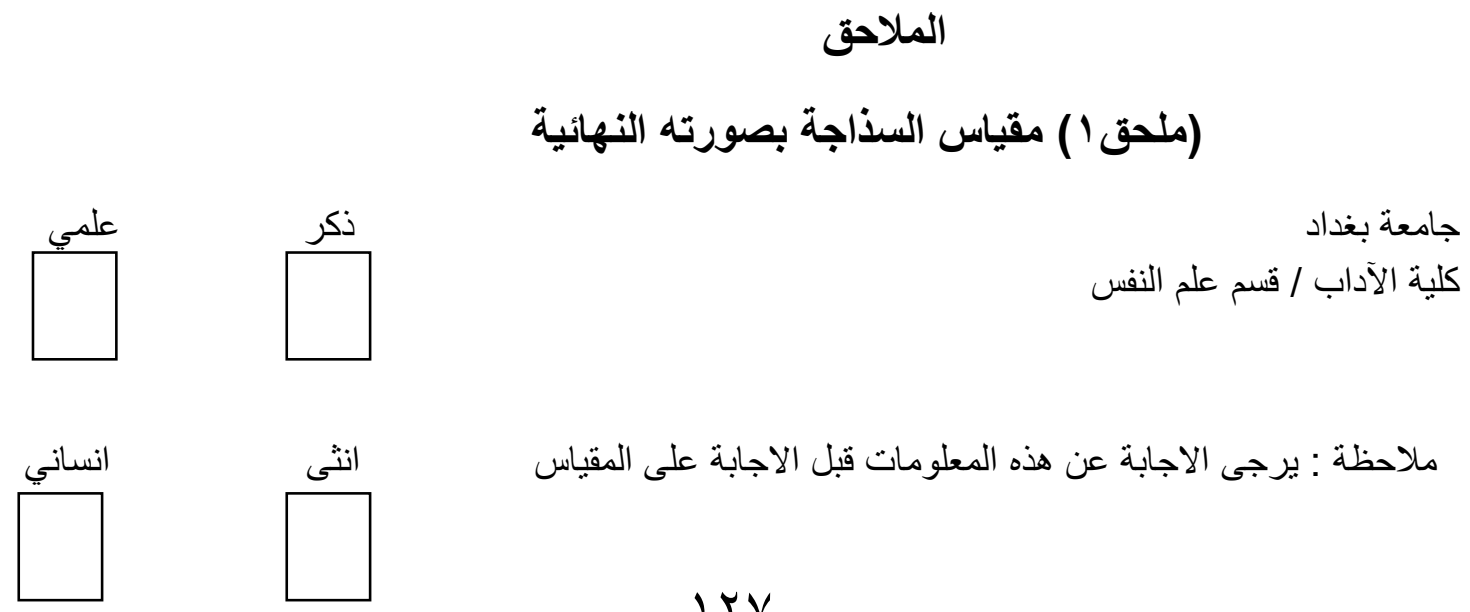

ملاحظة : يرجى الاجابة عن هذه المعلومات قبل الاجابة على المقياس 
عزيزي الطالب ... عزيزتي الطالبة ....

نرجو منك الاجابة عن الاستبيان الآتي حول معتقداتك وسلوكياتلك ، لاتفكر طويلا حول اجابتك فقط اقر أ كل

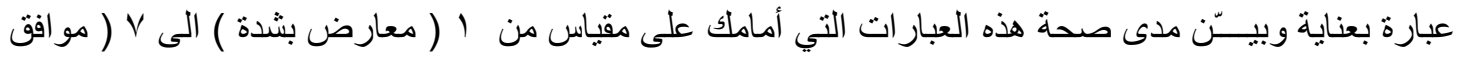

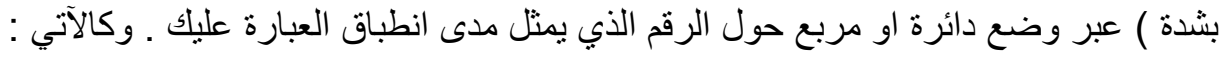
أ.م.د / علي تركي القريشي

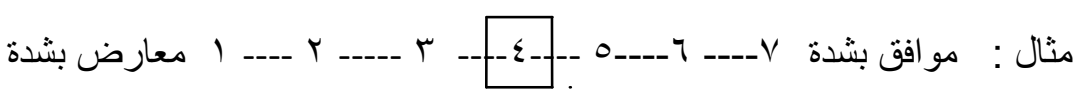

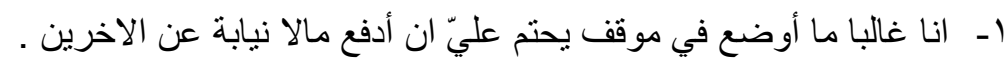

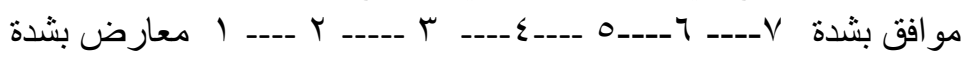

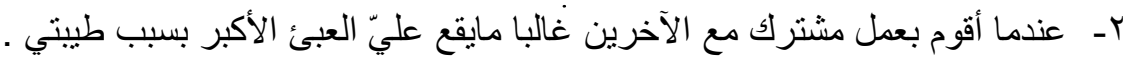

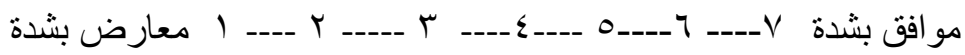

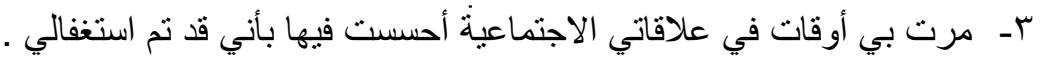

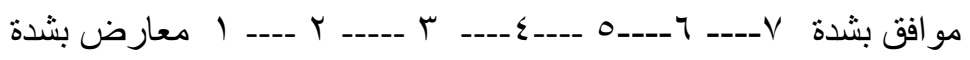

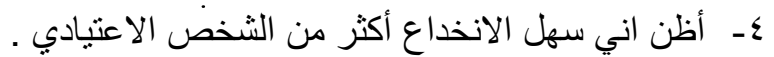

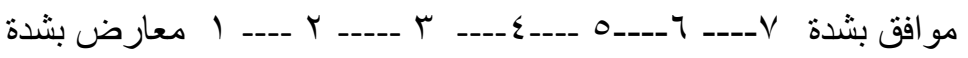

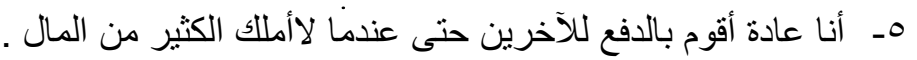

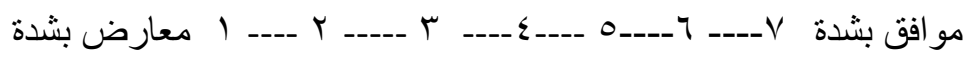

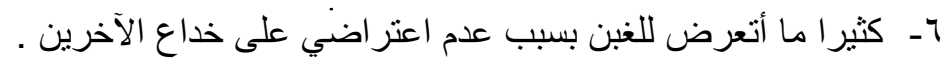

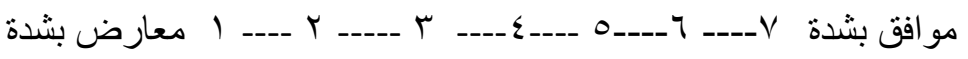

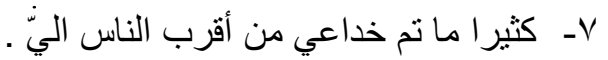

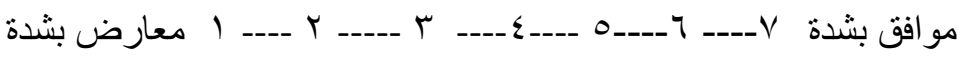
A- أفر اد عائلتي يعتقدون بأني هدف سهل للمحتالين .

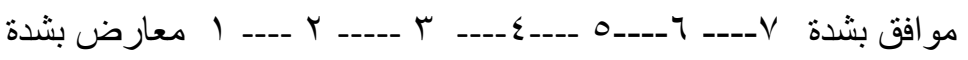

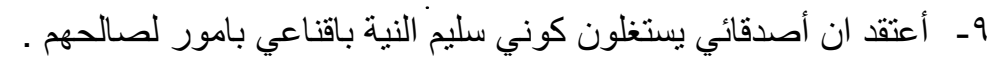

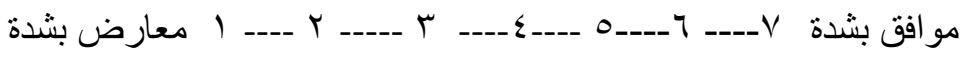

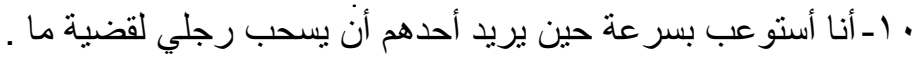

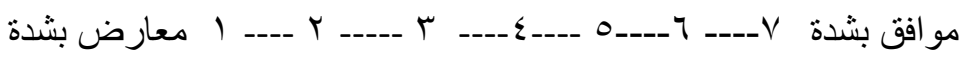

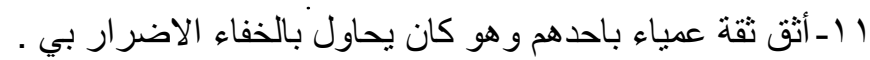

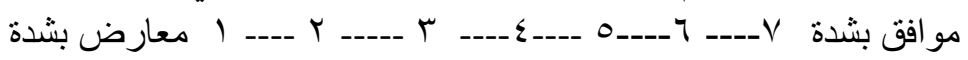

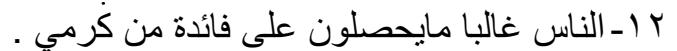

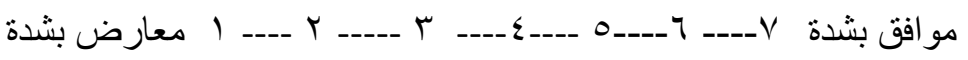
rا ـ أصدقائي يعتقدون بأني غير وثوق كثير ا بالآخرين .

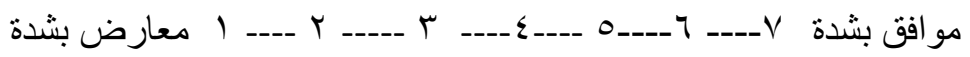

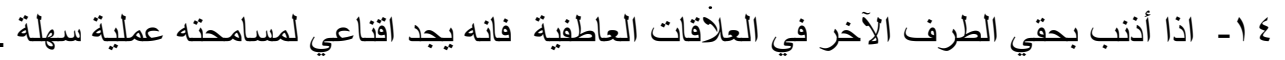

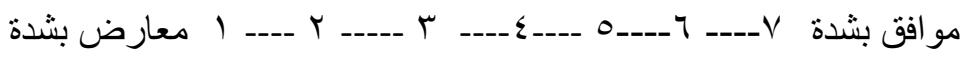


1 اـ أنا ضعيف تقريبا في التعامل أذا أر اد أحد ما ان يخدعني .

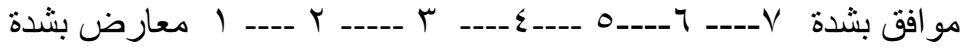

17

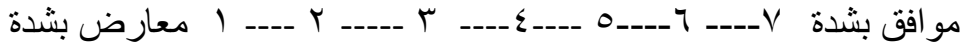

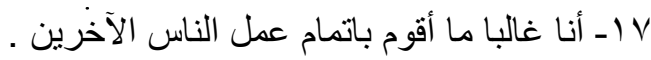

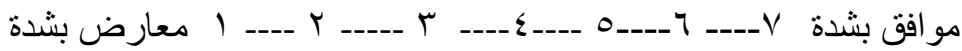

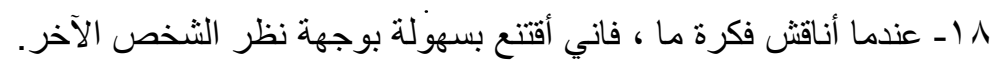

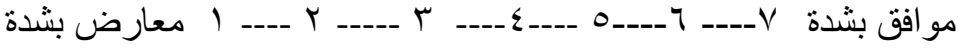

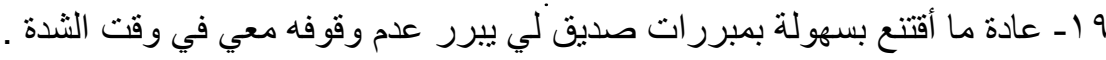

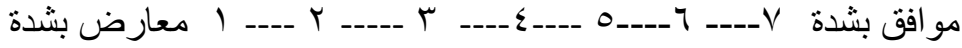

• Y- أعتقد ان سلامة نيتي أو طييتي قد حجبت عني رؤية خداع وحقيقة الآخرين .

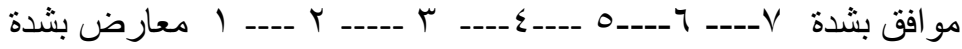

ا Y ي ينتقني أهلي على سكوني عن تصرفات الآخرين التي يقصدون منها استغلالي .

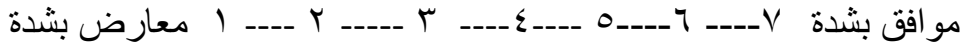

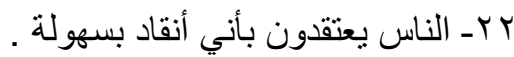

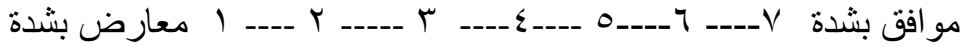

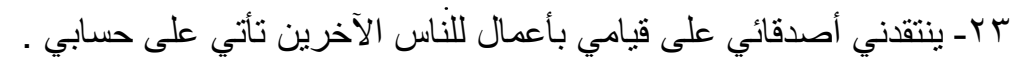

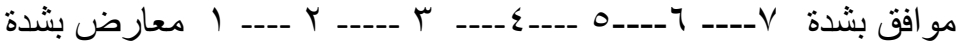

\section{(ملحق r) مقياس الذكاء الاجتماعي بصورته النهائية}

جامعة بغداد / كلية الآداب /قسم علم النفس

عزيزي الطالب .. عزيزتي الطالبة.. تحية طيبة...

تتطلب الدراسة التي يقوم به الباحث تطبيق المقياس الذي بين أيديكم ونظر الما نعهده فيكم من تعاون مثـر

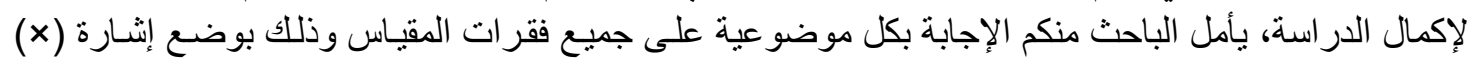

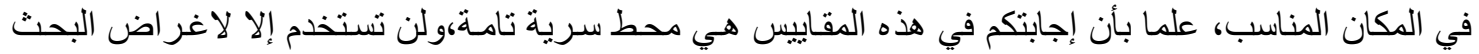

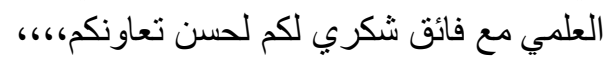

\begin{tabular}{|c|c|c|c|c|c|c|}
\hline مطلقا & ن ادرا & 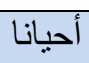 & غالبا & دائما & 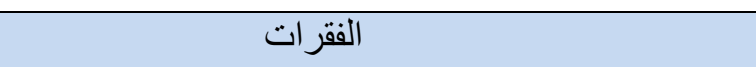 & $ت$ \\
\hline & & & & & أتعامل مع من هم أكبر مني سنا. & -1 \\
\hline & & & & & لا اتجنب الحديث مع الكبار. & $-{ }^{-1}$ \\
\hline & & & & & أندمج مع الأكبر مني سنا بسهولة. & -4 \\
\hline & & & & & لدي القدرة على تكوين صداقات بسهولة. & $-\varepsilon$ \\
\hline & & & & & أفتقر إلى طريقة التعامل الجيدة مع الأصغر سنا. & -0 \\
\hline & & & & & أتمتع بعلاقات جيدة مع الآخرين. & -7 \\
\hline & & & & & لدي المقدرة للتحدث مع جميع الافر ادومختلف الأعمار. & $-V$ \\
\hline & & & & & أستطيع أن اتعامل مع الاشخاص في أي موقف اجتماعي. & $-\Lambda$ \\
\hline
\end{tabular}




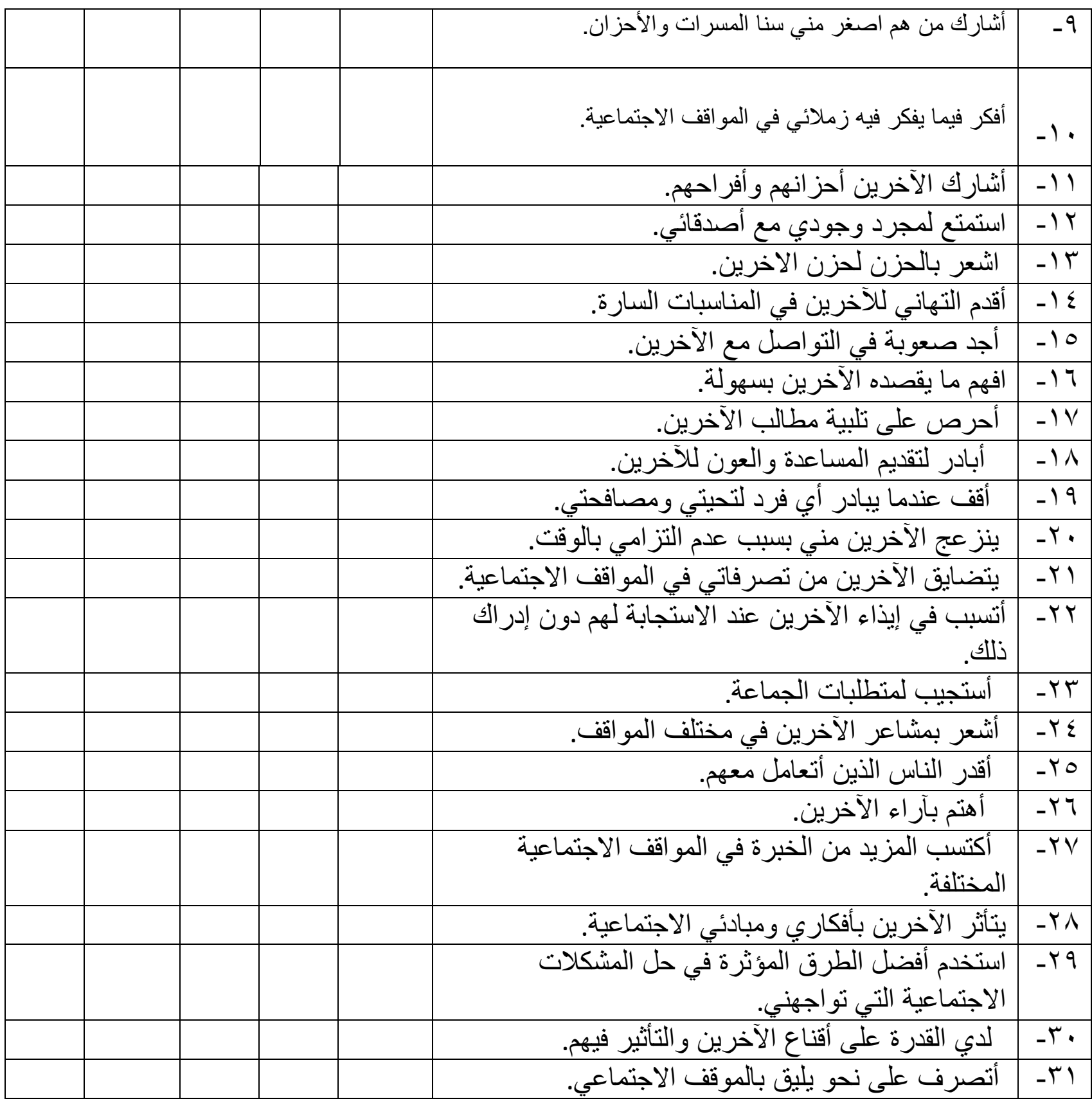

